\title{
Hanford Whole Body Counting Manual
}
H. E. Palmer
G. A. Rieksts
C. P. Brim
M. C. Rhoads

May 1987

Prepared for the U.S. Department of Energy under Contract DE-AC06-76RLO 1830

Pacific Northwest Laboratory

Operated for the U.S. Department of Energy by Battelle Memorial Institute 


\title{
LEGAL NOTICE
}

The uses to which this manual may be placed are limited by the timeliness of the content. Subject to continuous update and revisions, it is furnished solely as a guide or a typical facility description. As a dynamic document, it is not intended for any particular use or purpose and is not in any way warranted.

\section{DISCLAIMER}

This report was prepared as an account of work sponsored by an agency of the United States Government. Neither the United States Government nor any agency thereof, nor Battelle Memorial Institute, nor any of their employees, makes any warranty, expressed or implied, or assumes any legal liability or responsibility for the accuracy, completeness, or usefulness of any information, apparatus, product, or process disclosed, or represents that its use would not infringe privately owned rights. Reference herein to any specific commercial product, process, or service by trade name, trademark, manufacturer, or otherwise, does not necessarily constitute or imply its endorsement, recommendation, or favoring by the United States Government of any agency thereof, or Battelle Memorial Institute. The views and opinions of authors expressed herein do not necessarly state or reflect those of the United States Government or any agency thereof, or Battelle Memorial Institute.

\author{
PACIFIC NORTHWEST LABORATORY \\ operated by \\ BATTELLE MEMORIAL INSTITUTE \\ for the \\ UNITED STATES DEPARTMENT OF ENERGY \\ under Contract DE-AC06-76RLO 1830
}

\begin{tabular}{|c|c|}
\hline \multirow{2}{*}{\multicolumn{2}{|c|}{ Printed in the United States of America }} \\
\hline & \\
\hline \multirow{2}{*}{\multicolumn{2}{|c|}{$\begin{array}{l}\text { National Technical Information Service } \\
\text { United States Department of Commerce }\end{array}$}} \\
\hline & \\
\hline \multicolumn{2}{|c|}{$\mathbf{5 2 8 5}$ Port Royal Road } \\
\hline \multicolumn{2}{|c|}{ Springfield, Virginia 22161} \\
\hline \multirow{2}{*}{\multicolumn{2}{|c|}{$\begin{array}{l}\text { NTIS Price Codes } \\
\text { Microfiche A01 }\end{array}$}} \\
\hline & \\
\hline \multicolumn{2}{|c|}{ Printed Copy } \\
\hline & Price \\
\hline Pages & Codes \\
\hline 001-025 & $\mathrm{A} 02$ \\
\hline 026-050 & $\mathrm{A} 03$ \\
\hline $051-075$ & A04 \\
\hline $076-100$ & A05 \\
\hline $101-125$ & A.06 \\
\hline $126-150$ & A07 \\
\hline $151-175$ & A08 \\
\hline $176-200$ & A09 \\
\hline $201-225$ & A010 \\
\hline $226-250$ & A011 \\
\hline 251.275 & A012 \\
\hline $276-300$ & $\mathrm{~A} 013$ \\
\hline
\end{tabular}



H. E. Palmer
C. P. Brim
G. A. Rieksts
M. C. Rhoads

May 1987

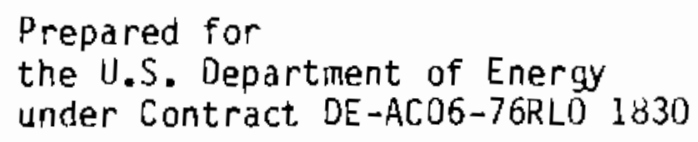

Pacific Northwest Laboratory Richland, Washington 99352 

FOREWORD

This document was originally published as a manual designed to train personne1, document operation procedures, outline quality assurance procedures, and provide information on the Hanford whole body counting facilities to the U.S. Department of Energy (DOE) Richland Operations Office and the contractor companies at Hanford. The authors are not aware of the existence of a published comprehensive document describing the operations of a whole body counting facility within the community of the DOE operations, and have received requests for copies of the manual from organizations outside the Hanford Site. In response to those requests, the Pacific Northwest Laboratory has published the Whole Body Counting Manual as a report entitled Hanford Whole Body Counting Manual, but has retained the original manual format.

The reader is reminded that equipment and procedures among the whole body counting facilities in the United States are not standardized. Therefore, following the methodology and calibration procedures will be of limited use to the reader. Nevertheless, the authors hope that this report will provide some useful information to the organizers of future whole body counting facilities and to the compilers of manuals describing existing whole body counting operations.

Requests for a copy of this document or requests to be included on a distribution list for updates to this document may be directed to:

H. E. Palmer

Pacific Northwest Laboratory

P.0. Box 999

Richland, Washington 99352 


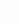


SUMMARY

This document is the reprint of the Whole Body Counting Manual, prepared for the U.S. Department of Energy Richland Operations Office by the Pacific Northwest Laboratory. The Whole Body Counting Manual was compiled to train personnel, document operation procedures, and outline quality assurance procedures. The following paragraphs describe the organization of the document.

The location, availability, and scope of services of Hanford's whole body counting facilities are discussed in the introductory section. An acronym list deciphers the regional terminology.

Section 1 covers the administrative aspect of the whole body counting operation: who is eligible for an in vivo count; what authorization is required; how counts are scheduled; what type of recordkeeping is required; and how results of in vivo counts are reported.

Hanford's whole body counting facilities are described in Section 2 . The various shielded rooms and mobile equipment, as well as the type of detectors, are described. The data acquisition and processing equipment are also discussed. Figures depicting the calibration phantoms accompany explanations of the calibration methods.

Section 3 outlines the step-by-step procedure involved in the different types of in vivo measurements. This section is designed to help the technician learn to perform a variety of in vivo counts, use the different detectors, and calculate the activity recorded by the detectors. A number of figures indicate the proper position of counting equipment in relation to the subject being measured.

The detectors, preamplifiers and amplifiers, and spectroscopy equipment. are discussed in Section 4. The quality assurance aspect of equipment calibration and recordkeeping are covered in Section 5 .

Data processing, record storage, results verification, report preparation, count summaries, and unit cost accounting are addressed in Section 6 . Section 7 covers the topics of minimum detectable amount and measurement accuracy and precision. 
Most of the sections include a reference list. A brochure entitled "The Hanford Whole Body Counting Center" is attached to the back cover of this report. This brochure is Appendix $A$ in the original manual. Appendix $B$, the quality assurance plan, is included in the bound portion of the report. 


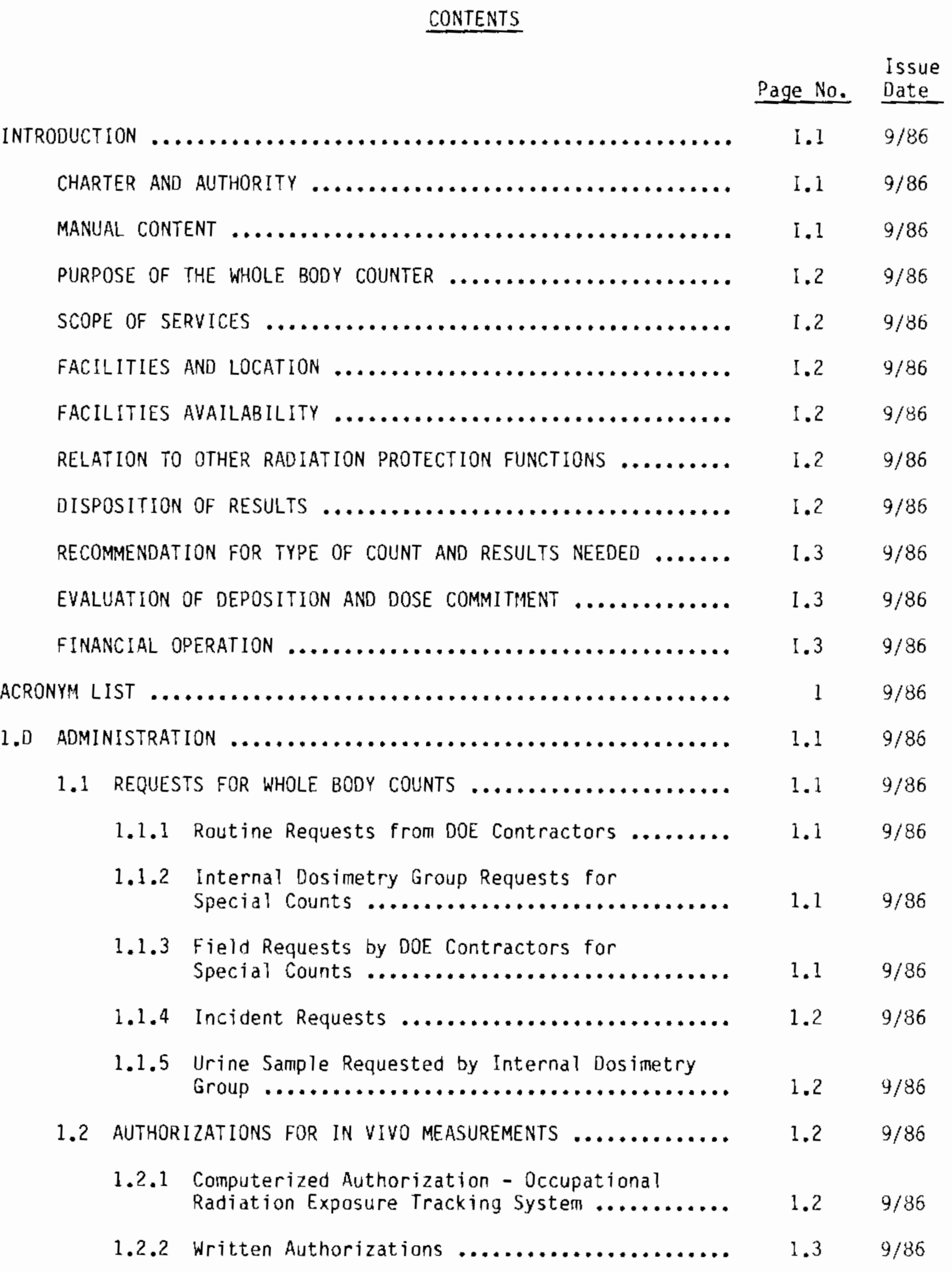

DATE ISSUED: $9 / 86$

A $1400-128$ (5-80)
PNL-MA-574

$$
\text { PNL-MA-574 }
$$

secrion Contents

PAGE vii 


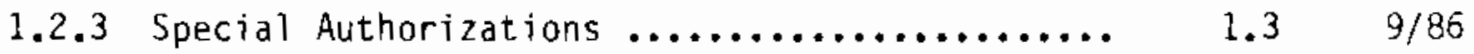

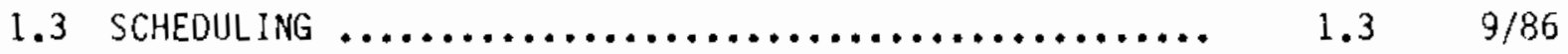

1.3.1 Routine Whole Body Counts ................. $1.4 \quad 9 / 86$

1.3.2 Lung and Head Counts .................... $1.4 \quad 9 / 86$

1.3.3 Handling DOE-Contractor Employees Without Authorization Papers ...................... $1.5 \quad 9 / 86$

1.3.4 Handling Non-DOE-Contractor Employees Without Authorization Papers ................ $1.5 \quad 9 / 86$

1.3.5 Visitors Entering Radiation Areas ........... $1.5 \quad 9 / 86$

1.3.6 Visitors who Come to the WBC for Special

Measurements .............................. $1.5 \quad 9 / 86$

1.3.7 Foreign Visitors $\ldots \ldots \ldots \ldots \ldots \ldots \ldots \ldots \ldots, \quad 1.7 \quad 9 / 86$

1.3.8 Non-DOE-Contractor Requests ............... $1.7 \quad 9 / 86$

1.4 PRELIMINARY PROCEDURES FOR IN VIVO MEASUREMENTS $\ldots \ldots . .1 .7 \quad 9 / 86$

1.4.1 In Vivo Count Request Form $\ldots \ldots \ldots \ldots \ldots \ldots \ldots . \quad 1.8 \quad 9 / 86$

1.4.2 Assuring Measurement of Internaliy
Deposited Radiation ........................ $1.8 \quad 9 / 86$

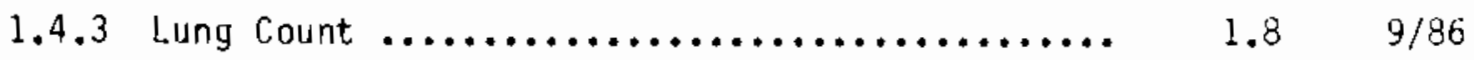

1.4.4 Potential Contamination in the Last

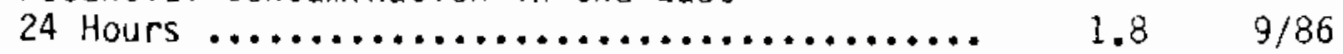

1.4 .5 Information and Safety Instructions for
the Subject ............................. $1.8 \quad 9 / 86$

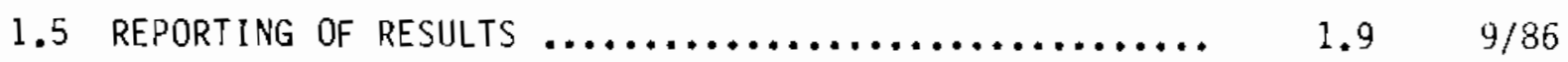

1.5.1 Routine Counts That Show No

Radioactivity: DDE Contractors.............. $1.9 \quad 9 / 86$

1.5.2 Field Requests, Incidents, or Positive

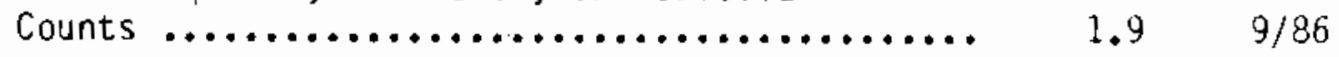

1.5.3 Handring Concerned Subjects' Questions
About Results ................................ $1.9 \quad 9 / 86$

1.5.4 Reporting Non-D0E-Contractor Results ......... $1.10 \quad 9 / 86$

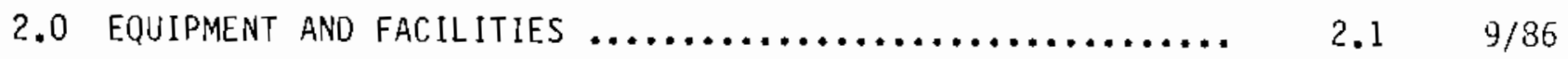

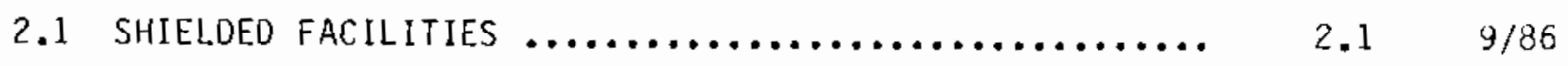


2.1.1 Shielded Rooms

$2.19 / 86$

2.1.2 Shadow Shields

$2.3 \quad 9 / 86$

2.1.3 Mobile Facilities

$2.49 / 36$

2.1.4 Equipment in the EOF

$2.59 / 86$

2.2 DETECTORS

$2.6 \quad 9 / 86$

2.2.1 Scintillation Detectors

$2.79 / 86$

2.2.2 Semiconductor Detectors

$2.7 \quad 9 / 86$

2.2.3 0ther Detector Types

$2.79 / 86$

2.3 DATA ACQUISITION ANO PROCESSING EQUIPMENT

$2.79 / 86$

2.4 CALIBRATION METHOOS

$2.89 / 86$

2.4.1 Bottle-Manikin-Absorption Phantom .......... $2.8 \quad 9 / 86$

2.4.2 Radiation-Equivalent-Manikin-Absorption

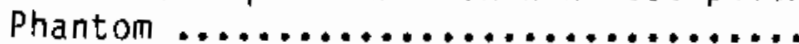

$2.89 / 86$

2.4.3 Tissue-Equivalent Torso Phantom ........... 2.8 9/86

2.4.4 Head Phantoms ........................ 2.12 9/85

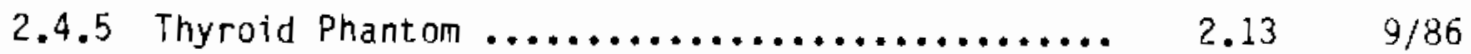

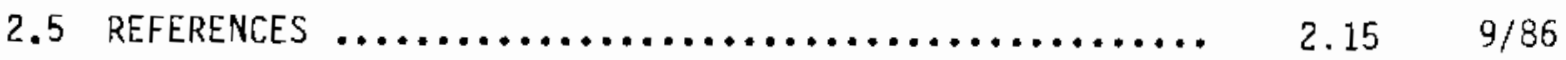

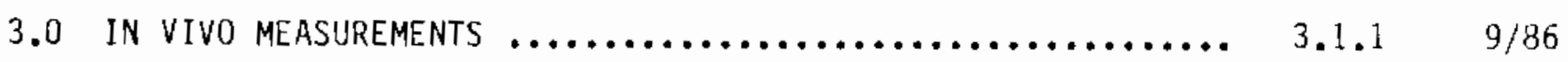

3.1 WHOLE BOOY IN VIVO MEASUREMENTS $\ldots \ldots \ldots \ldots \ldots \ldots \ldots \ldots . . \ldots .1 .1 . \ldots 65$

3.1.1 Procedure for Daily Whole Body Counter Energy

Calibration, Background Determination, and

Efficiency Check.

3.1 .1

$9 / 86$

3.1.2 Procedure for Subject Measurement .......... 3.1.4 9/36

3.1.3 Background Correction ....................... $3.1 .4 \quad 9 / 86$

3.1.4 Calculations for Total Body Activity ........ 3.1.4 9/86

3.1.5 Calculations for Lung Activity............ $3.1 .7 \quad 9 / 86$

3.1.6 Procedure for Handling Positive Cobalt-60

Whole Body Counts ....................... 3.1.7 9/86 
3.2 IN VIVO LUNG MEASUREMENTS OF LOW-ENERGY PHOTONS $\ldots \ldots . \quad 3.2 .1 \quad 9 / 86$

3.2.1 Procedure for Energy Calibration and

Efficiency Check of Germanium Planar Detectors

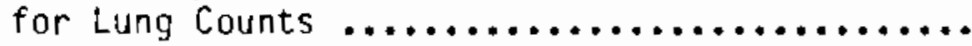

$3.2 .19 / 86$

3.2.2 Procedure for Subject Measurement

$3.2 .4 \quad 9 / 86$

3.2.3 Background Correction ................ 3.2.6 9/86

3.2.4 Calculation for Activity in the Lung ........ 3.2.6 $9 / 86$

3.2.5 Correction of the Lung Count for Activity

in the Bone and Liver .................. $3.2 .8 \quad 9 / 86$

3.3 IN VIVO MEASUREMENT OF RADIOACTIVITY IN THE LIVER $\ldots . .9 \quad 3.3 .1 \quad 9 / 86$

3.3.1 Procedure for Energy Calibration and Efficiency Check of the Germanium Planar Detectors .......

3.3.2 Procedure for Subject Measurement ........... 3.3.1 9/86

3.3.3 Background Correction .................. 3.3.1 9/86

3.3.4 Calculations for Liver Activity ........... 3.3.3 $9 / 86$

3.4 IN VIVO MEASUREMENT OF RADIOACTIVITY IN THE BONE $\ldots \ldots .3 .4 .1 \quad 9 / 86$

3.4.1 Procedure for Energy Calibration and Efficiency Check of the Germanium Planar Detectors ........

3.4.2 Procedure for Subject Measurement ......... 3.4.1 9/86

3.4.3 Background Correction ......................... 3.4. 9/86

3.4.4 Calculation for Bone Activity ............ 3.4.3 9/86

3.5 IN VIVO MEASUREMENT OF RADIOACTIVITY IN WOUNDS $\ldots \ldots \ldots \quad 3.5 .1 \quad 9 / 86$

3.5.1 Procedure for Energy and Efficiency Calibration of the Coaxial Germanium Detectors in the

Shielded Room or at the EDF ............. 3.5.1 9/86

3.5.2 Procedure for Subject Measurement .......... $3.5 .2 \quad 9 / 86$

3.5.3 Background Correction ................. 3.5.3 9/86

3.5.4 Calculations for Shallow Wound Activity ...... $3.5 .3 \quad 9 / 86$

3.6 IN VIVO MEASUREMENT OF RADIOACTIVITY IN THE

THYROID

$3.6 .19 / 86$ 
3.5.1 Procedure for Energy Calibration of the

Detectors for Thyroid Measurements .......... $3.6 .1 \quad 9 / 86$

3.6.2 Procedure for Subject Measurenent ........... $3.6 .1 \quad 9 / 86$

3.6.3 Background Correction ...................... 3.6.4 9/86

3.6.4 Calculations for Thyroid Activity .......... $3.6 .5 \quad 9 / 86$

3.7 IN VIVO MEASUREMENT OF TRANSURANIC NUCLIDES IN

AXILLIARY LYMPH NODES

ORANURANIC NUCLIOES In

3.7.1 Procedure for Energy Calibration of the

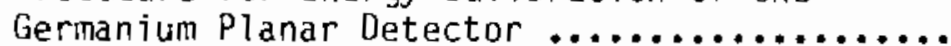

$3.7 .19 / 86$

3.7.2 Procedure for Subject Measurement and

Efficiency Calibration .................. 3.7.1 9/86

3.7.3 Background Correction ................. 3.7.3 9/86

3.7.4 Calculation of Axillary Lymph Node

Activity ........................... $3.7 .3 \quad 9 / 86$

3.8 IN VIVO MEASUREMENT OF TRANSURANIC NUCLIDES IN

TRACHIOBRONCHIAL LYMPH NODES

$3.8 .19 / 86$

3.9 IN VIVO MEASUREMENT OF RADIOACTIVITY USING $A$

LINEAR SCAN

$3.9 .1 \quad 9 / 86$

3.9.1 Procedure for Calibration of the Linear

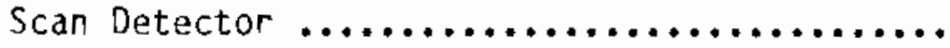

$3.9 .1 \quad 9 / 86$

3.9.2 Procedure for Subject Measurement ......... 3.9.4 9/86

3.9.3 Calculations for Activity Detected with

the Linear Scan ....................... 3.9.5 9/86

3.9.4 A1ternate Modes of Use ................. 3.9.5 9/86

3.10 DETERMINING CHEST WALL THICKNESS BY ULTRASOUND $\ldots \ldots \ldots \quad 3.10 .1 \quad 9 / 36$

3.10.1 Procedure for Determining Chest Wall

Thickness ............................ $3.10 .1 \quad 9 / 96$

3.11 IN VIVO COUNTING FOR CRITICALITY ACCIDENTS $\ldots \ldots \ldots \ldots .3 .11 .1 \quad 9 / 86$

3.11.1 Procedure for Energy and Efficiency

Calibration .................................... $3.11 .1 \quad 9 / 86$

3.11.2 Procedure for Measuring Activity Resulting

from Criticality Accidents ..................... $3.11 .1 \quad 9 / 86$

3.11.3 Background Correction ................ 3.11.2 9/85 
3.11 .4 Calculations of Activity $\ldots \ldots \ldots \ldots \ldots \ldots \ldots 3.11 .3 \quad 9 / 86$

3.12 IDENTIFICATION OF LNKNOWN RADIONUCLIDES $\ldots \ldots \ldots \ldots \ldots .3 .12 .1 \quad 9 / 86$

3.12.1 Procedure to Identify Unknown

Radionuclides .................................12.1 9/86

3.13 REFERENCES $\ldots \ldots \ldots \ldots \ldots \ldots \ldots \ldots \ldots \ldots \ldots \ldots \ldots \ldots \ldots .13 .1 . \ldots \ldots \ldots$

4.0 OPERATION OF COUNTING EqUIPMENT $\ldots \ldots \ldots \ldots \ldots \ldots \ldots \ldots \ldots \ldots . \ldots \ldots$

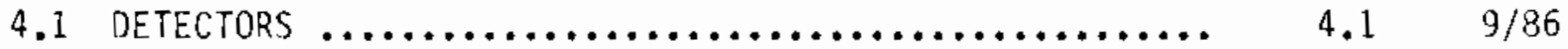

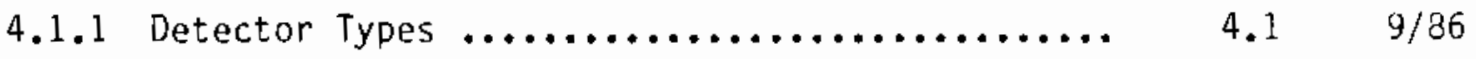

4.1 .2 Detector Hookup Design ................. 4... 4.1 96

4.1.3 Detector Maintenance and Repair ............ 4.2 4.2

4.1.4 Determination of Detector Resolution ....... 4.3 .96

4.1.5 Diagnosing Detector Probiems ............. 4.4 9/86

4.2 PREAMPLIFIERS AND AMPLIFIERS $\ldots \ldots \ldots \ldots \ldots \ldots \ldots \ldots \ldots \ldots \quad 4.5 \quad 9 / 86$

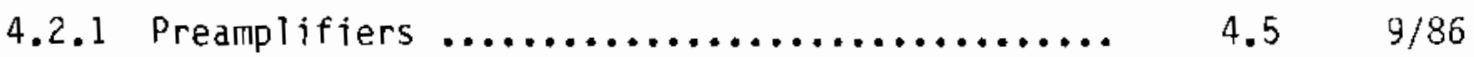

4.2 .2 Amplifiers ............................. $4.5 \quad 9 / 86$

4.3 SPECTROSCOPY EQUIPMENT: THE MULTICHANNEL ANALYZER ... 4.6 9/86

4.3 .1 MCA Calibration ....................... $4.7 \quad 9 / 86$

4.3.2 Example of Adjustment ................ $4.8 \quad 9 / 86$

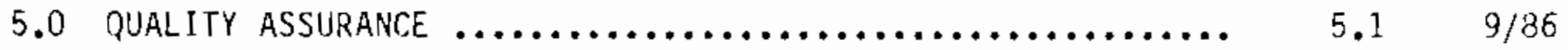

5.1 EqUIPMENT CALIBRATION $\ldots \ldots \ldots \ldots \ldots \ldots \ldots \ldots \ldots \ldots \ldots \ldots$

5.1 .1 Energy Calibration ................... $5.1 \quad 9 / 86$

5.1.2 Efficiency Calibration ....................... $5.1 \quad 9 / 86$

5.2 WHOLE BODY COUNTER RECORDS QUALITY ASSURANCE $\ldots \ldots \ldots \ldots \quad 5.3 \quad 9 / 86$

6.0 WHOLE BODY COUNTER DATA PROCESSING $\ldots \ldots \ldots \ldots \ldots \ldots \ldots \ldots \ldots \ldots . \ldots \ldots$

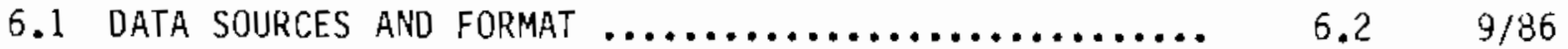

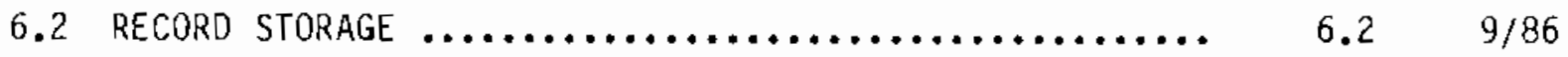

6.3 SUPPORTING PROCESSING FUNCTIONS $\ldots \ldots \ldots \ldots \ldots \ldots \ldots \ldots \ldots$

OATE ISSUED: $9 / 86$
PNL-MA.574

SECTION

PAGE
Contents

$x i j$ 
6.4 WEEKLY PROCESSING OF IN VIVO RESULTS $\ldots \ldots \ldots \ldots \ldots \ldots \ldots .6 .36 .36$

6.5 CHECKING RESULTS $\ldots \ldots \ldots \ldots \ldots \ldots \ldots \ldots \ldots \ldots \ldots \ldots \ldots . \ldots \ldots . \ldots \ldots$

6.6 WHOLE BODY COUNTER ANNUAL REPORT PREPARATION ........ $6.4 \quad 9 / 86$

6.7 UNIT COST ACCOUNTING AND SUBMISSION OF CHARGES $\ldots \ldots \ldots \quad 6.5 \quad 9 / 86$

6.8 MDNThLY COUNT SUMMARIES $\ldots \ldots \ldots \ldots \ldots \ldots \ldots \ldots \ldots \ldots \ldots . \ldots \ldots 6 . \ldots \ldots$

7.0 MINIMUM DETECTABLE AMOUNT, ACCURACY, AND PRECISION OF

IN VIVO MEASUREMENTS $\ldots \ldots \ldots \ldots \ldots \ldots \ldots \ldots \ldots \ldots \ldots \ldots \ldots \ldots \ldots . \ldots \ldots 6 . \ldots \ldots$

7.1 MINIMUM DETECTABLE AMOUNT $\ldots \ldots \ldots \ldots \ldots \ldots \ldots \ldots \ldots \ldots \ldots \ldots$

7.2 ACCURACY AND PRECISION .................... $7.5 \quad 9 / 36$

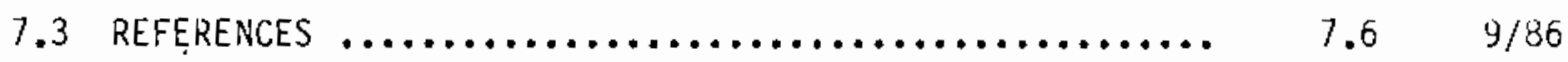

APPENDIX A - BROCHURE: "THE HANFORD WHOLE BODY COUNTING

CENTER" ............................... A.1 9/86

APPENDIX B - QUALITY ASSURANCE PLAN .................. 
2.1 Iron Shielded Room $\ldots \ldots \ldots \ldots \ldots \ldots \ldots \ldots \ldots \ldots \ldots \ldots \ldots \ldots$

$2.29 / 86$

2.2 Preview Counter $\ldots \ldots \ldots \ldots \ldots \ldots \ldots \ldots \ldots \ldots \ldots \ldots \ldots \ldots \ldots \ldots$

$2.39 / 86$

2.3 An Outside View of the Two Mobile Units Containing the Shadow-Shield Counters

2.4 A View of the Shadow-Shield Counter Inside One of the Mobile Units

2.5 Shadow-Shield Whole Body Counter Mounted in the Mobile Unit

2.6 BOMAB Phantorn ............................

$2.99 / 86$

2.7 REMAB Phantom

2.8 Tissue-Equivalent Torso Phantom ...

2.9 Head Phantom for the Calibration of Radioactivity in the Skull

2.10 Thyroid Phantom

3.1 The Preview Whole Body Counter

3.2 The Preview Whole Body Counter Schematic and Data Sheet

3.3 Flow Diagram for Whole Body Counting Procedure then Cobalt-60 is Detected

3.4 In Vivo Lung Count Equipment and Data Sheet

3.5 Calibration of Detectors for in Vivo Lung Count $3.2 .39 / 86$

3.6 Position of Detectors for a Lung Count ................ $3.2 .5 \quad 9 / 86$

3.7 Data Sheet and Position of Detectors for Liver Count .....

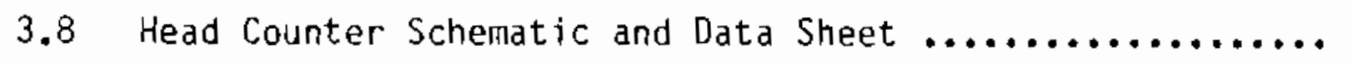

3.9 Position of Detectors for a head Count .............. 3.4.4 9/86

3.10 Wound Counter Schematic and System Data Sheet ......... 3.5.2 9/86

3.11 Placement of Detector for an Iodine-131 Measurement of the Thyroid 
3.12 Placement of Detectors for an Iodine-125 Measurement

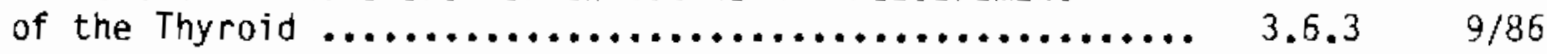

3.13 Sample Data Sheet for Lymph Count ................ 3.7.1 9/86

3.14 Proper Position of Detector for a Measurement of Radioactivity in the Axillary Lymph Node ............ 3.7.2 9/86

3.15 Two Germanium Planar Detectors Used to Measure the Tracheobronchial Lymph Nodes ................... $3.8 .2 \quad 9 / 86$

3.16 A Slot Collimator Which Extends Two Inches Below the Face of the Two Detectors Used to Measure the

Tracheobronchial Lymph Nodes ................... $3.8 .3 \quad 9 / 86$

3.17 Posterior Lateral Scan of Activity in the Lungs and the Tracheobronchial Lymph Nodes .................. 3.8.4 9/86

3.18 Subject Being Measured with the Linear Scan System ...... $3.9 .2 \quad 9 / 86$

3.19 Components of Linear Scan System .................. 3.9.3 9/86

3.20 Template Configuration $\ldots \ldots \ldots \ldots \ldots \ldots \ldots \ldots \ldots \ldots \ldots \ldots . \ldots . \ldots .1 . \ldots . \ldots$

3.21 Using the Template to Draw the Lines That Indicate

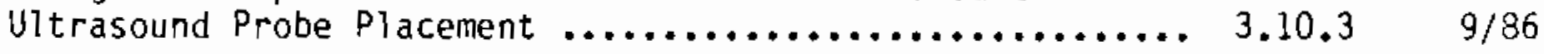

3.22 Positioning the UTtrasound Probe to Obtain a Good Interface with the Subject's Chest ............... 3.10.4 9/86

3.23 Detector in Normal Position ..................... 3.11.2 $9 / 86$

3.24 Detector in Raised Position ..................... 3.11.3 9/86

4.1 Schematic of a Scintillation Detector ................ $4.1 \quad 9 / 86$

4.2 Schematic of a Semiconductor Detector ............... $4.2 \quad 9 / 86$

4.3 Calculation of Detector Resolution $\ldots \ldots \ldots \ldots \ldots \ldots \ldots \ldots \ldots$........ $4.4 \quad 9 / 86$

4.4 Change in Peak Location with Conversion Gain .......... $4.7 \quad 9 / 86$

Change in Peak Location with Zero Level offset
Adjustment $\ldots \ldots \ldots \ldots \ldots \ldots \ldots \ldots \ldots \ldots \ldots \ldots \ldots \ldots \ldots \ldots \ldots \ldots \ldots$ 


\begin{tabular}{|c|c|c|c|}
\hline & & Page No. & $\begin{array}{l}\text { Issue } \\
\text { Date }\end{array}$ \\
\hline 1.1 & 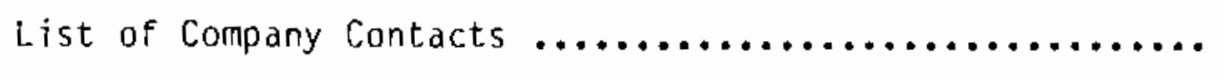 & 1.6 & $9 / 86$ \\
\hline 2.1 & Weight and Liquid Capacity of the BOMAB Phantom .......... & 2.9 & $9 / 86$ \\
\hline 3.1 & $\begin{array}{l}\text { Counting Efficiency for Common Radionuclides in the } \\
\text { Preview Counter } \ldots \ldots \ldots \ldots \ldots \ldots \ldots \ldots \ldots \ldots \ldots \ldots \ldots \ldots \ldots \ldots\end{array}$ & 3.1 .5 & $9 / 86$ \\
\hline 3.2 & $\begin{array}{l}\text { Counting Efficiency at Various Energies in the } \\
\text { Preview Counter } \ldots \ldots \ldots \ldots \ldots \ldots \ldots \ldots \ldots \ldots \ldots \ldots \ldots \ldots \ldots \ldots \ldots\end{array}$ & 3.1 .6 & $9 / 86$ \\
\hline 3.3 & 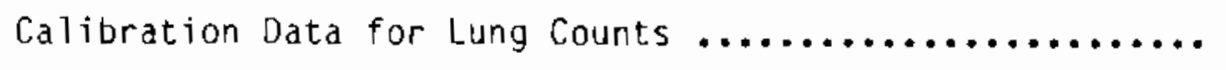 & 3.2 .6 & $9 / 86$ \\
\hline 3.4 & $\begin{array}{l}\text { Calibration Factor Versus Chest Wall Thickness for } \\
\text { Lung Counter Using the } 6 \text {-Germanium-Detector Array ........ }\end{array}$ & 3.2 .7 & $9 / 86$ \\
\hline 3.5 & 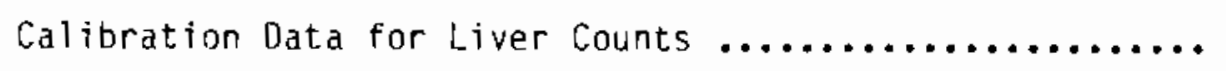 & 3.3 .3 & $9 / 86$ \\
\hline 3.6 & 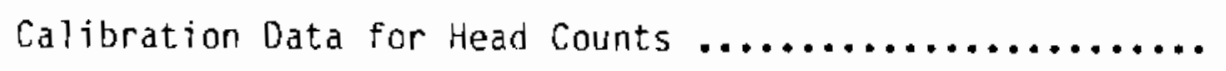 & 3.4 .5 & $9 / 86$ \\
\hline 3.7 & 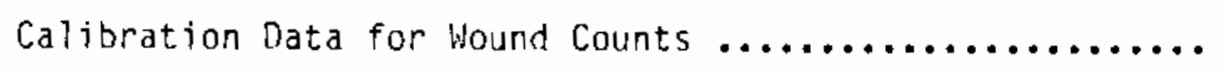 & 3.5 .4 & $9 / 86$ \\
\hline 5.1 & $\begin{array}{l}\text { Summary of Quality Assurance Checks for Counting } \\
\text { Systens } \ldots \ldots \ldots \ldots \ldots \ldots \ldots \ldots \ldots \ldots \ldots \ldots \ldots \ldots \ldots \ldots \ldots \ldots \ldots \ldots \ldots \ldots \ldots\end{array}$ & 5.2 & $9 / 86$ \\
\hline 7.1 & $\begin{array}{l}\text { Accuracy and Sensitivity for In Vivo Measurements of } \\
\text { Common Radionuclides Using Various Numbers of Germanium } \\
\text { Planar Detectors } \ldots \ldots \ldots \ldots \ldots \ldots \ldots \ldots \ldots \ldots \ldots \ldots \ldots \ldots \ldots \ldots \ldots \ldots \ldots \ldots \ldots \ldots \ldots \ldots \ldots\end{array}$ & 7.2 & $9 / 86$ \\
\hline 7.2 & $\begin{array}{l}\text { Accuracy and Sensitivity for Whole Body Counts in the } \\
\text { Preview Counter } \ldots \ldots \ldots \ldots \ldots \ldots \ldots \ldots \ldots \ldots \ldots \ldots \ldots \ldots \ldots \ldots \ldots \ldots\end{array}$ & 7.3 & $9 / 86$ \\
\hline 7.3 & $\begin{array}{l}\text { Accuracy and Sensitivity for Selected In vivo } \\
\text { Measurements } \ldots \ldots \ldots \ldots \ldots \ldots \ldots \ldots \ldots \ldots \ldots \ldots \ldots \ldots \ldots \ldots \ldots\end{array}$ & 7.4 & $9 / 86$ \\
\hline
\end{tabular}




\section{INTRODUCTION}

CHARTER AND AUTHORITY
MANUAL CONTENT
As part of its service responsibilities, the Health Physics, Department of the Pacific Northwest Laboratory (PNL) $(a)$ is charged with providing in vivo measurements of internaliy deposited radioactivity in the employees of the Hanford contractors. The authority and responsibility for providing this service are assigned through the Hanford Site Services Handbook issued by the U. S. Department of Energy's (DOE) Richland Operations office.

The DOE Order 5480.1, Chapter XI requires that monitoring for internal radioactivity be carried out where the potential exists for an individual to receive a dose commitment in any quarter of a calendar year in excess of $10 \%$ of the quarterly standard. The radiation protection personnel of the DOE contractors make decisions on which employees in their organizations have the potential to exceed those dose standards. These decisions, as well as the frequency of in vivo bioassay (whole body counting), are based on the guidance provided by PNL-MA-575, Hanford Dosimetry Evaluation Manual, and the Internal Dosimetry Program of the Personnel Dosimetry Section in the PNL Health Physics Department.

The work described in this manual is performed by the Whole Body Counter Group of the Personnel Dosimetry Section within the Heaith Physics Department. The manual replaces the previous internal "Whole Body Counting Procedure Manual" issued in 1980. This manual is different because the detailed procedures and instructions on the operation of the electronic equipment such as the multichannel analyzers and the computers are not included. The extensive instructions for equipment operation will be in separate manuals, which are referenced in the appropriate places in this manual.

The purposes of this manual are to:

- provide training for whole body counter personnel

- document the methods and procedures for identifying and quantifying radioactivity in radiation workers

- fulfill quality assurance requirements

(a) PNL is operated for the U.S. Department of Energy by the Battelle Memorial Institute. 
MANUAL CONTENT

(contd)

PURPOSE OF THE WHOLE BODY COUTTER

SCOPE OF SERVICES

FACIL ITIES AND LOCATION

FACILITIES

AVAILABILITY

RELATION TO

OTHER RADIATION

PROTECTION FUACT IONS

DISPOSITION OF

RESULTS
- provide references to documented calibration work from which calibration factors are derived

- provide information on the facility and its capability for the DOE and the Hanford Site contractor companies.

The technical information contained within this manual was largely developed by H. E. Palmer, G. A. Rieksts, and M. C. Rhoads. The manual was compiled and edited by C. P. Brim.

The Whole Body Counter (WBC) facilities provide in vivo measurements of internally deposited radioactivity in the employees of Hanford Site contractors. This service is needed to document the absence of radioactivity in most radiation workers and to determine the amount, distribution, and retention of radioactivity in those few employees who become internally contaminated. From the results of these and other types of measurements, the internal radiation dose can be calculated.

Whole body counting services are available to employees of all Hanford Site contractors. Whole body counting services are also extended to local private nuclear energybased companies and to selected research studies when time and facilities are available, and upon approval by the DOE.

Most of the WBC equipment is located in the 747A Building; other equipment for special purposes is maintained and operated in the Emergency Decontamination Facility (EDF) located adjacent to the Kadlec Hospital in the city of Richland, and in two mobile units.

Regular services are availabie weekdays, from 8:00 a.m. to 4:30 p.m. Emergency services are available at any time.

Except for routine scheduling of contractor employees for chest or lung measurements, communication with other radiation protection personnel is almost entirely with the Internal Dosimetry Group of the Personnel Dosimetry Section in PNL's Health Physics Department.

All in vivo bioassay results are comrnunicated to the Occupational Radiation Exposure (ORE) data base and the PNL Internal Dosimetry Group for evaluation and distribution to the Hanford Site contractors. A preliminary summary of results is given to each individual measured. Official measurement results are not given directly to the DOE contractors by WBC personnel. Questions from the DOE contractors about $W B C$ results are communicated through the 
DISPOSITION OF

RESULTS

(contd)

RECOMENDATIDN FOR TYPE OF COUNT AND RESULTS NEEDED

EVALUATION OF DEPOSITION AND DOSE COMITTENT

FIHANCIAL OPERATION
Interna Dosimetry Group. However, results of measurements made on employees of private companies and people involved in research studies are reported directly from the $\mathrm{WBC}$.

The Internal Dosimetry Group determines (based on information provided by the contractor representative) the appropriate measurements necessary to evaluate the deposition and clearance. The Internal Dosimetry Group will then advise the WBC staff of the type of measurement needed.

In the case of contamination incidents the Internal Dosimetry Group also contacts radiation monitoring for survey services. This manitoring is necessary to assure that the low background facilities do not become contaminated from external radioactivity that may be on the worker or his clothes.

The WBC staff will provide the Internal Dosimetry Group with their best determination of the burden at the time of the measurement. Based on this information, the Internal Dosimetry Group will then evaluate the deposition and dose cominitment.

The WBC operates as a small job center, funded by each DOE contractor or company through a unit charge assessed them for each measurement made. Each year a budget request for the $W B C$ operation (in the form of a work element plan) is prepared, reviewed with each contractor's radiation protection representative, and submitted to the DOE Richland Operations Office (DOE-RL) for approval. From the approved budget and an estimate of the number of measurements to be performed, the unit charges for each type of measurement are established for the fiscal year.

Billing for measurements performed is carried out once a month. Information on the type and number of measurements performed for each company is provided to PNL cost accounting near the end of each month. Cost accounting distributes the costs to the appropriate contractor's financial system or invoices the private company. 


\section{ACRONYM LIST}

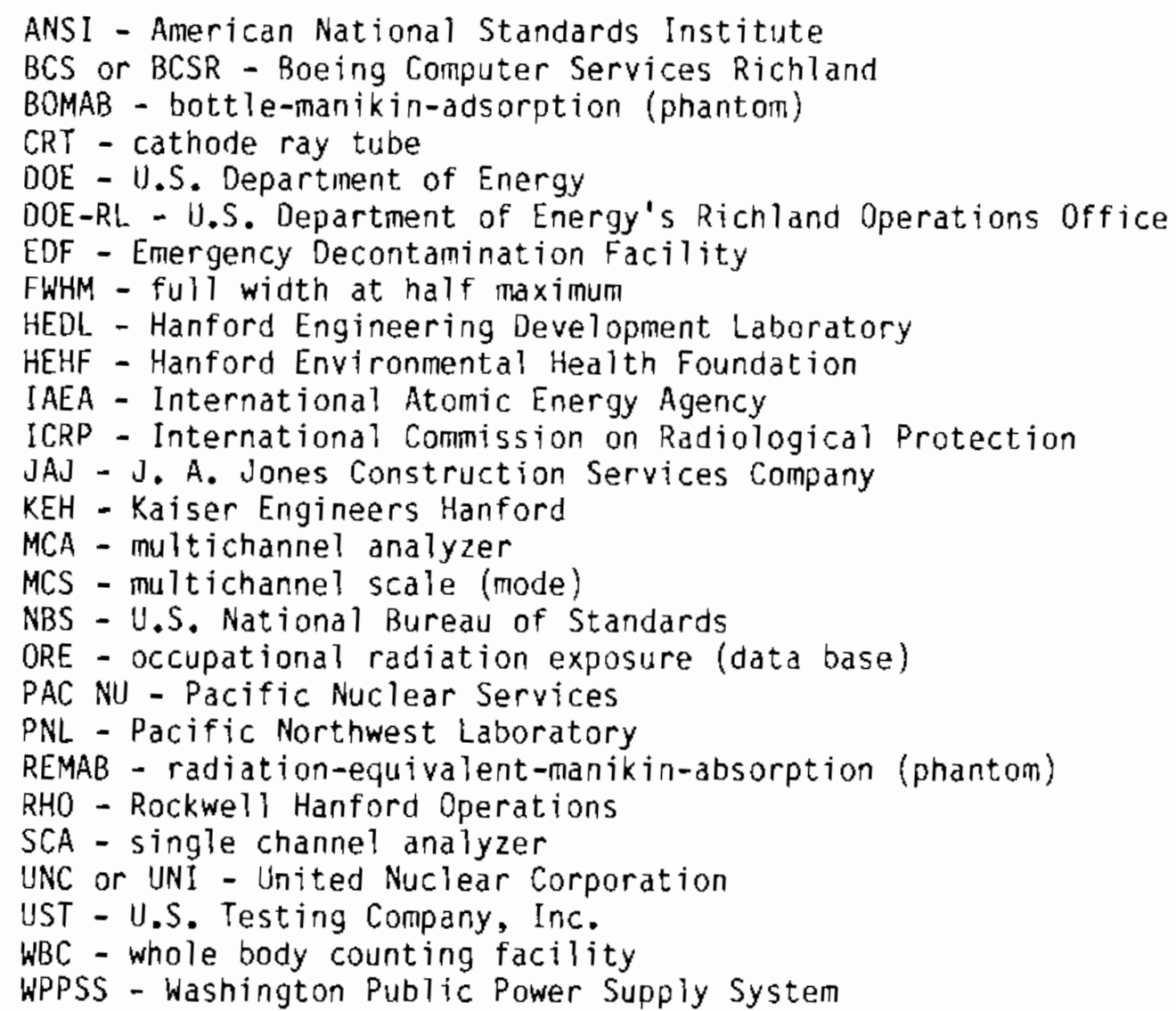




\subsection{ADMINISTRATION}

This section describes the request, scheduling, authorization, preliminary procedures, and result reporting for in vivo measurements.

\subsection{REQUESTS FOR WHOLE BODY COUNTS}

The types of requests for the authorization of whole body counts are described in the following section. A routine measurement is classified as a Type I and maximum sensitivity measurement is classified as Type II. A maximum sensitivity measurement involves a longer period of meas urement than a routine measurement. Because of the limited facilities it is not possible to perform Type II measurement for all routine measurements.

\subsubsection{Routine Requests from DOE Contractors}

Each contractor is responsible for determining the specific radionuclides an employee may work with. The contractor and the Internal Dosimetry Group then deternine the type of count required. These measurements are typically scheduled when an employee is newly hired, terminated, beginning or ending a special project involving radioactivity, or upon the request for a periodic routine measurement.

No appointments are required for whole body counts, but an appointment must be made for a lung count. In vivo examinations normally take place on the same day of the annual physical scheduled for all radiation workers.

\subsubsection{Internal Dosimetry Group Requests for Special Counts}

In some cases of internal contamination, the Internal Dosimetry Group needs more information to complete dosimetry calculations. This group will then request additional WBC measurements.

These specialized measurements will be scheduled in advance to allow enough time to prepare for the requested measurement5. When these requests conflict with the routine schedule, the routine measurements may be delayed or rescheduled.

\subsubsection{Field Requests by DOE Contractors for Special Counts}

A DOE contractor may request non-routine measurements for a number of reasons including skin contamination, elevated air samples, or concern of the worker. Such requests are termed "field requests" and the probability of the worker 


\subsubsection{Field Requests by OOE Contractors for Special Counts (contd)}

having internal contamination is considered to be very low. All field requests are channeled through the Internal Dosimetry Group.

The Internal Dosimetry Group determines which measurements should be performed and coordinates appointments with the WBC scheduler and the contractor.

\subsubsection{Incident Requests}

When a worker is involved in a contamination release where a high probability of internal deposition exists, the event is called an incident. Requests for WBC measurements for the worker are phoned immediately to the Internal Dosimetry Group.

\subsubsection{Urine Sample Requested by Internal Dosimetry Group}

The Internal Dosimetry Group may request a spot urine sample from selected individuals involved in potential exposures. Employee information obtained and attached to the sample bottle includes (Exhibit 1.1):

- initials and last name

- payroll or social security number

- contractor

- current date

- analysis request code.

United States

Testing Company
Normally the United States Testing Company (UST) will pick up any samples at the WBC on the same day they are given. Should additional sampling kits be required, a detailed map showing the location of the individual's home should be obtained and given to UST so that the kits can be delivered.

\subsection{AUTHORIZATIONS FOR IN VIVO MEASUREMENTS}

In vivo measurements are performed whenever a count authorization has been received. The three types of recognized and accepted authorizations are described in the following sections.

\subsubsection{Computerized Authorization - Occupational Radiation Exposure Tracking System}

The occupational radiation exposure (ORE) system allows any $D O E$ contractor to input the initial request for a $W B C$ measurement. All WBC requests for measurements for new hires, terminations, and employees beginning or ending a 


\subsubsection{Computerized Authorization - Occupational Radiation Exposure Tracking System (contd)}

special project involving radioactivity, and routine measurements should be scheduled by this method. Any questions regarding ORE should be directed to:

\section{Technical Specialist/Radiation Records} 376-6549

Federal Building, Room 301-F

PNL 700

Computerized scheduling eliminates the need for an employee to transmit the written authorization for a WBC measurement. This method of automated-measurement request aids the scheduling by tallying the number of counts that are requested daily. The WBC staff is also alerted to the worker's previous WBC measurement history through the automated system.

The WBC staff updates the ORE tracking systern file daily, by recording whether or not employees keep their scheduled appointments for measurements. Each contractor has access to this updated file to record any appointments that were not kept.

\subsubsection{Written Authorizations}

Written authorizations are normally hand carried by the employee and presented to the WBC technician upon arrival. The request specifies the employee's name, payroll number, social security number, the reason for the count, and type of measurement required. Although these written requests are honored, the automated scheduling using ORE should be utilized whenever possible.

\subsubsection{Special Authorizations}

This type of authorization is requested by the Internal Dosimetry Group. Additional measurements may be performed on individuals for any of the following reasons:

- unusual exposures

- field request

- evaluator requests

- follow-up measurements.

\subsection{SCHEDULING \\ The procedures for scheduling the different in vivo meas -} urements are described in this section. 


\subsubsection{Routine Whole Body Counts}

For DOE contractors, no specific time is assigned for the routine whole body count and a measurement will be performed on a walk-in basis as long as proper authorization has been received.

\subsubsection{Lung and Head Counts}

All contractors should contact the $W B C$, scheduler at 376-4785 in advance for an appointment (a) for a routine lung or head count. The contractor then prepares a list containing the following information for each employee tentatively scheduled for an appointment

- initials of first and middle name and complete last name

- payroll number

- social security number

- count reason (new hire, routine, beginning or end of special project involving radioactivity, visitor, or termination)

- desired appointment time and date

- Type I or Type II measurement.

This list is forwarded to:

$$
\begin{aligned}
& \text { WBC Scheduler } \\
& 747 A / 700 \\
& \text { PNL }
\end{aligned}
$$

The scheduler confirms the appointment and notifies the contractor if any exam requires rescheduling. Appointments are scheduled at times that will not interrupt the in vivo examinations in progress. An answering machine is used to record requests during the times that technicians are busy. The DOE-contractor appointments are scheduled during the most convenient times of the workday. Non-DOE contractors may have the remaining appointment openings.

(a) The Internal Dosimetry Group may have contacted the contractor about performing special measurements in conjunction with the next routinely scheduled count. The WBC scheduler should be notified of this by the contractor when the routine lung count is scheduled. 


\subsubsection{Handling DOE-Contractor Employees Without Authorization Papers}

Any contractor employee arriving at the WBC for a who?e body count without prior authorization must fill out the preliminary record information (name, payroll number, and social security number). The WBC technician will then call the designated contractor representative from the Company Contacts List (Table 1.1).

The representative will specify the type of count(s) required. If the representative requests a lung count in addition to the whole body count, both counts will he performed that day only if the current schedule could continue without interruption. If not, the WBC technician will schedule an appointment on another day.

\subsubsection{Handling Non-DOE-Contractor Employees Hithout Authorization Papers}

A non-DOE-contractor employee requesting $\mathrm{WBC}$ measurement without prior authorization should be asked to wait in the reception area. Before any count is performed, the contract and count type should be verified with the WBC manager or the senior WBC technician. Any telephone contact with these company representatives should be handled by the WBC manager.

\subsubsection{Visjtors Entering Radiation Areas}

Visitors sometimes require measurements before and after entering radiation areas. Most visitors to DOE contractors will have a special payroll number issued to them by Radiation Records (PNL) before arriving at the WBC.

Typically these visitors are employed as under special programs (e.g., NORCUS). Issued payroll numbers usually begin with $A G---, \varphi G---, O G---, I G--$, RG--., and $X G---$.

A release form (see Exhibit 1.2) must be signed at the WBC for all visitors issued an $R G---$ payroll number. The signed release form allows all radiological exposure information to be forwarded. All release forms are given to:

Specialist/Radiation Records

376-6342

Federal Building 301-i

PNL 700

\subsubsection{Visitors Who Come to the WBC for Special Measurements}

In vivo measurements by special request shait have a special visitor payroll number FG-.-. This type of request usually would come for an individuai who is not from the Hanford Site. The specia? measurement is 
TABLE 1.1 List of Company Contacts

\begin{tabular}{|c|c|c|c|c|c|}
\hline Company Name/Code & Code & $\begin{array}{l}\text { Payro11 } \\
\text { Numbers } \\
\end{array}$ & $\begin{array}{c}\text { Company } \\
\text { Representative }\end{array}$ & Count Types & $\begin{array}{l}\text { Telephon } \\
\text { Number }\end{array}$ \\
\hline $\begin{array}{l}\text { Boeing Computer } \\
\text { Services (BCS) }\end{array}$ & $E$ & 4---- & Mary Ann Hensyel & All & $376-3538$ \\
\hline $\begin{array}{l}\text { U.S. Department } \\
\text { of Energy (DOE) }\end{array}$ & 9 & G- - - & Gerry Yesberger & A17 & $376-7463$ \\
\hline Exxon & $x$ & $X V X--$ & $\begin{array}{l}\text { Kathy Kendall } \\
\text { Tom Probasco (alt.) }\end{array}$ & $\begin{array}{l}\text { A11 } \\
\text { A11 }\end{array}$ & $\begin{array}{l}375-8197 \\
375-8193\end{array}$ \\
\hline $\begin{array}{l}\text { Hanford } \\
\text { Engineering } \\
\text { Development } \\
\text { Laboratory (HEDL) }\end{array}$ & $v$ & $9-\ldots$ & $\begin{array}{l}\text { Nancy Perfect } \\
\text { Iva Schrimsher }\end{array}$ & $\begin{array}{l}\text { All } \\
\text { All }\end{array}$ & $\begin{array}{l}376-5315 \\
376-5083\end{array}$ \\
\hline $\begin{array}{l}\text { Hanford Environ- } \\
\text { mental Health } \\
\text { Foundation (HEHF) }\end{array}$ & M & $B G--$ & Mary Ann Hensyel & All & $376-3538$ \\
\hline J.A. Jones (JAJ) & $\begin{array}{l}T \\
S\end{array}$ & $\begin{array}{l}\text { Y or } Z-\cdots- \\
\text { YA--- }\end{array}$ & $\begin{array}{l}\text { Nancy Lucke } \\
\text { Carole Weaver }\end{array}$ & $\begin{array}{l}\text { All } \\
\text { (Sub-cont) }\end{array}$ & $\begin{array}{l}376-9665 \\
376-6616\end{array}$ \\
\hline Kaiser (KEH) & $k$ & $k-\cdots$ & Steve Letson & A11 & $376-5291$ \\
\hline $\begin{array}{l}\text { Pacific Northwest } \\
\text { Laboratory (PNL) }\end{array}$ & $D$ & $3-\cdots$ & $\begin{array}{l}\text { Denise Martin } \\
\text { Mary Ann Hensyel }\end{array}$ & $\begin{array}{l}\text { Rout ines } \\
\text { All others }\end{array}$ & $\begin{array}{l}376-4830 \\
376-3538\end{array}$ \\
\hline $\begin{array}{l}\text { Rockwe } 11 \text { Hanford } \\
\text { Operations (RHO) }\end{array}$ & B & $6---$ & $\begin{array}{l}\text { Teresa Wirth } \\
\text { Corrine Corbin }\end{array}$ & $\begin{array}{l}\text { A11 } \\
\text { Routines }\end{array}$ & $\begin{array}{l}373-4277 \\
373-3477\end{array}$ \\
\hline $\begin{array}{l}\text { United Nuclear } \\
\text { Corporation (UNC) }\end{array}$ & $H$ & $5--$ & $\begin{array}{l}\text { Karen Sheeran } \\
\text { Vicki Llewellyn (alt.) }\end{array}$ & $\begin{array}{l}\text { Routines } \\
\text { All others }\end{array}$ & $\begin{array}{l}373-4938 \\
373-4546\end{array}$ \\
\hline U.S. Ecology & N & XVN-- & Mike Nolan & All & $377-241$ \\
\hline $\begin{array}{l}\text { Allied Nuclear } \\
\text { Company }\end{array}$ & 2 & $X V Z--$ & (a) & & \\
\hline $\begin{array}{l}\text { Pacific Nuclear } \\
\text { Systems }\end{array}$ & $\mathrm{L}$ & $X V L=$ & (a) & & \\
\hline $\begin{array}{l}\text { Teledyne } \\
\text { Wah Chang, } \\
\text { Albany }\end{array}$ & 0 & FG--- & (a) & & \\
\hline
\end{tabular}

(a) Contact WBC manager at 376-6257. 


\subsubsection{Visitors tho Come to the WBC for Special Measurements \\ (contd)}

requested by the WBC manager or DOE. Under this circumstance, the WBC technician will call PNL Radiation Records at 376-1513 for the payroll number assignment.

\subsubsection{Foreign Visitors}

Foreign nationals do not have social security numbers. Since data input requires information in this field, a special number is generated. The number for a foreign visitor would be $999-X X-X X X X$. These special numbers have a 999 prefix and the individual's birthdate is entered (month/day/year) in place of the Xs to complete the number. A special payroll number is assigned to foreign visitors by Radiation Records.

\subsubsection{Non-DOE-Contractor Requests}

Whole Body Count

Whenever five or more employees from the same company are to be measured on one day, the WBC scheduler (376-4785) should be notified in advance. This advance notice will allow the WBC staff to schedule a specific time for the measurements that will not interfere with any DOEcontractor appointments. A written authorization should be hand carried by the employee and presented to the WBC technician upon arrival at the $W B C$.

Lung Count This measurement requires an appointment by calling the $W B C$ scheduler at $376-4785$.

Emergency Counting Notify the WBC Manager at 376-6257.

\subsection{PRELIMINARY PROCEDURES FOR IN VIVO NEASUREMENTS}

Subjects arriving at the WBC will fall into one of three categories:

- the routine scheduled whole body count

- the routine scheduled lung or head count

- a nonroutine count resulting from a contamination incident or a field request or a follow-up count from an incident or field request.

A description of these counting procedures is given in Section 3. 


\subsubsection{In Vivo Count Request Form}

When the routinely scheduled subjects arrive they will be listed on the computer scheduling sheet or have an In Vivo Count Request form generated by their employer's radiation protection operation. This request will be checked for accuracy and the subject will be asked to fill out the top part of an In Vivo Count Record, form A-1200-269(3-84) shown in Exhibit 1.3.

\subsubsection{Assuring Measurement of Internally Deposited Radiation}

To assure that only internally deposited radioactivity is measured and to limit the amount of naturally occurring radioactivity being transferred into the shielded enciosures, several precautions are taken.

For a routine whole body count the person removes only his shoes and puts on a pair of paper slippers. If the measurement shows a detectable amount of radioactivity, the person then showers, washes his hair and changes into a pair of cotton coveralis and is counted again to deterinine if the radioactivity was located on the skin, clothing, or if it is truly internaliy deposited.

1.4.3 Lung Count For a routine lung count, the person showers, puts on a pair of cotton coveralls and paper slippers. If the lung measurement shows a detectable amount of radiaoactivity, the person showers again, washes his hair, and is recounted.

\subsubsection{Potential Contamination in the Last 24 Hours}

In cases where the person has potential internal contamination from an incident that happened in the last

24 hours, the person must first be monitored at the WBC for external contamination by a radiation protection technologist. After this monitoring, which is done in the change room, the person showers, washes his hair, and puts on a pair of coveralls before being counted.

\author{
Storage of Street \\ Clothes and Personal \\ Effects
}

When a change of clothing is necessary, the street clothing is placed in lockers in the change room. The person brings all valuable personal items with him to be placed nearby and in view while he is being counted. Valuable personal items can also be checked with the WBC technician.

\subsubsection{Information and Safety Instructions for the Subject}

The person being measured should be asked if he has had a previous whole body count. If the answer is yes, he can be placed in the WBC while briefly reviewing the safety aspects of the counting procedure. If the answer is no, a 


\subsubsection{Information and Safety Instructions for the Subject (contd)}

brief description on the purpose, method, safety precautions, and noninvasiveness of the procedure should be given to him by the technician. A brochure on the whole body counting operation should also be offered to him at the completion of the measurement (see Appendix A). If the person has further questions, he should be referred to the $W B C$ manager.

\subsection{REPORTING OF RESULTS}

Results are communicated to ORE and the Internal Dosimetry Group. It is the responsibility of the Internal Dosinetry Group to assure that contractors are aware of the resuits. Completed in vivo measurement results are transmitted by magnetic tape into the ORE data base on a weekly basis. An audit and reconciliation of the rejected records is performed by the PNL Radiation Records staff. After the records have been accepted, each contractor may access results for their employees. Letters to each individual are generated based upon predetermined reporting levels of radioactivity.

\subsubsection{Routine Counts That Show No Radioactivity: DOE Contractors}

Routine measurements during which no activity was detected, are reported to the Internal Dosimetry Group on a weekly basis.

\subsubsection{Field Requests, Incidents, or Positive Counts}

Results of the examination are immediately conveyed to the Internal Dosimetry Group. This group interprets the internal occupational dose for the contractor representative and involved employee. Additional follow-up measurements as well as bioassay sampling may be requested to complete the evaluation.

\subsubsection{Handling Concerned Subjects' Questions About Results}

Many individuals are unaware that naturally occurring radiation such as potassium- 40 is contained in the human body. When potassium-40 is the only radionuclide detected, the WBC technician gives the subject a brief explanation that the count was normal.

The brochure, The Hanford whole Body Counting Center is also available in the lobby for individuals wanting more information. A copy is included in Appendix A. 


\subsubsection{Handling Concerned Subjects' Questions About Results}

(contd)

Subjects who have detectable activity are instructed to call their radiation protection officer for exam results. If the subject wants inmediate information or seems worried, a staff member from the Internal Dosinetry Group will talk to the individual in person or by telephone.

Those individuals needing technical information are referred to the WBC Manager.

\subsubsection{Reporting Non-DOE-Contractor Resu1ts}

A11 results are mailed biweekly to the company representative for radiation protection. Results are telephoned to the representative immediately when any subject is measured at the specified company's reporting level. Any questions regarding results are referred to the WBC manager at 376-6257. 
EXHIBIT 1.1 Urine Sampie Bottie Label Form

NAME :

SS OR PAYROLL \#:

CONTRACTOR :

DATE:

ANALYSIS REQUEST CODE:

DATE ISSUED: $9 / 86$ supersedes

ISSUE DATED:
PNL-MA-574

PNLMA.576




\section{EXHIBIT 1.2 Release Form}

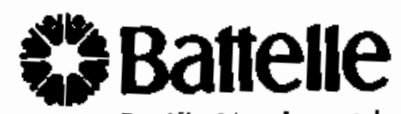

Pacific Northwest Laboratories P.O. Box 999

Richland, Washington U.5.A. 99352

Telephone (509)

Telex 15-2874

I authorize release of my updated radiation exposure records to:

Company Name:

Company Address:

My payrolt number is and my Social Security Number is

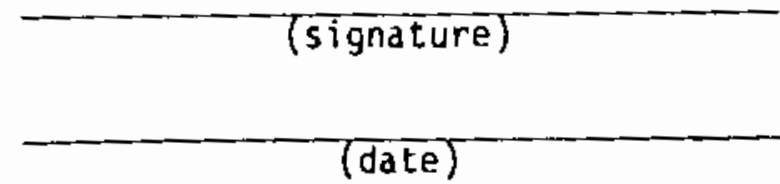




\section{G Bantelle}

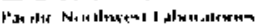

\section{IN - VIVO COUNT RECORD}

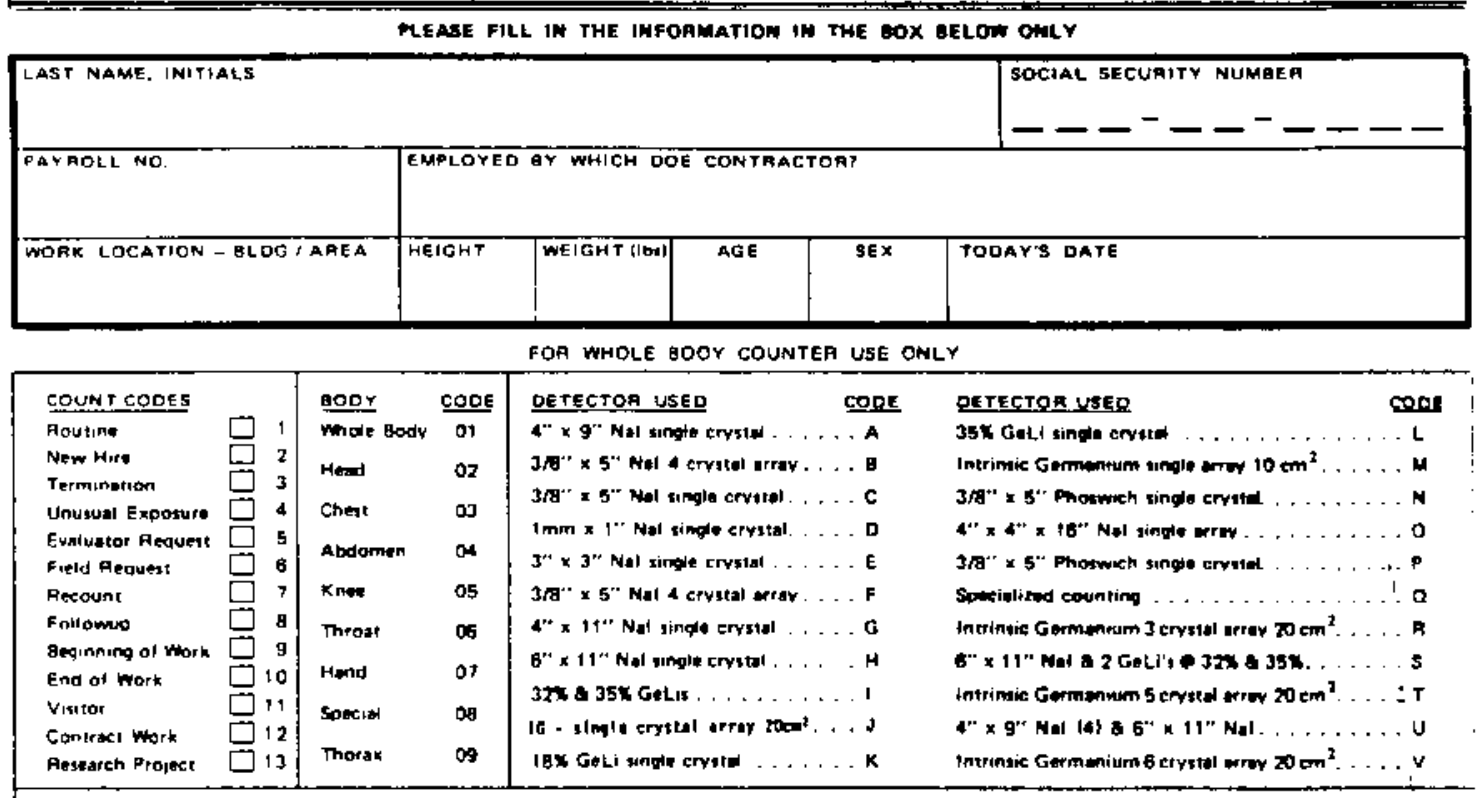

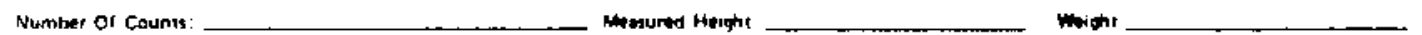

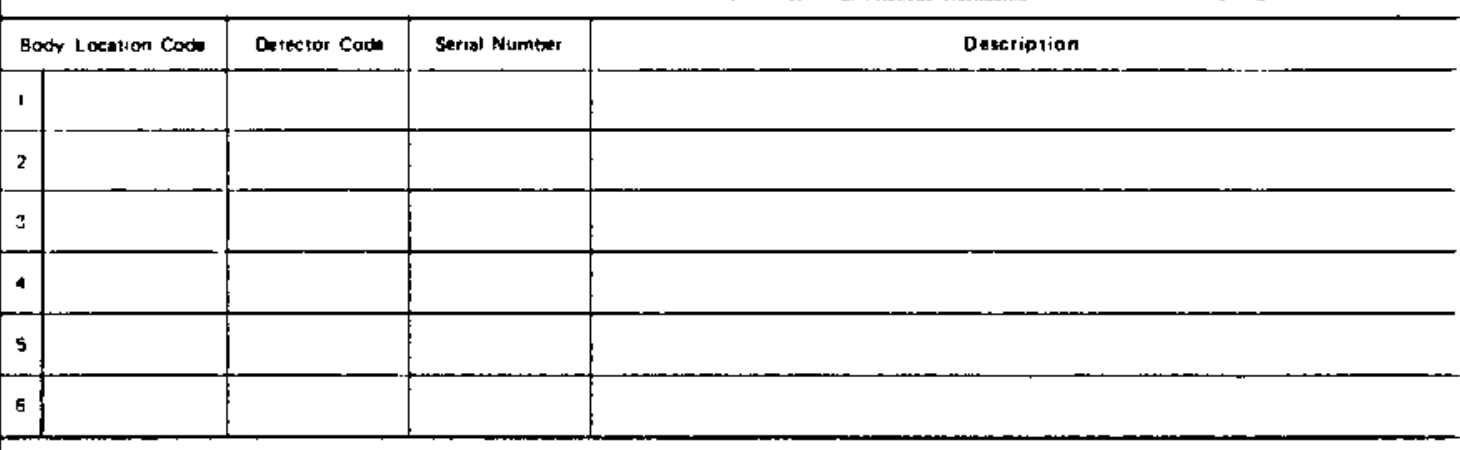

REDUIREO

PAOCEDUAEISI

1. Sample

2. Calc.WBC

J. Colc.CHEST

4 Calc.Snex

5 Precard.SPLOG

6. Accountobitity
AEQUIFED

PAOCEOURE (S)

COMPLETED

7. Form Raturn

g. Protisi.

9. Phone Exalupior

rd. Add Comment

11. Oiner 



\subsection{EQUIPMENT AND FACILITIES}

The Hanford Whole Body Counting (WBC) facility maintains state-of-the-art equipment to provide the best results possible for the approximately 11,000 measurements that are made each year. Most of the measurements are made with equipment located in the $747 \mathrm{~A}$ Building. However, other facilities do exist in the Emergency Decontamination Facility (EDF) located adjacent to Kadlec Hospital in the city of Richland, and in two mobile units that can be transported to any location when needed.

\subsection{SHIELDED FACILITIES}

Most of the procedures used in whole body counting require shielding to significantly reduce the natural background radioactivity associated with building materials, soil, air, and cosmic rays. These shielded facilities reduce the background by a factor of 50 to 100, depending on the energy of the radiation. The shielded facilities are briefly described in the following sections.

\subsubsection{Shielded Rooms}

The largest of these shielded rooms (shown in Figure 2.1) has 10-in.-thick iron walls, ceiling, and floor. The iron is material of low-background activity salvaged from a World War II battleship. A lung counter is installed in this room to measure plutonium, americium, uranium, and other low-energy photon emitters. A graded shield of lead, then cadmium, and then copper has been added to the inside of the room to further reduce the background at low energies. For further details on this room refer to the report Hanford Whole Body Counter 1959 Activities by Roesch, McCall and Palmer, available in the WBC Tibrary.

A second room has 4-in.-thick lead walls, ceiling, and floor that are covered by a thin layer of copper. This room is used for special types of measurements associated with contamination incidents. The room is also used for detailed linear scanning, for calibration studies, and the development of improved instrumentation and methods for in vivo measurement of radionuclides.

A third room (Figure 2.2) is also made of 4-in.-thick lead and is only large enough for a person to stand. This counter is called the preview counter (also known as the upright counter) because almost all people who come to the whole body counter are measured in this counter first to quickly determine if any significant gamma-ray-emitting radionuclide is present. Any significant quantity is then more thoroughly evaluated on a shadow shield counter. For 


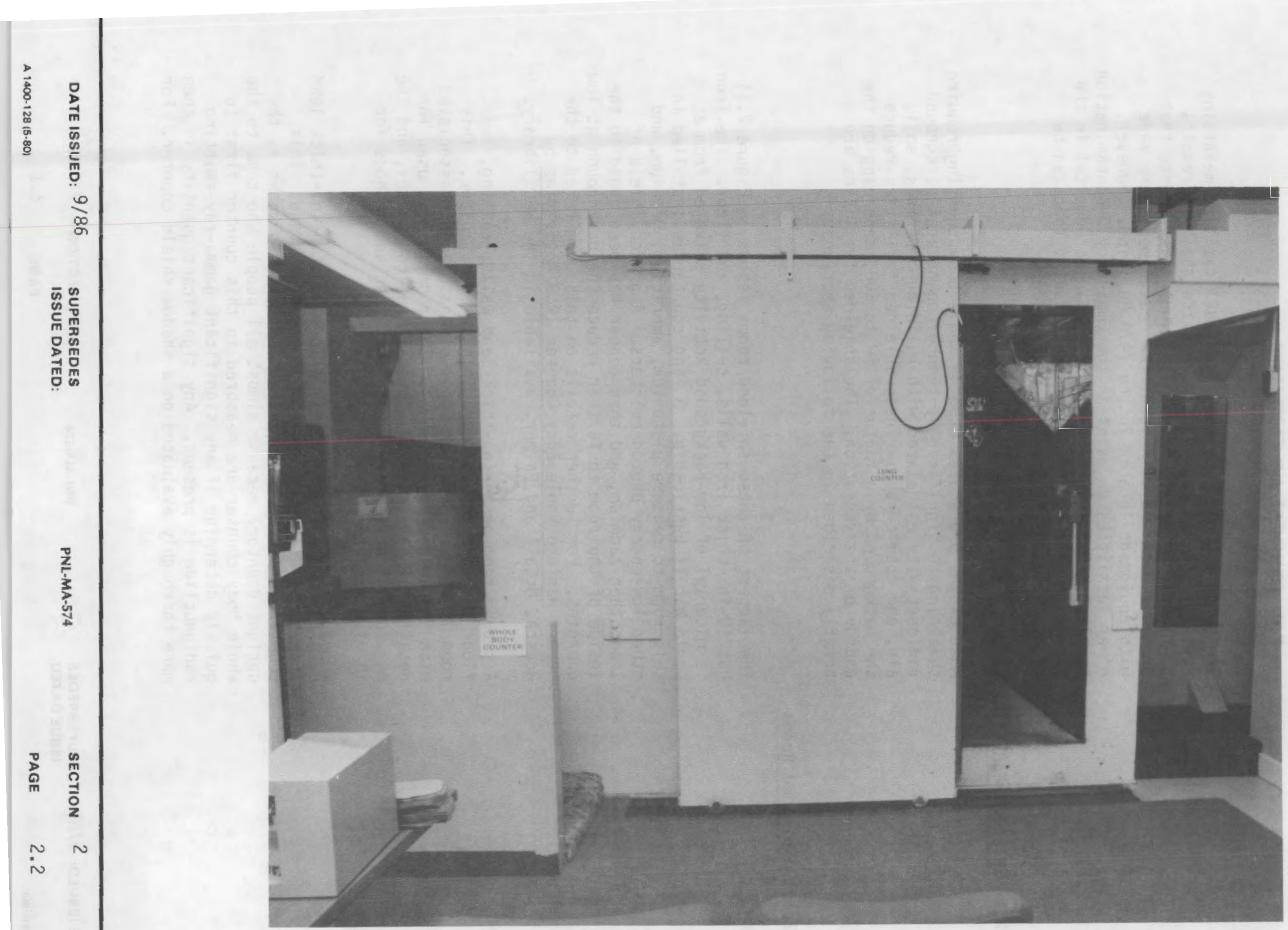

FIGURE 2.1. Iron Shielded Room 


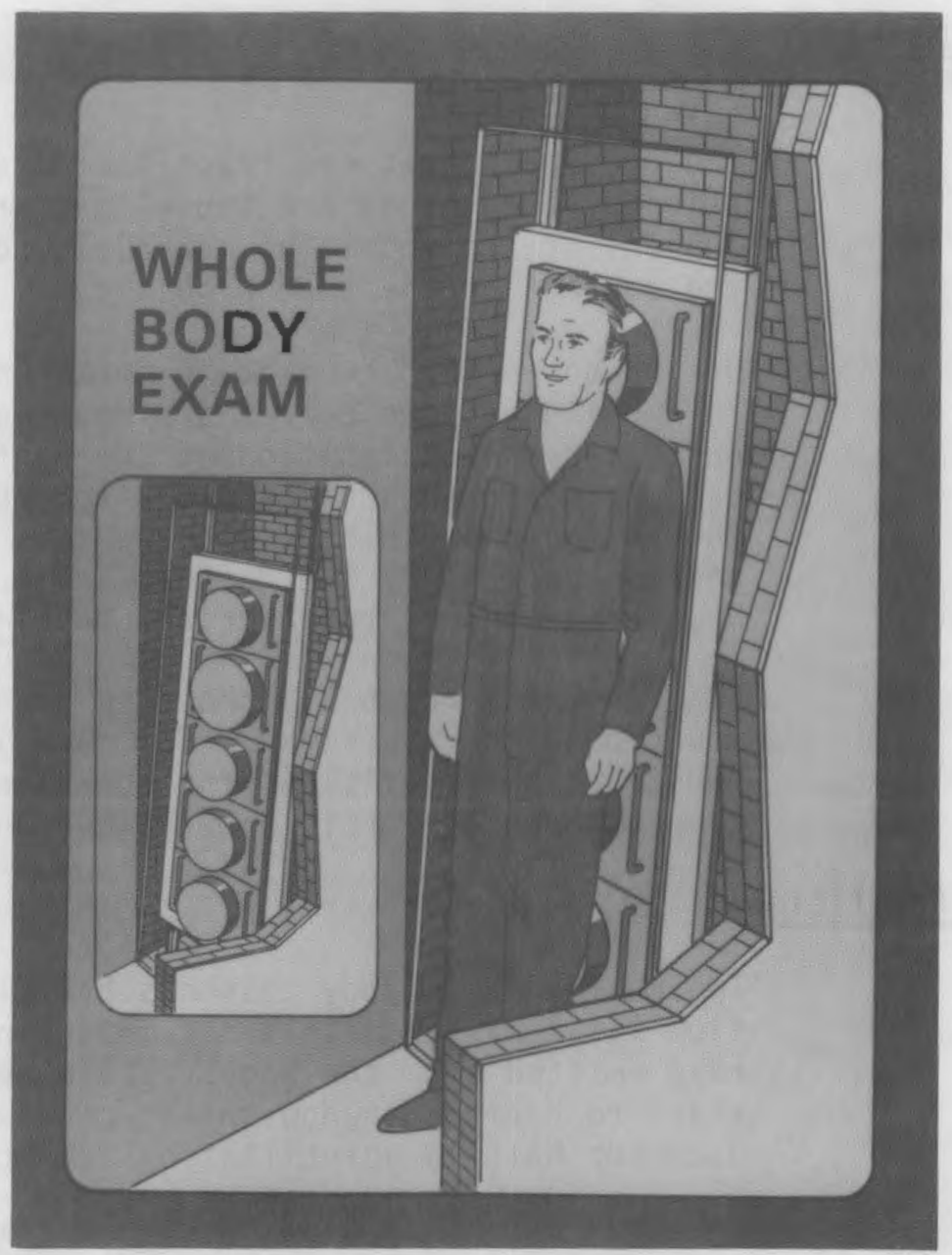

FIGURE 2.2. Preview Counter

$2.1 .1 \frac{\text { Shielded Rooms }}{(\text { contd })}$

more details on this room refer to the report Hanford
Whole Body Counter 1983 Activities.

\subsubsection{Shadow Shields}

In shadow-shield-type counters a shield surrounds all but one side of the detector. The subject is in front of this open side. A shield behind the subject, the "shadow shield," is large enough and placed so that no photon traveling in a straight line from that side can enter the detector without passing through the shield. This shield "casts a shadow" over the opening in the detector shield.

(a) Palmer, H. E., G. A. Rieksts and H. B. Spitz. 1984. Hanford Whole Body Counter 1983 Activities. Internal report of the Pacific Northwest Laboratory, Richland, Washington. 


\subsubsection{Shadow Shields \\ (contd)}

The only rays that can reach the detector without attenuation by the shield are those that are emitted from the subject or the shielding material and those scattered from the subject or the shadow shield.

One shadow-shield counter is permanently installed in the 747A Building, two others are mounted in mobile truck units for use on location at the Hanford Site, emergency use, or research studies away from the Hanford Site. A fourth shadow-shield-type counter is located in the EDF and is operated by the Hanford Environmental Health Foundation (HEHF) radiosurgery facility.

Figures 2.3 through 2.5 show the shadow-shield counters mounted in the truck/van. For more information on the construction details and the operation of shadow-shield counters see the article by Palmer and Roesch (1965).

\subsubsection{Mobile Facilities}

Two mobile whole body counters briefly described in Section 2.1.2 are available for measuring high-energy gamma rays emitted from the body. These units contain the standard Hanford shadow-shield counter with 11.5-in.diameter $\mathrm{NaI}(\mathrm{TI})$ scintillation detectors.

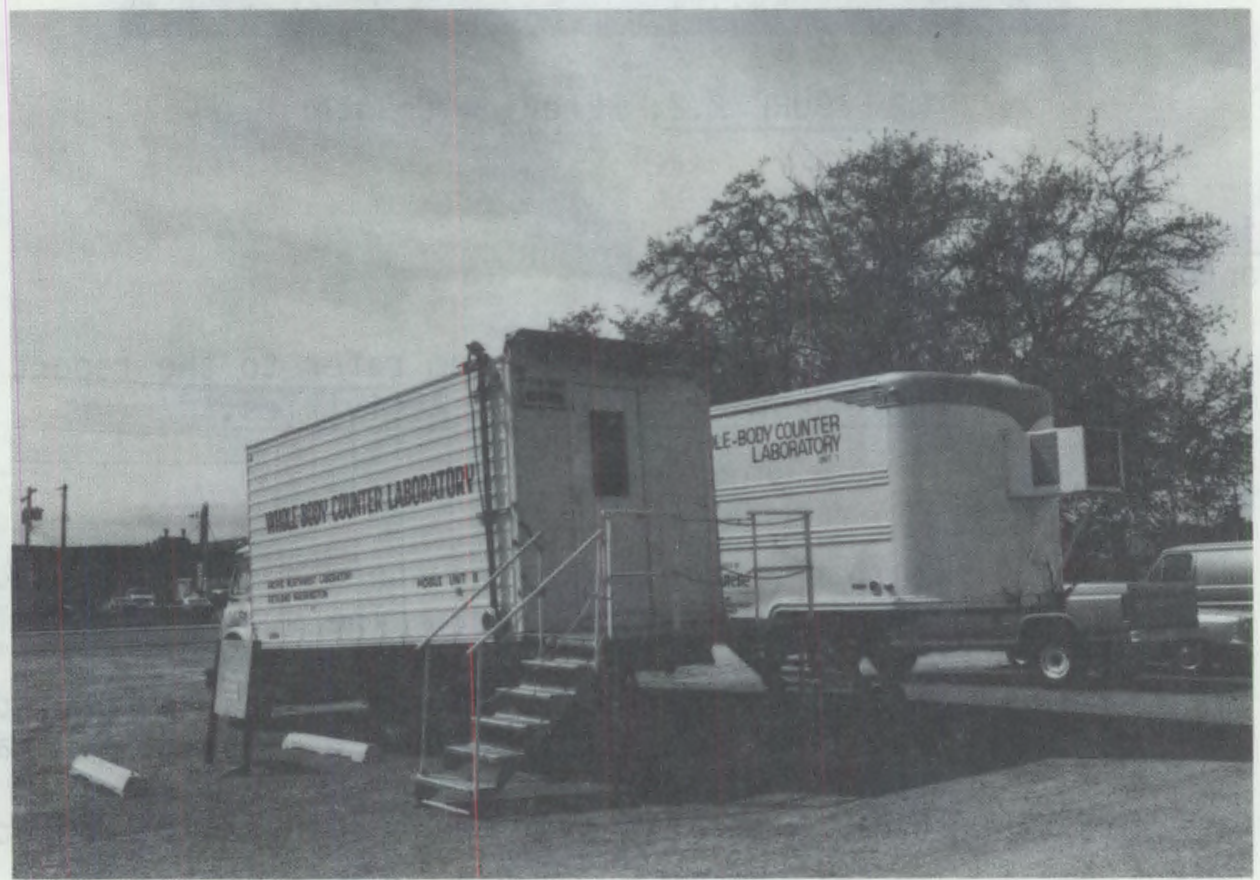

FIGURE 2.3. An Outside View of the Two Mobile Units Containing the Shadow-Shield Counters 


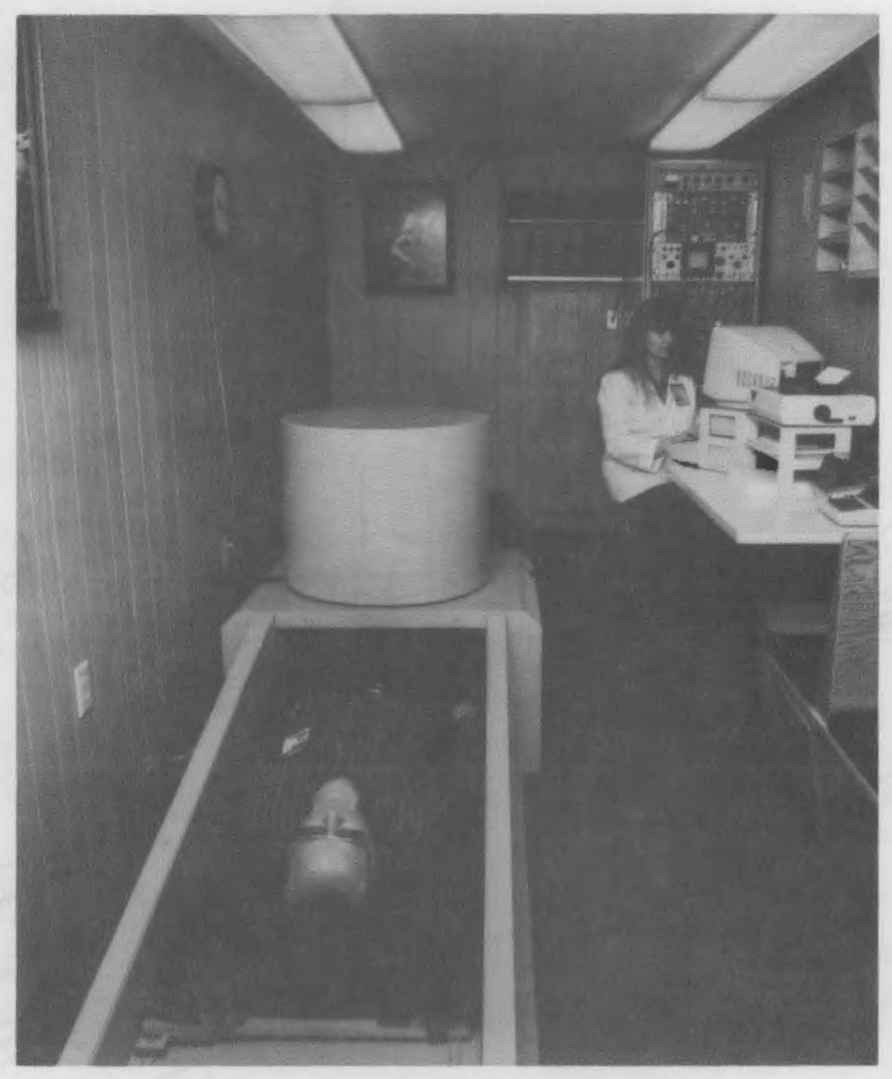

FIGURE 2.4. A View of the Shadow-Shield Counter Inside One of the Mobile Units

\subsubsection{Mobile Facilities}

One unit is mounted in a truck/van and the other is mounted in a semitrailer. These units can be powered from existing 115 - or $230-V$ commercial power or by a portable power generator unit. The background and sensitivity of these counters is very similar to that of the shielded rooms except at locations near nuclear facilities.

More detailed information on these units is available in two reports that are available in the WBC library (Swanberg 1963; Eichner 1969).

\subsubsection{Equipment in the EDF}

Occasionally in vivo measurements are done at the EDF when a worker becomes so extensively contaminated that he may contaminate the low background WBC facilities in the 747 Building or when a contaminated injury has occurred. For these purposes some equipment is maintained at the EDF. 


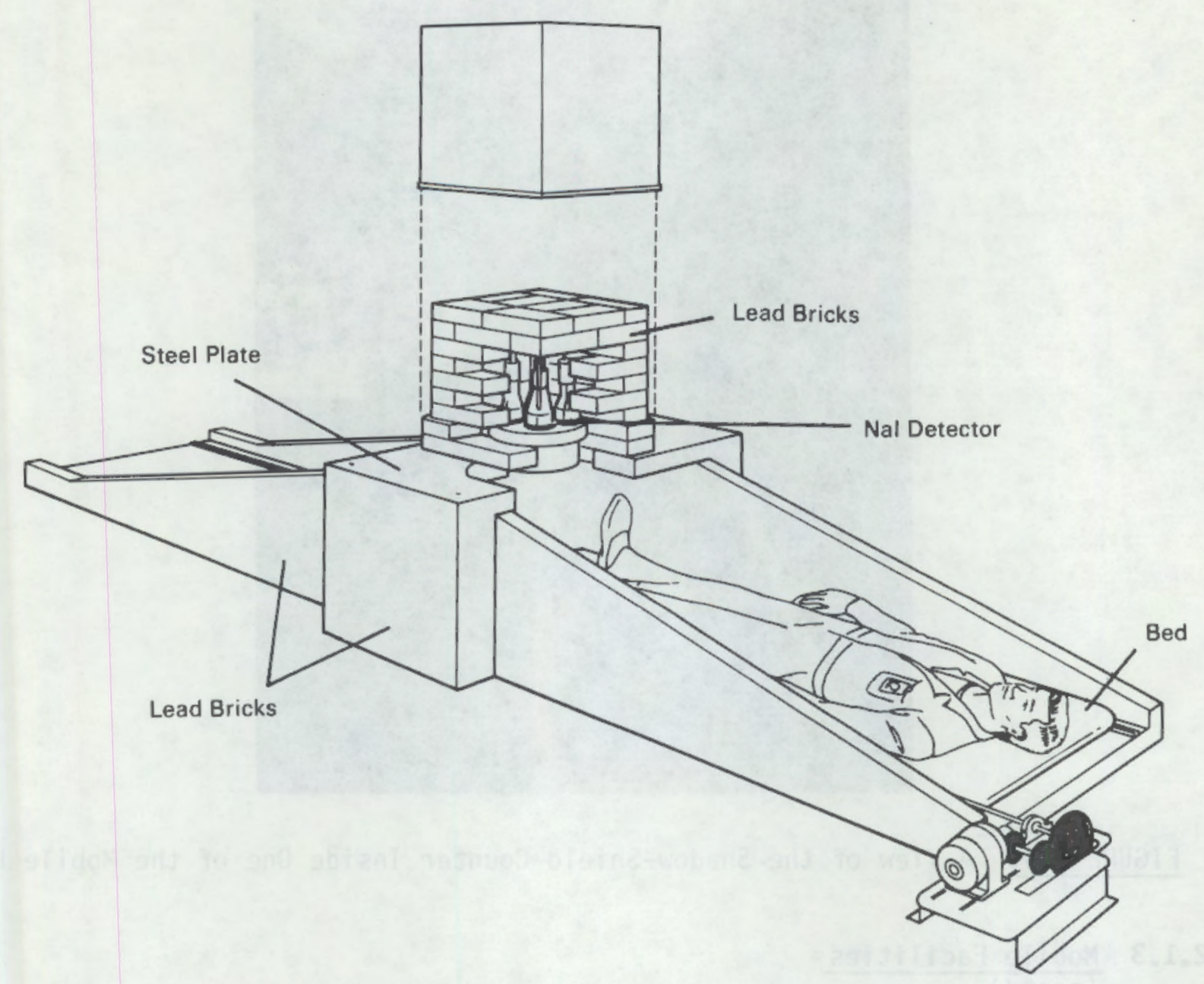

FIGURE 2.5. Shadow-Shield Whole Body Counter Mounted in the Mobile Unit (truck/van)

\subsubsection{Equipment in the EDF (contd)}

2.2 DETECTORS

This equipment includes a modified shadow-shield whole body counter in which the total body and lung, liver, or bone measurements can be made; a planar germanium detector and a multichannel analyzer (MCA) for measuring plutonium239 and americium-241 in wounds; and a medical gamma camera for imaging high levels of radioactivity in the various organs of the body. The laboratory and hood at the EDF are also utilized in the preparation of radioactive calibration solutions and sources, and phantom organs for calibrating the whole body counters.

The two main types of detectors used for whole body counting are scintillation and semiconductor detectors. Refer to the book by G. F. Knoll entitled Radiation Detection 


\subsection{DETECTORS \\ (contd)}

and Measurement, located in the WBC library for a detailed description of the following detectors.

\subsubsection{Scintillation Detectors}

The scintillation detectors are mostly NaI(Ti) crystals ranging in size from $1 \mathrm{~mm}$ thick and $1 \mathrm{in}$. in diameter to 6 in. thick and $11.5 \mathrm{in}$. in diameter.

\subsubsection{Semiconductor Detectors}

Three types of semiconductor detectors are used for whole body counting: coaxial germanium detectors used for higher-energy gamina-ray measurements; planar germanium detectors used for low-energy photons between 10 and $200 \mathrm{keV}$; and lithium-drifted silicon detectors used to measure and separate the 20.16- and 20.78-keV L-gamma peaks for determining the plutonium-239-to-americium-241 ratio in plutonium wounds.

\subsubsection{Other Detector Types}

Other detectors that are used occasionally are the CdTe probe for use on plutonium wounds and the Phoswich detectors.

\subsection{DATA ACQUISITION AMD PROCESSING EQUIPMENT}

The electronic pulses from the detectors are analyzed, stored, and displayed by several MCAs. These spectra are then transferred to a Hewlett Packard HP-9000 minicomputer. This computer has 2 megabytes of memory and has a hard disk capacity of 404 megabytes.

Spectra files are handled by a data base management system called IMAGE. The computer system has a built-in graphics capability for displaying spectra on a cathode ray tube (CRT), $X-Y$ plotter, or graphics printer.

Once the spectra are in the computer, all calculations, storage, and reporting of data and results are handled by the main FORTRAN 77 program called EXEC. The computer is also interfaced to the ORE data base system on the UNIVAC $1100 / 44$.

The routine counting operations are controlled by the computer which provides instantaneous calculation of results and plots of unusual spectra.

For more detailed information, consult Section 6 of this manual, and the hardware, software, and maintenance manuals that are available in the WBC library. 


\subsection{CALIBRATION METHODS}

To determine the amount of radioactivity in the body, the detector response must be calibrated in terms of counts per photon emitted from the body. This is done by placing known amounts of radioactivity in an anthropomorphic phantorn or an organ of the phantom and making a measurement of the activity in a standard reproducible position that will be used with people.

Details on calibration procedures, factors, and curves are given in Section 3 of this manual. Several types of phantorns are used and described in the following sections.

\subsubsection{Bottle-Manikin-Absorption Phantom}

The bottle-manikin absorption (BOMAB) phantom shown in Figure 2.6 consists of 10 polyethylene containers of sizes, which when appropriately assembled, are roughly equal to the size, weight, and shape of a Reference Man (ICRP 1975). The containers can be filled with solutions of known quantities of a radionuclide for calibration purposes. The liquid capacity of each part of the phantom is given in Table 2.1.

This phantom is used for the whole-body calibration of radionuclides uniformly distributed throughout the body. The phantom does not provide quite the amount of absorption as an actual human body and the correction factor which ranges from $10 \%$ to $25 \%$ must be applied, depending on the gamma-ray energy. Details of this correction will be given in Section 3 on calibrations.

\subsubsection{Radiation-Equivalent-Manikin-Absorption Phantom}

The radiation-equivalent-manikin absorption (REMAB) phantom shown in Figure 2.7 is constructed of radiolucent plastic shells and contains a human skeleton. The entire body and organs can be filled with known quantities of radioactive solutions. The skeletons come from India and are typically smaller than the average U.S. male; therefore, this phantom is rarely used at Hanford for whole body calibration purposes.

\subsubsection{Tissue-Equivalent Torso Phantom}

The tissue-equivalent torso phantom is shown in Figure 2.8. This phantom was specifically constructed for calibration of counting systems used to measure transuranic nuclides in the lung, liver, and pulmonary lymph nodes. However, it is also useful for high-energy gammaemitting radionuclides in the lung and liver. 


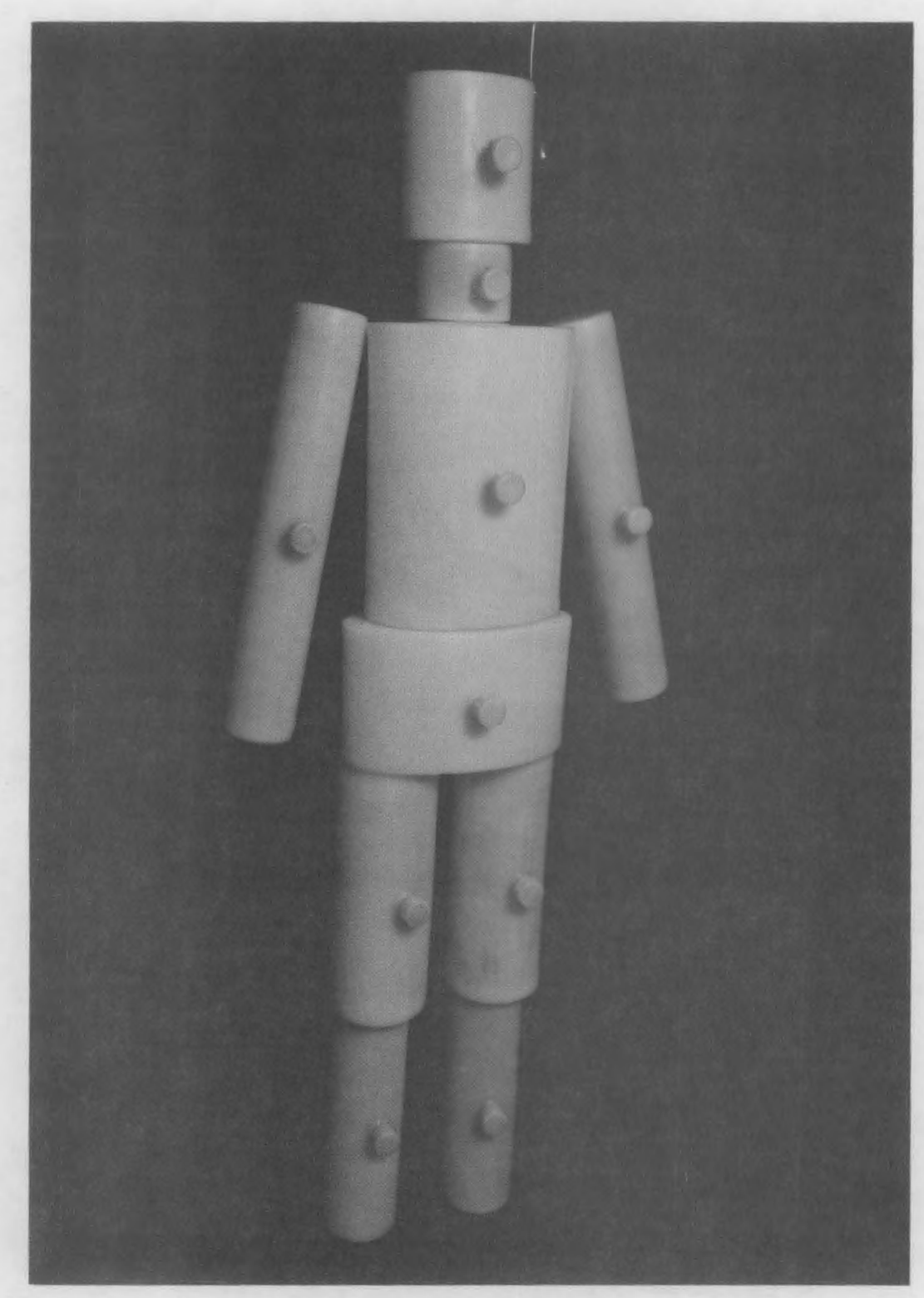

\section{FIGURE 2.6. BOMAB Phantom}

TABLE 2.1. Weight and Liquid Capacity of the BOMAB Phantom

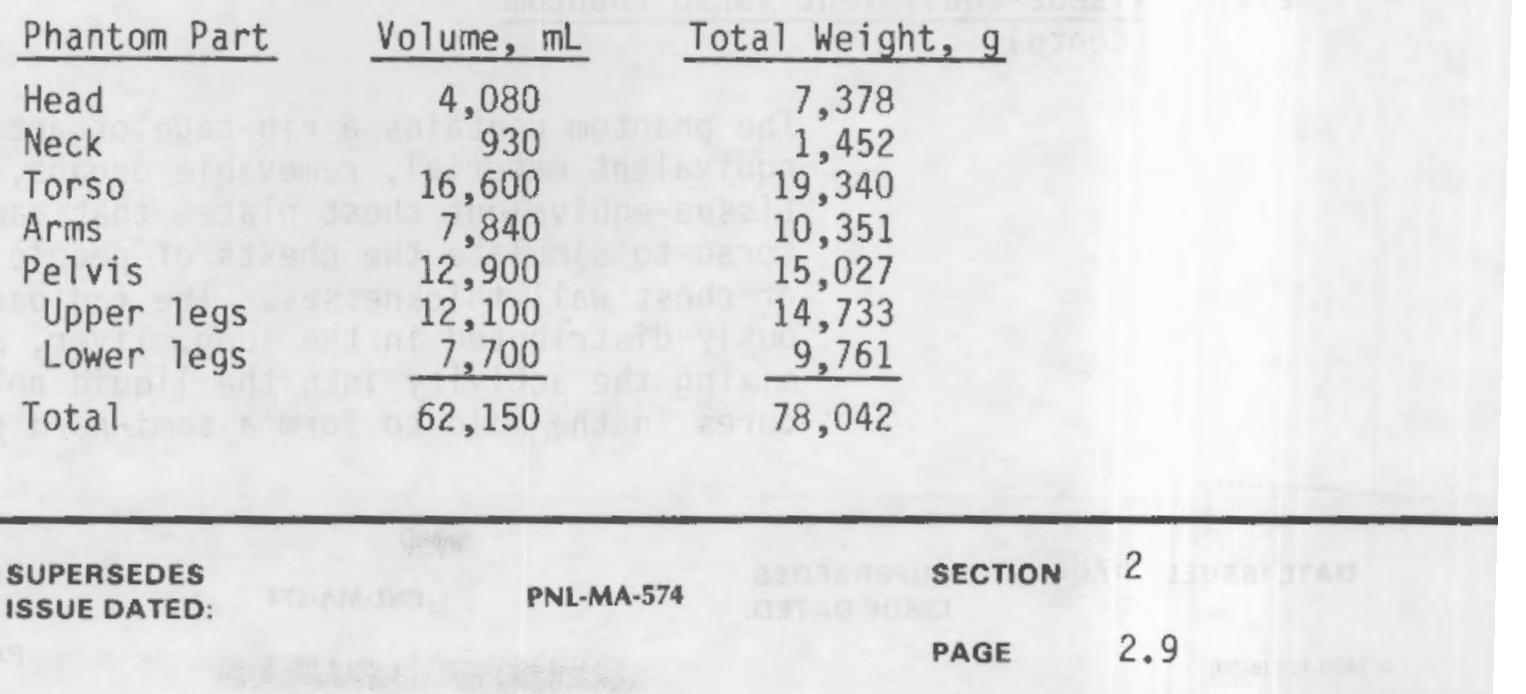




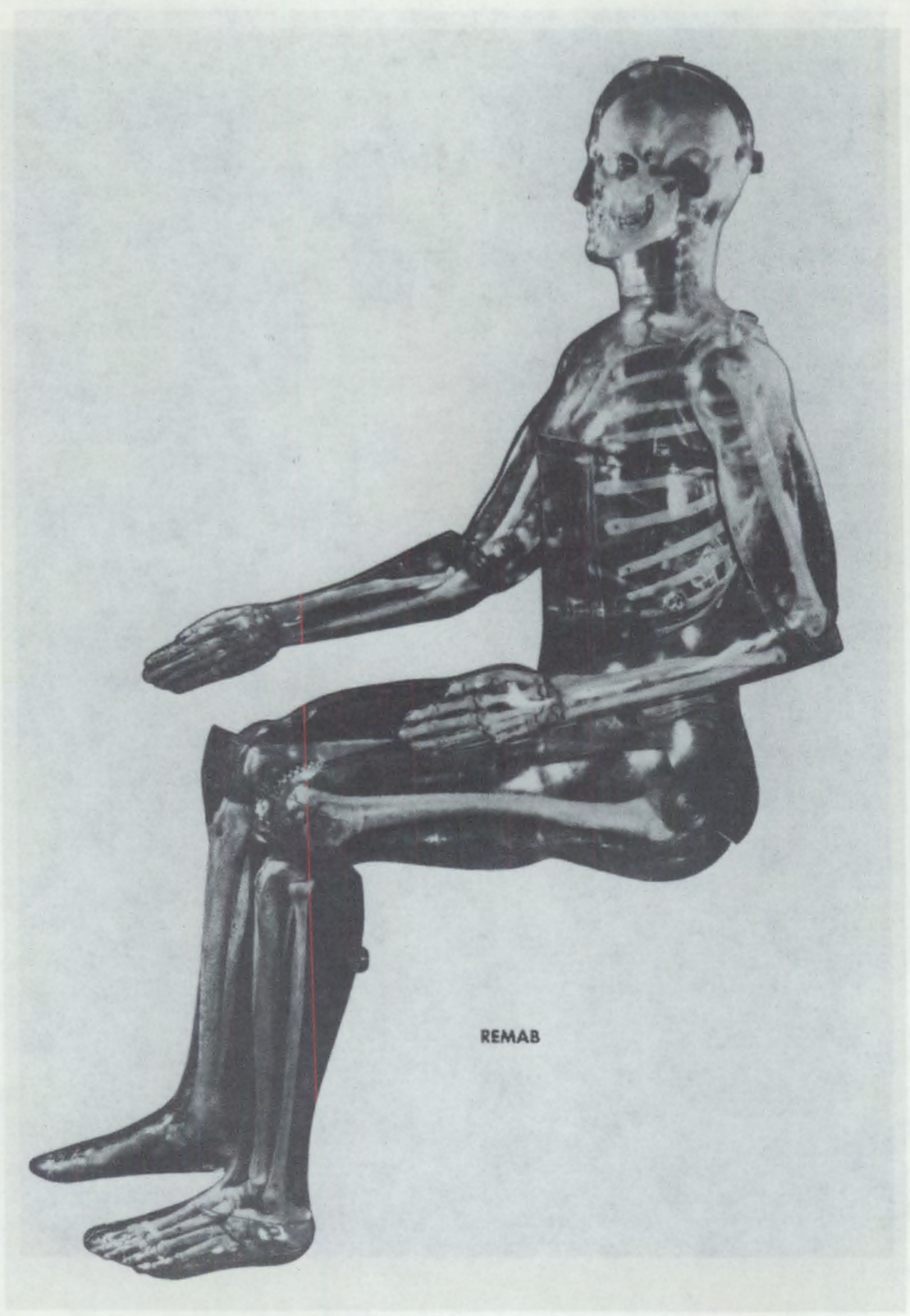

FIGURE 2.7. REMAB Phantom

\subsubsection{Tissue-Equivalent Torso Phantom}

The phantom contains a rib cage of artificial boneequivalent material, removable organs, and includes tissue-equivalent chest plates that can be placed over the torso to simulate the chests of people with a wide range of chest wall thicknesses. The radioactivity is homogeneously distributed in the lung, liver, and lymph nodes by mixing the activity into the liquid polyurethane before it cures in the mold to form a semi-hard plastic organ. 

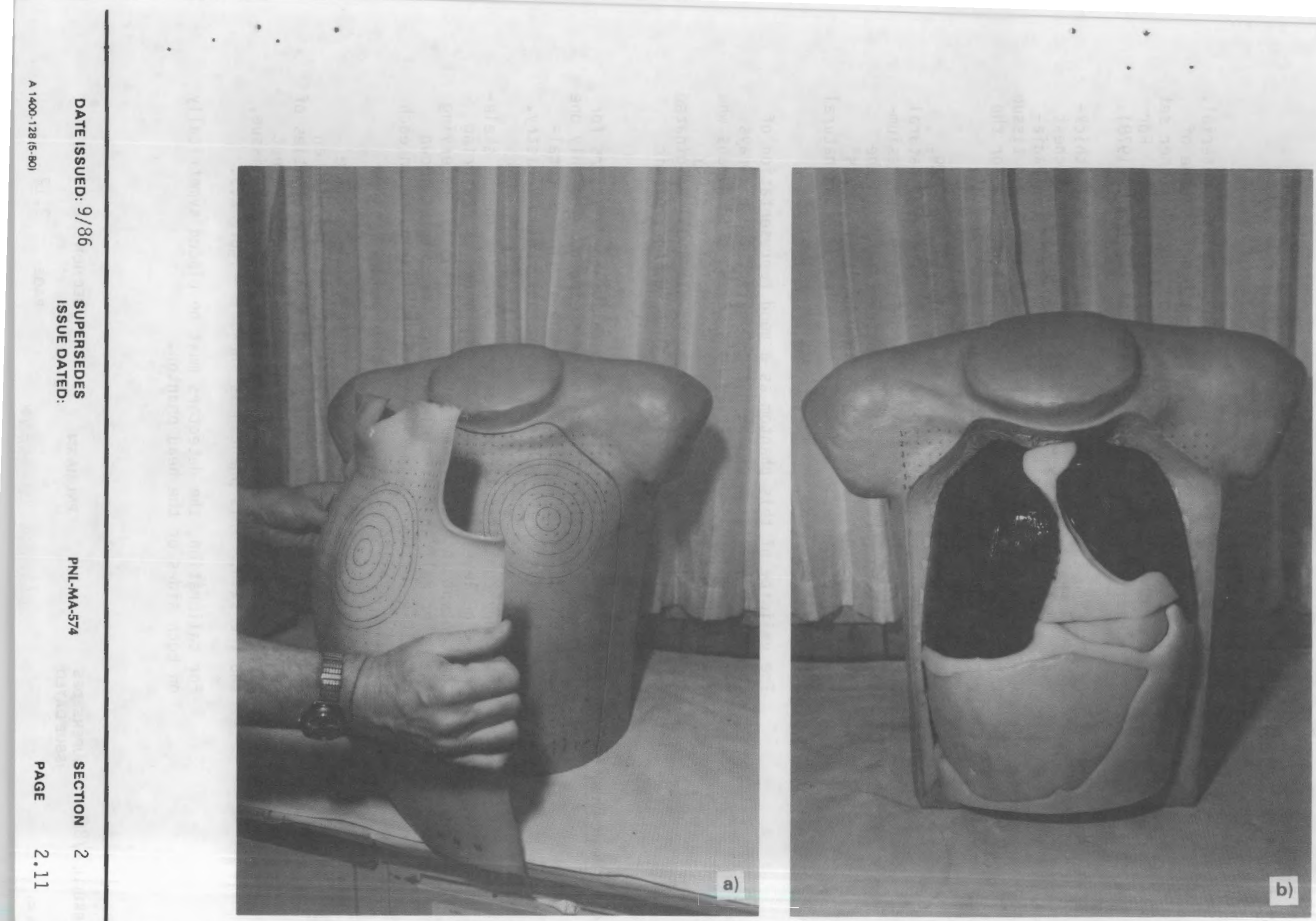

FIGURE 2.8. Tissue-Equivalent Torso Phantom (a) Removal of the chest plate. (b) Phantom without chest plate, organs visible. 


\subsubsection{Tissue-Equivalent Torso Phantom \\ (contd)}

The basic phantom is made from muscle-equivalent material. There are two sets of chest plates: one set is made of $50 \%$ fat-to $-50 \%$ muscle-equivalent tissue, and the other set is made of $87 \%$ fat-to-13\% muscle-equivalent tissue. For more details on this phantom see Griffith, et a1. (1978).

Calibration curves corresponding to the chest wall thickness and the fat content are developed using these chest plates. The chest wall thickness of contaminated radiation workers is determined using medical ultrasound tissue thickness measurement equipment (see Section 3.10 for the details of the ultrasound procedure).

Separate lung sets containing plutonium-238 and -239 , americium-241, natural uranium, enriched uranium, natural thorium, cobalt-60, cerium-144, europium-154, and cesium137 have been purchased or constructed for use in the phantom. Radioactively tagged standard liver organs include plutonium-238 and -239 , americium-241, and natural thorium.

The validity of this phantom as a good representation of absorption qualities of the human body for the $L x$-rays from plutonium has been proven by studies on 18 humans who inhaled known quantities of niobium-92m. This study (Gunston and Jeffries 1986; Newton et al. 1985) originated in England and was funded by the International Atomic Energy Agency (IAEA).

\subsubsection{Head Phantoms}

Various head phantoms are used to calibrate detectors for the amount of radioactivity in the skeleton. The only one owned by PNL was constructed from the skull of a totalbody donation to the HEHF and U.S. Transuranium Registry.

This body contained $118 \mathrm{nCi}$ of americium-241 in the skeleton. The level of activity was determined by measuring the content in exactly half of the skeleton and reserving the other half so that skeletal parts containing known quantities of americium-241 naturally distributed in each bone are available.

The head phantom contains half of the skull from the donated body. The half skull has been matched with an opposite half of a noncontaminated skull. The cavities of the composite skull were filled with tissue-equivalent material that simulates the brain, the inner soft tissue, and the skin. This phantom is shown in Figure 2.9.

For calibration, the detectors must be placed symetrically on both sides of the head phanton. 


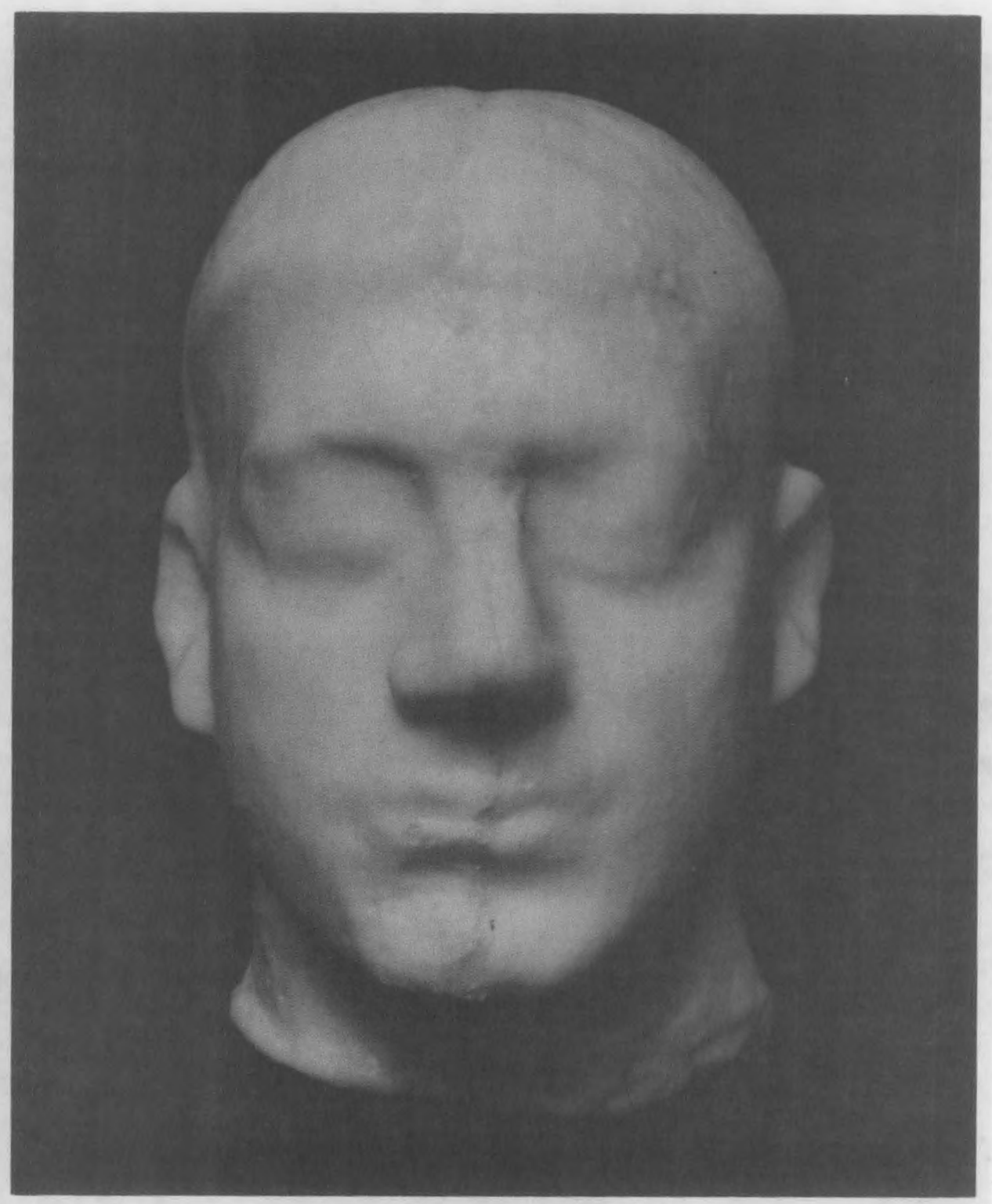

FIGURE 2.9. Head Phantom for the Calibration of Radioactivity in the Sku11

\subsubsection{Thyroid Phantom}

A thyroid phantom is shown in Figure 2.10. The phantom is made of tissue-equivalent plastic and the thyroid lobes can be filled with radioactive solutions for calibration. 


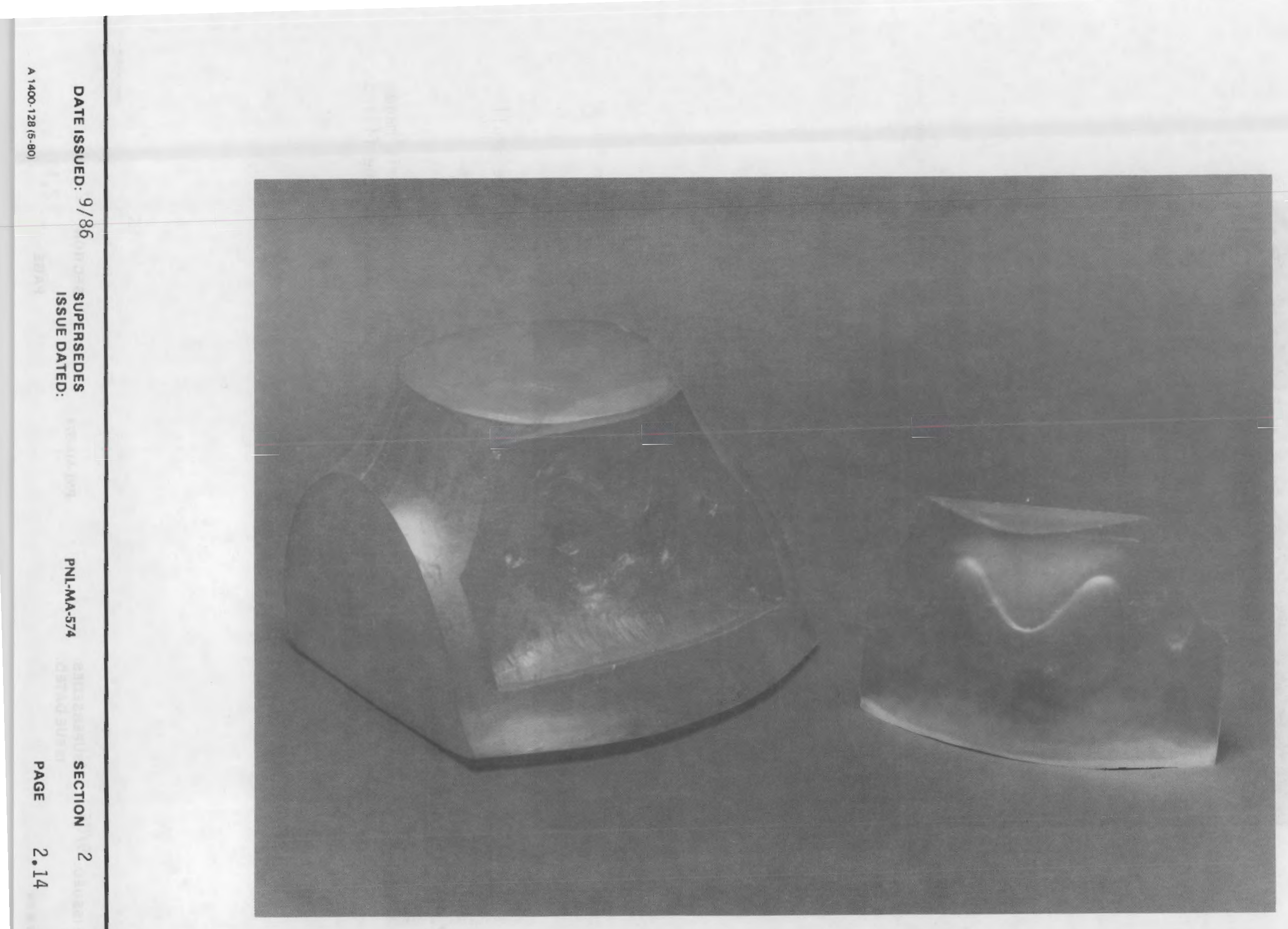

FIGURE 2.10. Thyroid Phantom 


\subsection{REFERENCES}

Eichner, F. N. 1969. Whole Body Counter Laboratory Mobile Unit B Description and Operation. BNWL-1154. Pacific Northwest Laboratory, Richland, Washington.

Griffith, R. V., P. N. Dean, A. L. Anderson and J. C. Fisher. 1978. "Fabrication of a Tissue-Equivalent Torso Phantom for Intercalibration of In-Vivo

Transuranic-Nuclide Counting Facilities." Presented at the Symposium on Advances in Radiation Protection Monitoring, June 26-30, 1978, Stockholm, Sweden.

Gunston, K. J., and S. J. Jeffries. 1986. Calibration of X-Ray Counters for Assessment of Internal Lung Contamination, with Low Energy X-Ray Emitters, in Women, Part I Measurements Made at AWRE. Final Report to IAEA, Technical Contract 3362/TC. Vienna, Austria.

International Commission on Radiological Protection (ICRP). 1975. Report of the Task Group on Reference Man. ICRP Publication 23, Pergamon Press, Oxford.

Knoll, G. F. 1979. Radiation Detection and Measurement. John Wiley and Sons, New York.

Newton, D., A. C. Wells, S. Mizushita, R. E. Toohey, J. Y. Sha, R. Jones, S. J. Jeffries, H. E. Palmer, G. A. Rieksis, A. L. Anderson and G. W. Campbell. 1985. "The Livermore Phantom as a Calibration Standard in Assessment of Plutonium in Lungs." In Proceedings of an International Symposium on Assessment of Radioactive Contamination in Man, pp. 183-199. IAEA-SM-276/01, International Atomic Energy Agency, Vienna.

Palmer, H. E., and Roesch. 1965. "A Shadow Shield Whole Body Counter." Health Physics 11(11):1213-1219.

Roesch, W. C., R. C. McCall and H. E. Palmer. 1960. Hanford Whole Body Counter 1959 Activities. HW-67045, Hanford Atomic Products Operation, General Electric Company, Richland, Washington.

Swanberg, Jr., F. 1963. Hanford Mobile Whole Body Counter. HW-80216. Hanford Atomic Products Operation, General Electric Company, Richland, Washington. 


\subsection{IN VIVO MEASUREMENTS}

This section describes the procedures for performing the various in vivo measurements at the WBC and related facilities.

\subsection{WHOLE BODY IN VIVO MEASUREMENTS}

Whole body in vivo measurements are done in the preview whole body counter. This counter consists of a column of five sodium iodide ( $\mathrm{NaI}$ ) detectors, mounted in a leadshielded booth (Figures 3.1 and 3.2 ). These detectors are used to determine whether detectable quantities of highenergy gamma-emitting radionuclides (such as cesium-137, cobalt-60, and manganese-54) are present anywhere in the body.

Data from the five detectors are recorded as a sum of the counts of from all five detectors, as well as an individual count from each of the upper three detectors and a combined count from the two lower detectors. The relative counts from each detector output provide a measure of the distribution of activity in the body.

Virtually all people who come to the WBC will be measured in the preview counter first. If any significant activity is detected, the subject may be measured on another type of counter for further evaluation.

\subsubsection{Procedure for Daily Whole Body Counter Energy Calibration,} Background Determination, and Efficiency Check

Energy Calibration

Background Determination
- Obtain the combination cesium-137 and potassium-40 sources used for large $\mathrm{NaI}(\mathrm{Tl})$ energy calibrations.

- Calibrate all 5 detectors of the preview counter using a multichannel analyzer (MCA) so that each channel represents $20 \mathrm{keV}$ (refer to Section 4, Operation of Counting Equipment and see Figure 3.2).

- Vertically stack each of the 4 containers filled with plastic beads against the detectors to simulate the presence of a nonradioactive subject.

- Rotate the adjusting wheer on the outside of the counter until the detectors are at the lowest position.

- Take a 1000-second background count.

- Enter this background spectra into the computer.

- Remove the containers from the preview counter. 


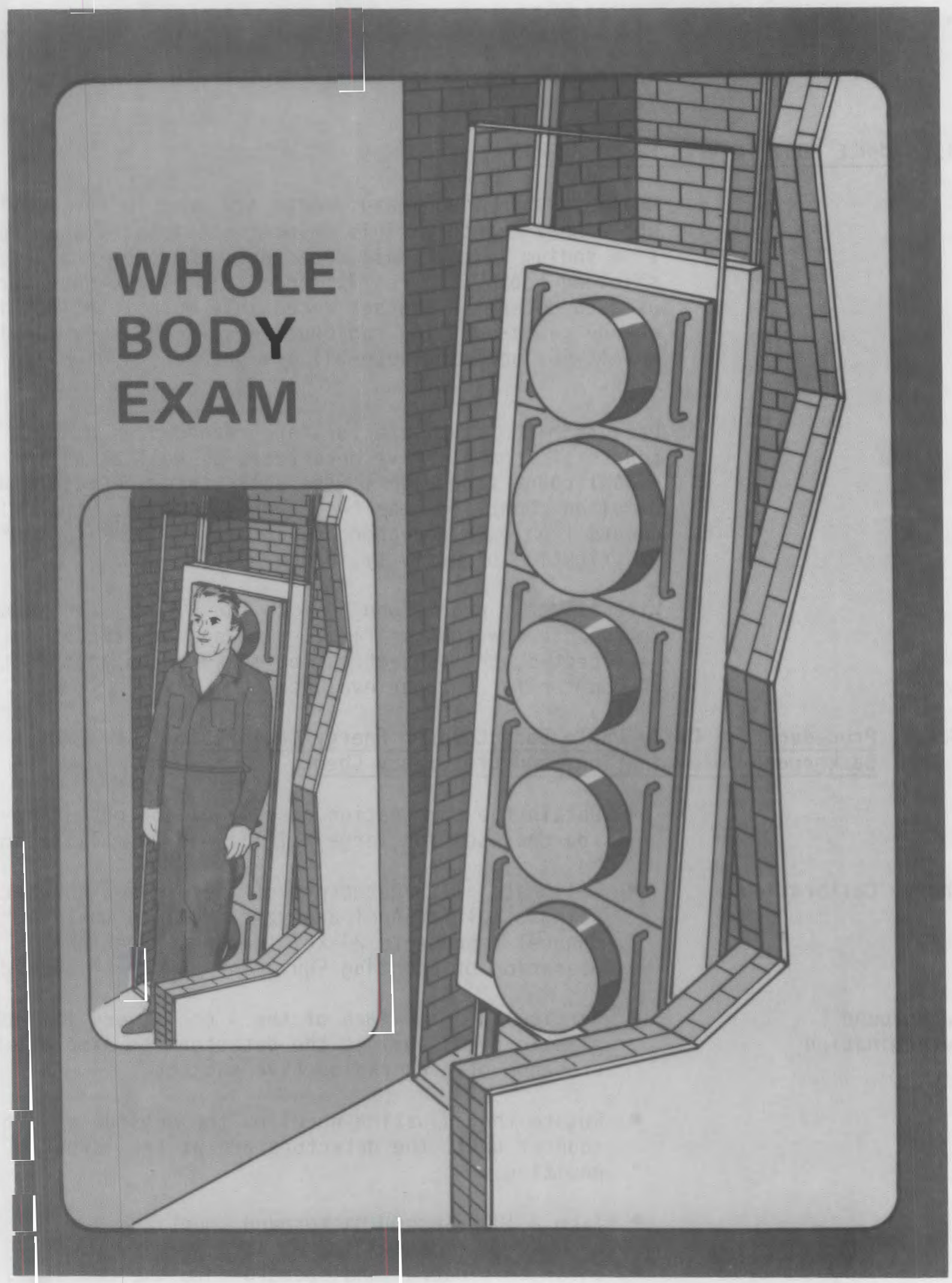

FIGURE 3.1. The Preview Whole Body Counter

DATE ISSUED: $9 / 86$
SUPERSEDES

ISSUE DATED:
PNL-MA-574

PAGE
3.1

3.1 .2 


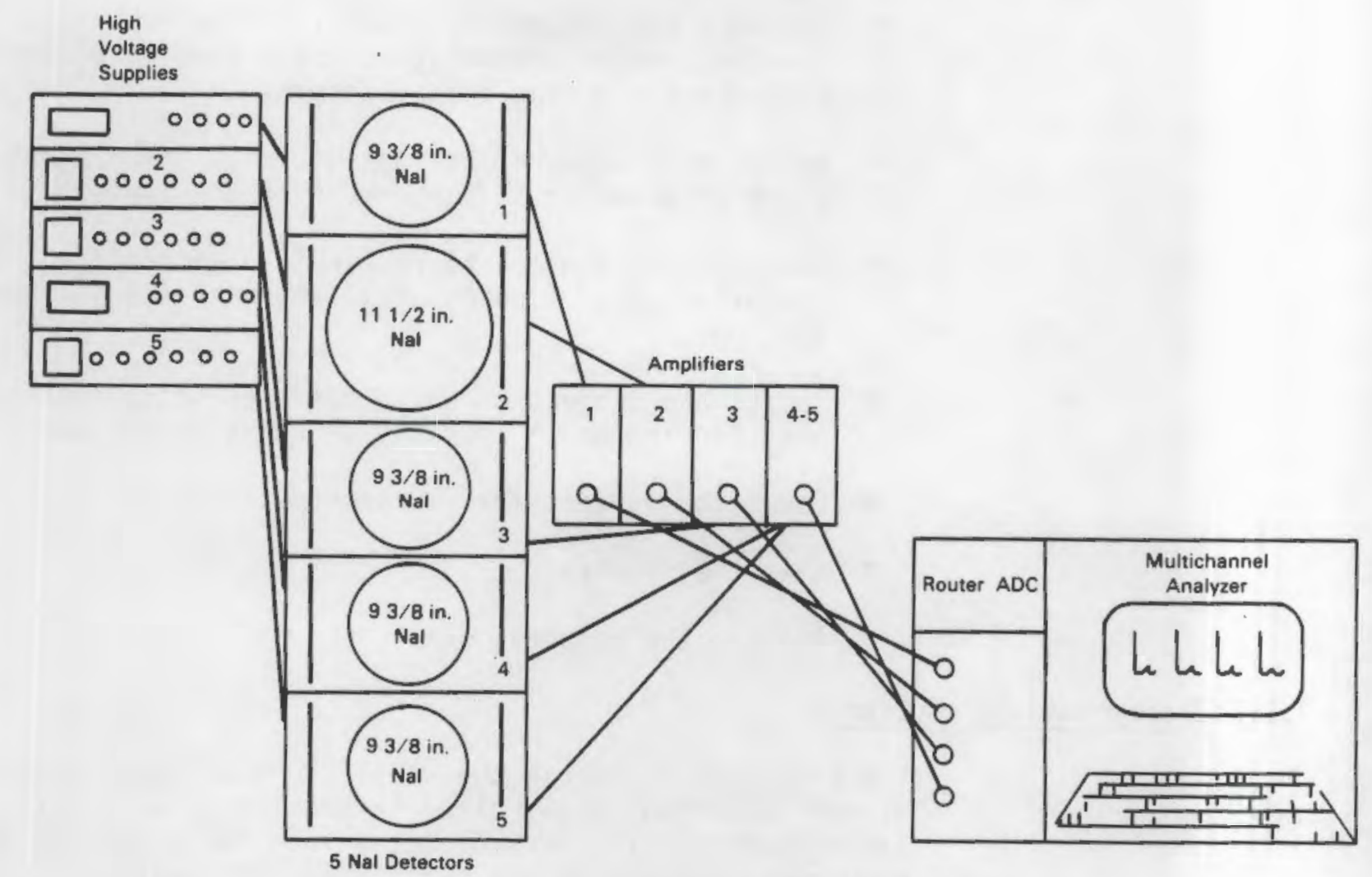

Data Sheet for Nal Preview Whole Body Counter
keV per channel
\# of detectors
Detector code
Body location code
\# of channels
Routine count length, sec
Background length, sec
Source used for calibration
Source count used length

FIGURE 3.2. The Preview Whole Body Counter Schematic and Data Sheet

\subsubsection{Procedure for Daily Whole Body Counter Energy Calibration, Background Determination, and Efficiency Check (contd) \\ Efficiency Check \\ - Place the 9-container standard potassium-40 source in its standard position and count for 200 seconds. \\ - Save the spectra on the computer.}




\subsubsection{Procedure for Subject Measurement}

- Instruct the subject to carefully step into the counting booth: standing, backside leaning against plexiglass covering the detectors.

- Adjust the height of the detectors so the largest diameter detector is centered over the lungs.

- Instruct the subject to remain in position for approximately 3 minutes until the "Finished" light. goes on.

- Remind the subject to watch his step while exiting the counting booth when the count is finished.

- Count the subject for 200 seconds.

- Save the spectra.

- Analyze the results.

\subsubsection{Background Correction}

The procedure to obtain the daily count of the room background radiation is described in Section 3.1.1. This background activity is subtracted from the subject's whole body count spectra before quantifying any radionuclides.

\subsubsection{Calculations for Total Body Activity}

Computer analysis is provided automatically for the radionuclides listed in Table 3.1. The computer calculation is the same as that for the manual calculation.

For manual calculation of the total body count, the following equation is used:

$n C i$ in the body $=\frac{\text { net counts per minute in the photopeak of interest }}{\text { counts } / \mathrm{min} / \mathrm{nCi}}$

The count per minute per nCi (counts/min-nCi) factor is

listed in the fourth column of Table 3.1 .

For radionuclides not listed in Table 3.1, use the counts per gammas for the appropriate energy listed in Table 3.2 using the following equation: 
TABLE 3.1 Counting Efficiency for Common Radionuclides in the Preview Counter

\begin{tabular}{|c|c|c|c|c|}
\hline Radionuclide & $\begin{array}{c}\text { Gamma Ray } \\
\text { Energy, MeV } \\
\end{array}$ & $\begin{array}{c}\text { Energy } \\
\text { Channels } \\
\text { Used }\end{array}$ & $\begin{array}{l}\text { Counts } / \min -n C i \\
\text { in the } \\
\text { Total Body }(a) \\
\end{array}$ & $\begin{array}{l}\text { Counts/min-nC } \\
\text { in the Lung }(\mathrm{b}) \\
\end{array}$ \\
\hline $40_{K}$ & 1.460 & 68 to 78 & 6.9 & 9.1 \\
\hline${ }^{60} \mathrm{Co}$ & 1.173 & 52 to 62 & 65.0 & 84.4 \\
\hline${ }^{137} \mathrm{Cs}$ & 0.662 & 30 to 36 & 56.7 & 76.2 \\
\hline${ }^{54} \mathrm{Mn}$ & 0.840 & 38 to 44 & 66.3 & 87.5 \\
\hline${ }^{154} \mathrm{Eu}$ & 1.274 & 57 to 68 & 23.2 & 38.0 \\
\hline${ }^{22} \mathrm{Na}$ & 1.274 & 57 to 68 & 65.4 & 86.3 \\
\hline${ }^{59} \mathrm{Fe}$ & 1.099 & 48 to 59 & 27.2 & 35.9 \\
\hline${ }^{95} \mathrm{Zr}$ & $\begin{array}{l}0.724 \\
0.756\end{array}$ & 34 to 42 & 65.9 & 87.0 \\
\hline${ }^{65} \mathrm{Zn}$ & 1.115 & 52 to 60 & 33.3 & 43.0 \\
\hline $106_{R u}$ & 0.512 & 22 to 28 & 13.8 & 18.2 \\
\hline $131_{I}$ & 0.364 & 15 to 19 & 54.6 & 72.1 \\
\hline $140 \mathrm{La}$ & 1.596 & 76 to 84 & 61.9 & 81.7 \\
\hline${ }^{232} \mathrm{Th}$ & 2.612 & 125 to 135 & 23.6 & 31.1 \\
\hline${ }^{226} \mathrm{Ra}$ & 1.764 & 83 to 97 & 12.2 & 16.1 \\
\hline${ }^{144} \mathrm{Ce}$ & 2.18 & 100 to 120 & 0.5 & 0.7 \\
\hline${ }^{51} \mathrm{Cr}$ & 0.320 & 13 to 17 & 6.0 & 7.9 \\
\hline $110_{\mathrm{Ag}}$ & 0.658 & 29 to 35 & 63.1 & 83.3 \\
\hline${ }^{24} \mathrm{Na}$ & 2.75 & 131 to 147 & 62.7 & B2. 7 \\
\hline
\end{tabular}

(a) These calibration factors were developed from measurements on the $B O M A B$ phantom containing various radionuclides uniformly distributed throughout the phantom. A known "phantom-to-people" correction has also been applied.

(b) These calibration factors were developed from measurements on the tissue-equivalent torso phantom with the 11 1/2-in.-diameter detector located over the lungs with various radionuclides uniformly distributed in the lungs. 
TABLE 3.2. Counting Efficiency at Various Energies in the Preview Counter (count per gamma emitted from the body)

Preview Counter Efficiency

Factors (using all counts in the photopeaks)

\begin{tabular}{ccc}
\hline Energy for & WBC Factor, & Lung Factor, \\
Total Body, keV counts per gamma ray counts per gamma ray
\end{tabular}

$\begin{array}{rrr}100 & 3.06 \times 10 \mathrm{E}-2 & 4.08 \times 10 \mathrm{E}-2 \\ 200 & 3.05 \times 10 \mathrm{E}-2 & 4.03 \times 10 \mathrm{E}-2 \\ 300 & 3.04 \times 10 \mathrm{E}-2 & 3.97 \times 10 \mathrm{E}-2 \\ 400 & 3.03 \times 10 \mathrm{E}-2 & 3.92 \times 10 \mathrm{E}-2 \\ 500 & 3.02 \times 10 \mathrm{E}-2 & 3.86 \times 10 \mathrm{E}-2 \\ 600 & 3.01 \times 10 \mathrm{E}-2 & 3.81 \times 10 \mathrm{E}-2 \\ 700 & 3.00 \times 10 \mathrm{E}-2 & 3.76 \times 10 \mathrm{E}-2 \\ 800 & 2.99 \times 10 \mathrm{E}-2 & 3.71 \times 10 \mathrm{E}-2 \\ 900 & 2.98 \times 10 \mathrm{E}-2 & 3.65 \times 10 \mathrm{E}-2 \\ 1000 & 2.97 \times 10 \mathrm{E}-2 & 3.60 \times 10 \mathrm{E}-2 \\ 1100 & 2.96 \times 10 \mathrm{E}-2 & 3.55 \times 10 \mathrm{E}-2 \\ 1200 & 2.96 \times 10 \mathrm{E}-2 & 3.50 \times 10 \mathrm{E}-2 \\ 1300 & 2.95 \times 10 \mathrm{E}-2 & 3.46 \times 10 \mathrm{E}-2 \\ 1400 & 2.94 \times 10 \mathrm{E}-2 & 3.41 \times 10 \mathrm{E}-2 \\ 1500 & 2.93 \times 10 \mathrm{E}-2 & 3.36 \times 10 \mathrm{E}-2 \\ 1600 & 2.92 \times 10 \mathrm{E}-2 & 3.32 \times 10 \mathrm{E}-2 \\ 1700 & 2.91 \times 10 \mathrm{E}-2 & 3.27 \times 10 \mathrm{E}-2 \\ 1800 & 2.90 \times 10 \mathrm{E}-2 & 3.22 \times 10 \mathrm{E}-2 \\ 1900 & 2.89 \times 10 \mathrm{E}-2 & 3.18 \times 10 \mathrm{E}-2 \\ 2000 & 2.88 \times 10 \mathrm{E}-2 & 3.14 \times 10 \mathrm{E}-2 \\ 2100 & 2.87 \times 10 \mathrm{E}-2 & 3.09 \times 10 \mathrm{E}-2 \\ 2200 & 2.87 \times 10 \mathrm{E}-2 & 3.05 \times 10 \mathrm{E}-2 \\ 2300 & 2.86 \times 10 \mathrm{E}-2 & 3.01 \times 10 \mathrm{E}-2 \\ 2400 & 2.85 \times 10 \mathrm{E}-2 & 2.97 \times 10 \mathrm{E}-2 \\ 2500 & 2.84 \times 10 \mathrm{E}-2 & 2.93 \times 10 \mathrm{E}-2 \\ 2600 & 2.83 \times 10 \mathrm{E}-2 & 2.89 \times 10 \mathrm{E}-2 \\ 2700 & 2.82 \times 10 \mathrm{E}-2 & 2.85 \times 10 \mathrm{E}-2 \\ 2800 & 2.81 \times 10 \mathrm{E}-2 & 2.81 \times 10 \mathrm{E}-2 \\ 2900 & 2.80 \times 10 \mathrm{E}-2 & 2.77 \times 10 \mathrm{E}-2 \\ 3000 & 2.80 \times 10 \mathrm{E}-2 & 2.73 \times 10 \mathrm{E}-2\end{array}$




\subsubsection{Calculation for Total Body Activity \\ (contd)}

$$
n C i \text { in the body }=\frac{A}{B \times C \times D}
$$

where $A=$ net counts per minute in photopeak of interest

$B=2.22 \times 10^{3} \mathrm{dpm} / \mathrm{nCi}$

$C=$ photon yield per disintegration $(a)$

$D=$ count per gamma from second column of Table 3.2.

\subsubsection{Calculations for Lung Activity}

Computer analysis is provided automatically for radionuclides listed in Table 3.1. For manual calculation of the lung content the following equation is used:

$n C i$ in the body $=\frac{\text { net counts per minute in the photopeak of interest }}{\text { count per minute per nCi }}$

The count per minute per $n C i$ (counts/min-nCi) factor is listed in the fifth column of Table 3.1 For radionuclides not listed in Table 3.1, use the counts per gamma for the appropriate energy 1 isted in the third column of Table 3.2 using the following equation:

$$
n C i \text { in the lung }=\frac{A}{B \times C \times D}
$$

where $A=$ net count per minute in photopeak of interest

$B=2.22 \times 10^{3} \mathrm{dpm} / \mathrm{nC} j$

$C=$ photon yield per disintegration (a)

$D=$ count per gamma from third column of Table 3.2.

\subsubsection{Procedure for Handling Positive Cobalt-60 Whole Body Counts}

The level of cobalt-60 in the body indicates the need for further studies to look for other associated, but difficult-to-detect radionuclides that may provide significant radiation exposure. A good example of such a radionuclide is cerium-144.

When cobalt-60 activity is detected follow the whole body counting procedure outlined in the flow diagram of Figure 3.3.

(a) The photon yield per disintegrations for radionuclides can be found in Radioactive Decay Data Tables by D. C. Kocher located in the WBC library. 


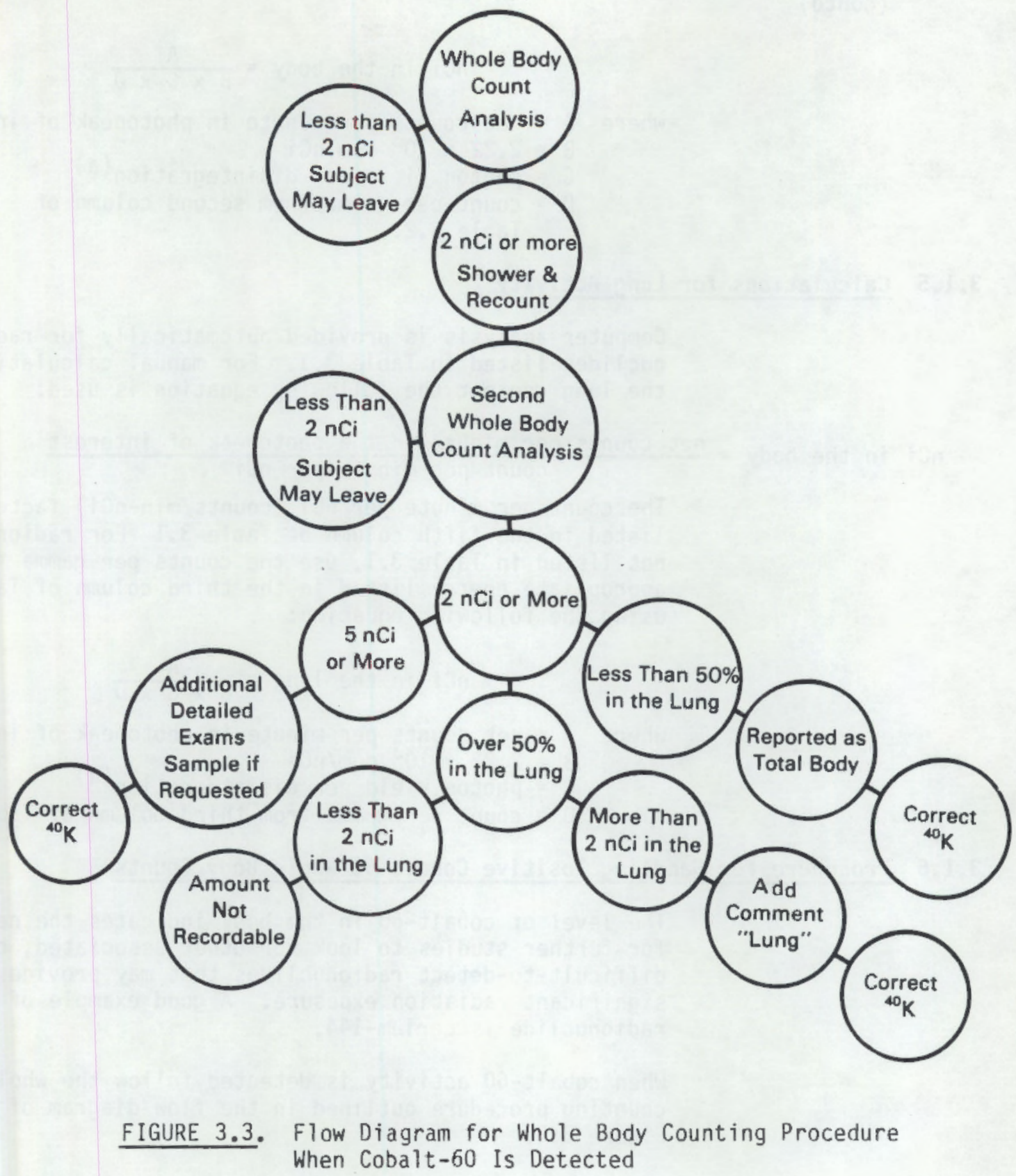




\subsection{IN VIVO LUNG MEASUREMENTS OF LOW-ENERGY PHOTONS ( $200 \mathrm{keV})$}

In vivo lung measurements focus on activity deposited in the respiratory system. The low-energy photons of radiation emitted from the lung are measured by an array of 6 germanium planar detectors. These detectors are placed over the subject in a supine or semireclining position; a semireclining position affords the highest counting efficiency for women and overweight men.

The activity detected in the lung is affected by the chest wall thickness of the subject and any activity that might be emitted from the ribs. To obtain an accurate measurement of activity that has been initially detected by the lung counter, a chest wall thickness measurement is made (see Section 3.10).

To determine the activity, if any, emitted from the ribs (bone), a head count is taken to measure skeletal activity. From this value measured lung activity can be corrected.

\subsubsection{Procedure for Energy Calibration and Efficiency Check of} Germanium Planar Detectors for Lung Counts

Energy Calibration

Efficiency Check
- Review system data sheet in Figure 3.4 .

- Obtain the americium-241 and uranium-235 sources.

- Calibrate and balance each planar germanium detector using an MCA so that each channel represents

$0.500 \mathrm{keV}$. (Refer to Section 4, Operation of Counting Equipment)

- Remove calibration sources.

- Close iron room door.

- Preset time for 1000 seconds.

- Count background.

- Save and enter background spectra in the computer.

- Open the iron room.

- Position the plexiglass jig containing the americium241 source and adjust all detectors as close as possible to the jig (see Figure 3.5).

- Close the door. 


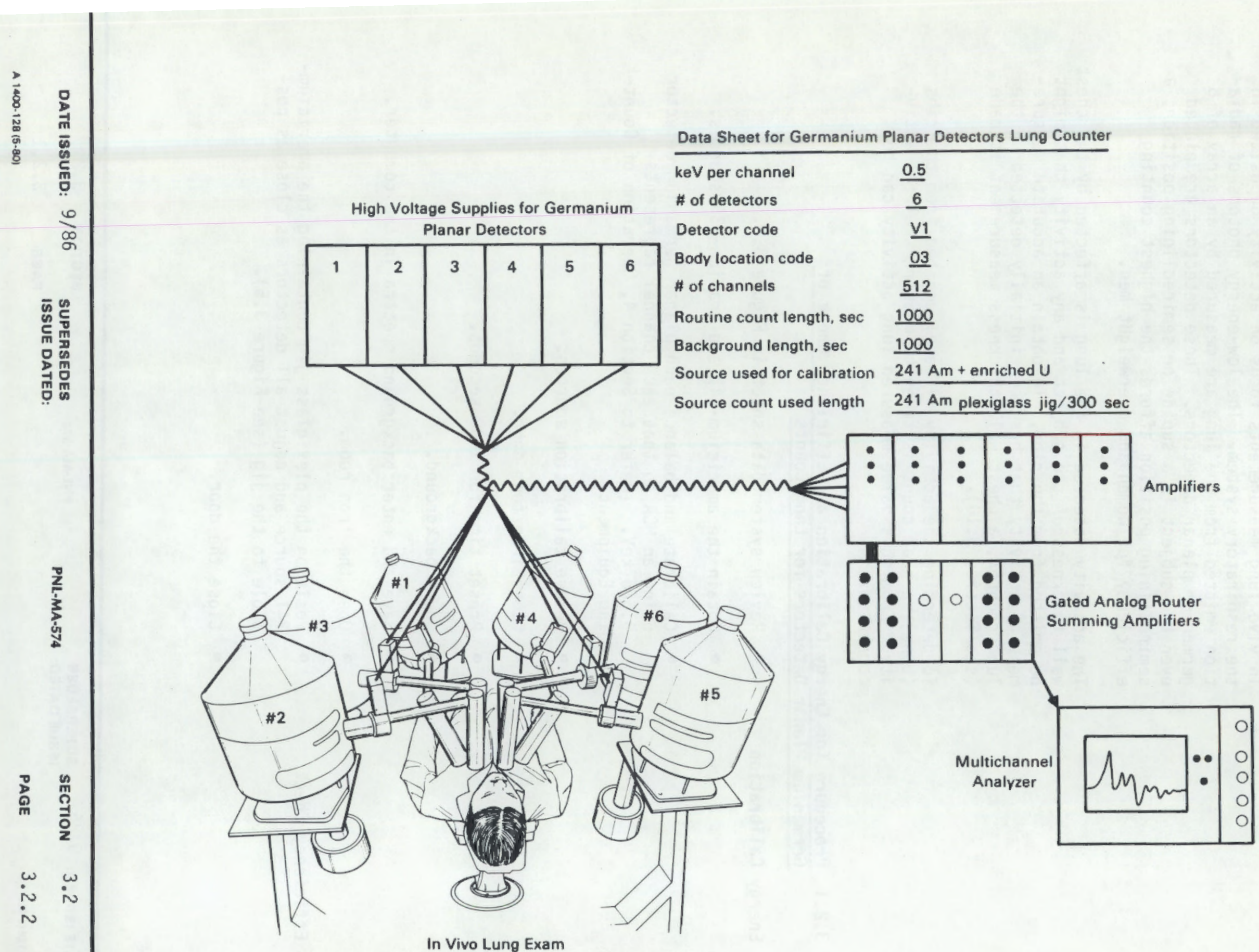

FIGURE 3.4. In Vivo Lung Count Equipment and Data Sheet 


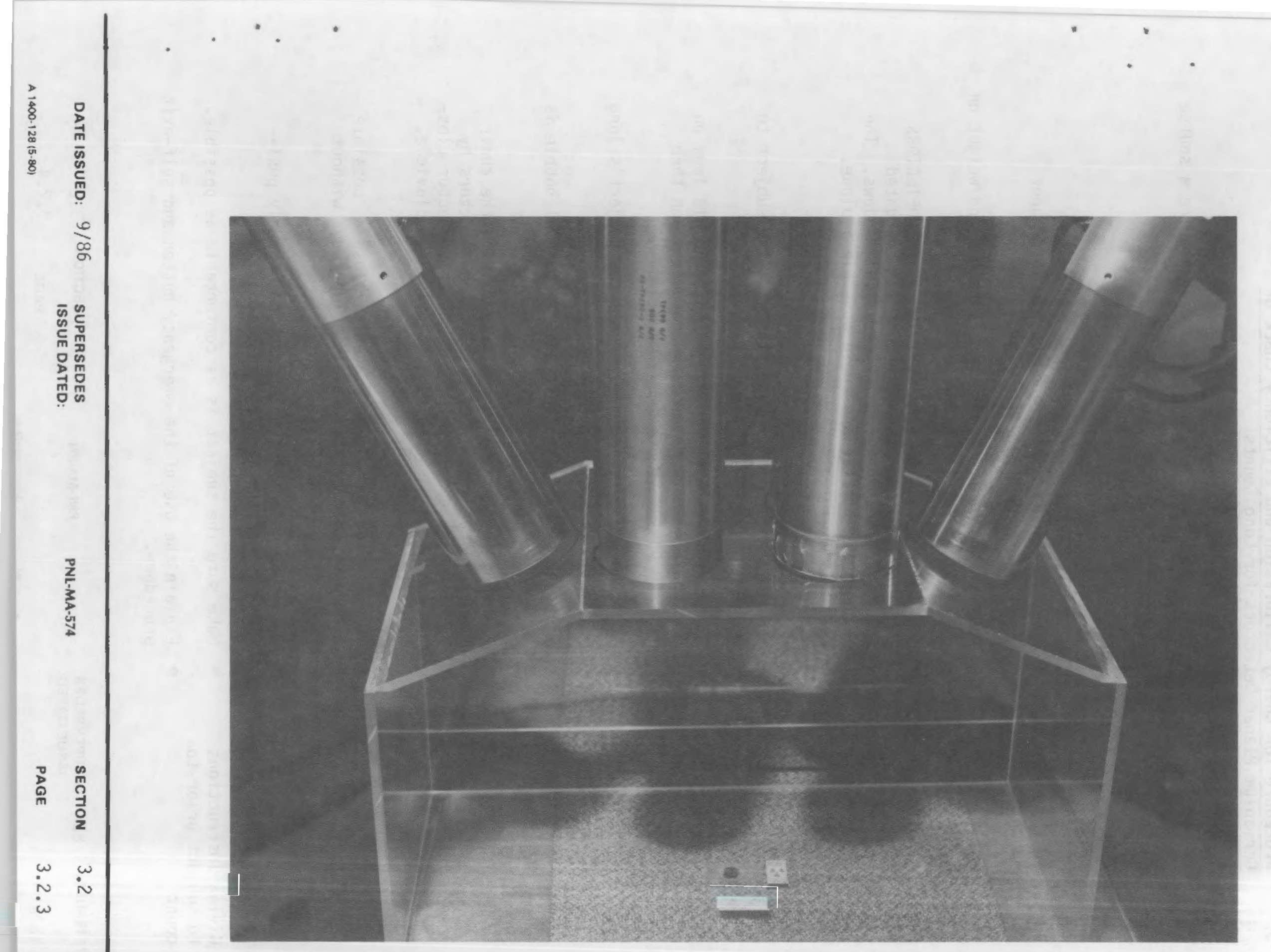

FIGURE 3.5. Calibration of Detectors for In Vivo Lung Count 


\subsubsection{Procedure for Energy Calibration and Efficiency Check of}

Germanium Planar Detectors for Lung Counts

(contd)

- Preset the time for 300 seconds and acquire a source count.

- Save the spectra on the computer.

\subsubsection{Procedure for Subject Measurement}

Preparing the subject for the count

\section{Positioning the} detectors
Giving Instructions to subject prior to count.
- Have the subject shower and change into paper slippers and cotton coveralls.

- Measure and record the subject's height and weight on the In Vivo Count Record.

- USE EXTREME CAUTION WHEN POSITIONING THE DETECTORS OVER THE SUBJECT. The detectors are evacuated underneath the 20-mil-thick beryllium windows. The windows are brittle and could possible implode.

- Pull chair from underneath the detectors.

- Holding the chair in place, instruct the subject to sit down.

- Instruct the subject to carefully swing his legs on the chair without bumping the detectors and then recline on the chair.

- Move the chair horizontally until the subject's lung area is beneath the detectors.

- Tilt the back of the chair until the level bubble is centered.

- Position the detectors by slowly raising the chair height and adjusting the tilt of the detectors by rotating the handle. The edge of the detector closest to the head should be just below the clavicle. Refer to Figure 3.6.

- The detectors should be placed as close as possible to the surface of the subject's lung area without restricting breathing.

- When the subject and detectors are properly positioned, lock the carriage in place.

- Make sure the subject is as comfortable as possible.

- Explain the use of the emergency button and self-exit procedure. 


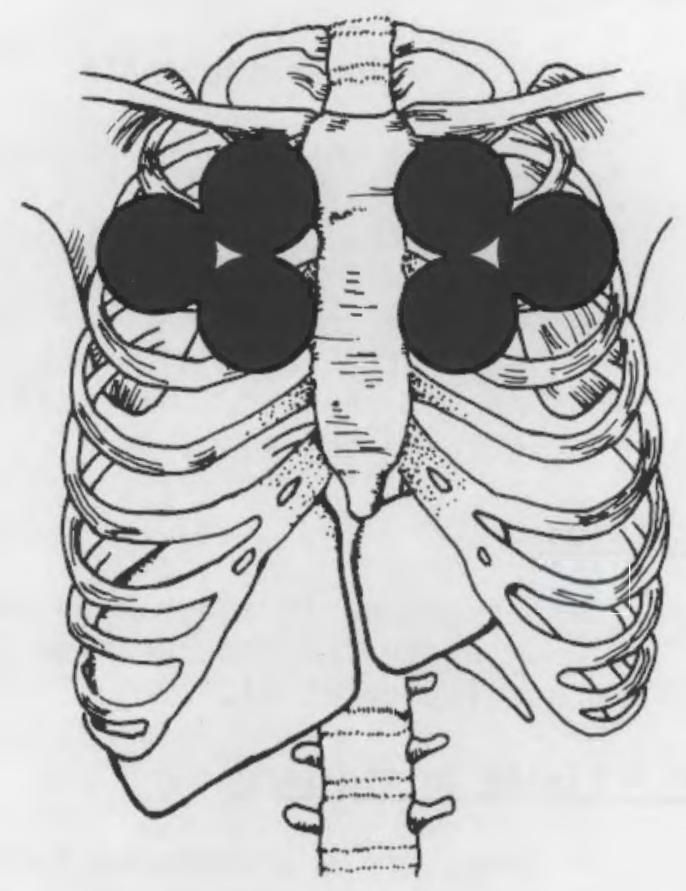

FIGURE 3.6. Position of Detectors for a Lung Count

\subsubsection{Procedure for Subject Measurement (contd)}

- Instruct the subject not to move from underneath the detectors and to lie still for the duration of the count.

- Inform the subject of the length of the count.

Taking the count

- Close shielded room door.

- Start count.

- Count for preset time (usually 1000 or 2000 seconds).

- Save count on the computer.

- When the count is completed, open the shielded room door.

Giving directions after the count

- Instruct the subject not to move until asked to do so. 


\subsubsection{Procedure for Subject Measurement \\ (contd)}

- Slowly lower the chair.

- Release the locking mechanism.

- Slide the chair from underneath the detectors.

- Hold on to the chair and instruct the subject to carefully swing his legs to the side of the chair, stand, and watch his step while standing up and exiting the roorn.

\subsubsection{Background Correction}

The background is subtracted using the 12-channel continuum above the photopeak or the 11-point smoothing method (Spitz et a1. 1984).

\subsubsection{Calculation for Activity in the Lung}

The computer is programmed to provide calculations using the estimated or actual chest wall thickness for the radionuclides listed in Table 3.3 .

TABLE 3.3. Calibration Data for Lung Counts

\begin{tabular}{ccr} 
Radionuclide & Photon Energy, keV & Channel Group \\
\cline { 1 - 2 } $\mathrm{Am}$ & 59.5 & 117 to 120 \\
$239 \mathrm{Pu}$ & 17 & 33 to 36 \\
$238 \mathrm{Pu}$ & 17 & 33 to 36 \\
$235 \mathrm{U}$ & 185 & 370 to 373 \\
$234 \mathrm{Th}$ & 63 & 125 to 128 \\
${ }^{144} \mathrm{Ce}$ & 133 & 265 to 268 \\
${ }^{155} \mathrm{Eu}$ & 86 & 171 to 174 \\
${ }^{154} \mathrm{Eu}$ & 123 & 244 to 247 \\
$232 \mathrm{Th}$ & 238 & 474 to 477
\end{tabular}

To manually calculate the lung activity, determine the chest wall thickness using the Equation (3.5). Using this chest wall thickness, refer to Table 3.4 and obtain the calibration factor corresponding to the determined chest wall thickness. This calibration factor used in Equation (3.6) provides the lung content. 
TABLE 3.4. Calibration Factor Versus Chest Wall Thickness for Lung Counter Using the 6-Germanium-Detector Array (counts per minute per nCi)

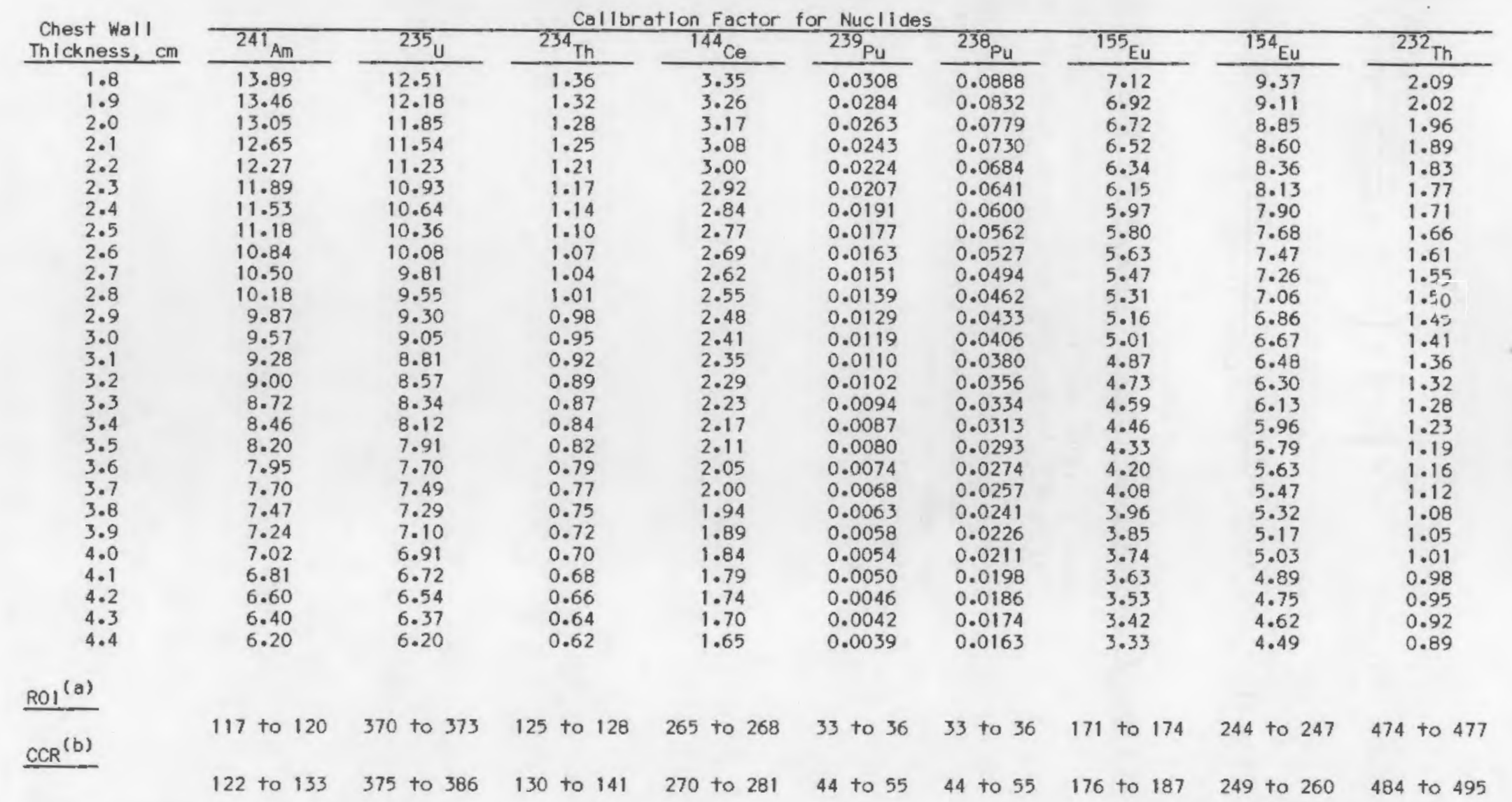

(a) ROI = region of interest for a given nuclide by channel.

(b) $\quad C C R=$ region for background continuum correctlon by channel (not kev) spectra ot $0.5 \mathrm{keV} / \mathrm{channel}$. 


\subsubsection{Calculations for Activity in the Lung \\ (contd)}

$$
\begin{gathered}
\text { chest wall thickness in } c m=\left[0.68+\left(0.974 \times \frac{\text { weight (1bs) }}{\text { height (in.) })}\right]\right. \\
\text { nCi activity in lung }=\frac{\text { net counts per minute in lung }}{\text { counts } / \mathrm{min} / \mathrm{nCi}}
\end{gathered}
$$

\subsubsection{Correction of the Lung Count for Activity in the Bone and Liver}

When activity such as americium-241 exists in the lung, liver, and bone, the lung count must be corrected for the contribution from the other organs. The bone contribution to the lung count is 0.46 times the net counts measured in the head when using the same number and size of detectors for both measurements (see method for measuring bone content Section 3.4). 


\subsection{IN VIVO MEASUREMENT OF RADIOACTIVITY IN THE LIVER}

Some radionuclides such as the transuranics and the rare earth elements have a preferential uptake in the liver after they are absorbed into the bloodstream of the body. Liver measurements are made using an array of three germanium planar detectors for low-energy photon emitters.

\subsubsection{Procedure for Energy Calibration and Efficiency Check of the Germanium Planar Detectors}

- Review data sheet in Figure 3.7.

Energy Calibration

Efficiency Check
- Calibrate the MCA so that each channel is equivalent to $0.500 \mathrm{keV}$ for the germanium planar detector (see Section 4 Operation of Counting Equipment).

- See Section 3.2.1 for daily efficiency check of these detectors.

\subsubsection{Procedure for Subject Measurement}

- Have the subject lie on his back underneath the array of 3 germanium planar detectors.

- Place the detectors over the liver in contact with the body.

- Place two of the detectors on the rib cage just above the lower edge and one detector on the edge of the rib cage as shown in Figure 3.7 .

- Instruct the subject not to move and to keep in light contact with the dectectors.

- Describe the use of the emergency button and the self-exit procedure.

- Close the shielded room door.

- Start the count.

- Count for the preset time (usually 2000 seconds).

\subsubsection{Background Correction}

The background for the array of the germanium detectors is subtracted using the 12-channel continuum above the photopeak or the the 11-point smoothing method (Spitz et al. 1984). 


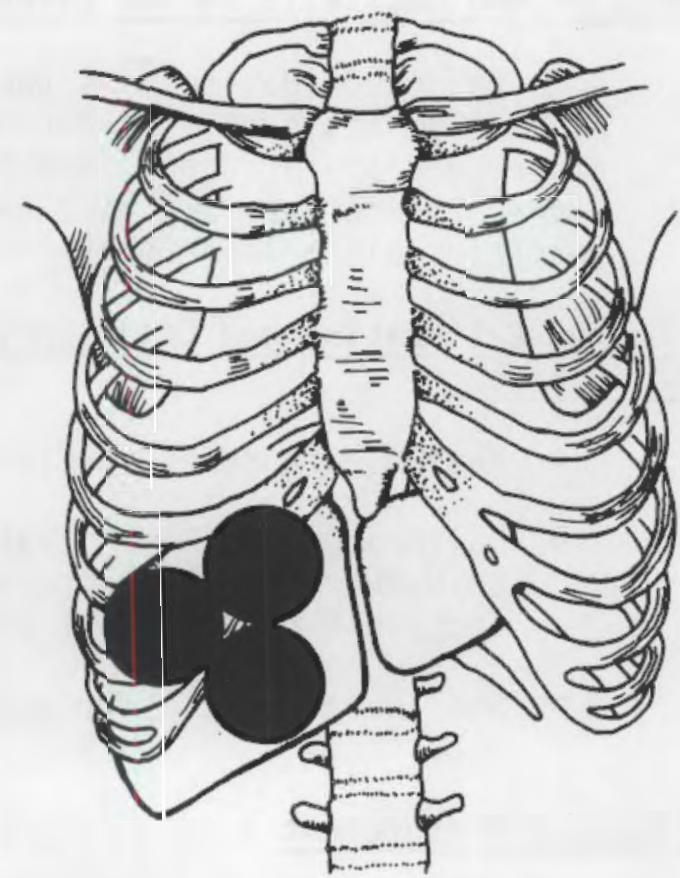

Position of Detectors for Liver Count

Data Sheet for Liver Count

$\begin{array}{ll}\begin{array}{ll}\text { keV per channel } \\ \text { \# of detectors }\end{array} & \frac{0.5}{3} \\ \text { Detector code } & \frac{\mathrm{R} 1}{\mathrm{08}} \\ \text { Body location code } & \frac{512}{2000} \\ \begin{array}{l}\text { of channels } \\ \text { Routine count length, sec }\end{array} & \frac{\mathrm{NA}}{241} \text { Am + enriched U } \\ \text { Background length, sec } \\ \begin{array}{l}\text { Source used for calibration } \\ \text { Source count used length }\end{array} & \frac{241 \text { Am plexiglass jig from 6-Germanium }}{\text { Planar Detector Lung Count }}\end{array}$

FIGURE 3.7. Data Sheet and Position of Detectors for Liver Count 


\subsubsection{Calculations for Liver Activity}

Computer analysis is provided automatically for the radionuclides shown in Table 3.5 when the 3-germanium planar detector array is used.

\section{TABLE 3.5 Calibration Data for Liver Counts}

\begin{tabular}{|c|c|c|c|}
\hline Radionuclide & Energy, keV & Channel Group & $\begin{array}{c}\text { Counts per } \\
\text { Minute per } \\
\text { nCi for } 3.2-\mathrm{cm} \\
\text { Chest Wall Thickness }\end{array}$ \\
\hline $239 p_{u}$ & 17.0 and 20.4 & 32 to 35 & Calibrate for each case \\
\hline $238 \mathrm{pu}$ & 17.0 and 20.4 & 32 to 35 & Calibrate for each case \\
\hline $241_{\mathrm{Am}}$ & 59.5 & 117 to 120 & 8.17 \\
\hline${ }^{144} \mathrm{Ce}$ & 134 & Calibration pending & \\
\hline${ }^{154} \mathrm{Eu}$ & 123 & Calibration pending & \\
\hline${ }^{155} \mathrm{Eu}$ & 86 & Calibration pending & \\
\hline${ }^{232} \mathrm{Th}$ & 239 & Calibration pending & \\
\hline
\end{tabular}

The formula for manual calculation of activity in the liver is given below:

$n C i$ in liver $=\frac{\text { net counts } / \text { min }}{\text { counts/min/nCi }}$

The counts per minute per nCi factors are obtained from Table 3.5. This value is for an average tissue thickness of $3.2 \mathrm{~cm}$ overlaying the liver. Calibration factors for different thickness overlays have not been derived. If the overlay thickness is significantly different than $3.2 \mathrm{~cm}$, a calibration factor can quickly be obtained by measuring a standard liver organ with the appropriate overlay shell on the phantom. The thickness of tissue over the liver of a subject is determined by an ultrasound method as derived in Section 3.2 for lung counting.

If activity is also present in the skeleton, the liver count must be corrected for contribution from the bone that is viewed by the detectors. For americium-241, the bone contribution to the liver count rate is 0.28 times the head count rate when using the same number of germanium planar detectors for both the head and the liver. 



\subsection{IN VIVO MEASUREMENT OF RADIOACTIVITY IN THE BONE}

Radioactivity in the bone can usually be identified by noting that relatively high levels (determined by the whole body counter and compared to other parts of the body) exist in the head or in the bone joints. For radionuclides emitting high-energy gamma rays above $100 \mathrm{keV}$, a normal whole body count gives a good measurement of the content when activity does not exist in soft tissues. Most bone measurements presently made are for low-energy $x$-rays or gamma rays below $100 \mathrm{keV}$.

A count is made by measuring the activity content in the skull with germanium planar detectors (usually two detectors are used). The head is the preferred place for a measurement because of the high sensitivity and the low Tevel of interference from other parts of the body. However, other parts of the body such as the knee or ankle may be used for a bone measurement if the head has extensive contamination (Palmer, Rieksts and Icayan 1983).

Efficiency Check

- Place the two detectors on the marked standard positions of the americium-241-labeled head phantom.

- Count for 2000 seconds.

- Compare the results with the original calibration results. The two sets of results should be the same.

\subsubsection{Procedure for Energy Calibration and Efficiency Check of} Germanium Planar Detectors

- Review the system data sheet in Figure 3.8.

Energy Calibration

- Calibrate the MCA with the americium-241 and uranium235 sources so that each channel is equivalent to $0.500 \mathrm{keV}$ (see Section 4, Operation of Counting Equipment).

\subsubsection{Procedure for Subject Measurement}

- Have the subject shower and wash hair to remove dust and attached radon daughter activity.

- The subject's hair should not be dried because dry hair attracts radon daughter activity from the air.

- Have the subject put on cotton coveralis for the measurement.

- Escort the subject into the shielded room and have him lie on his back on the bed that is supported by a hydraulic lifter. 


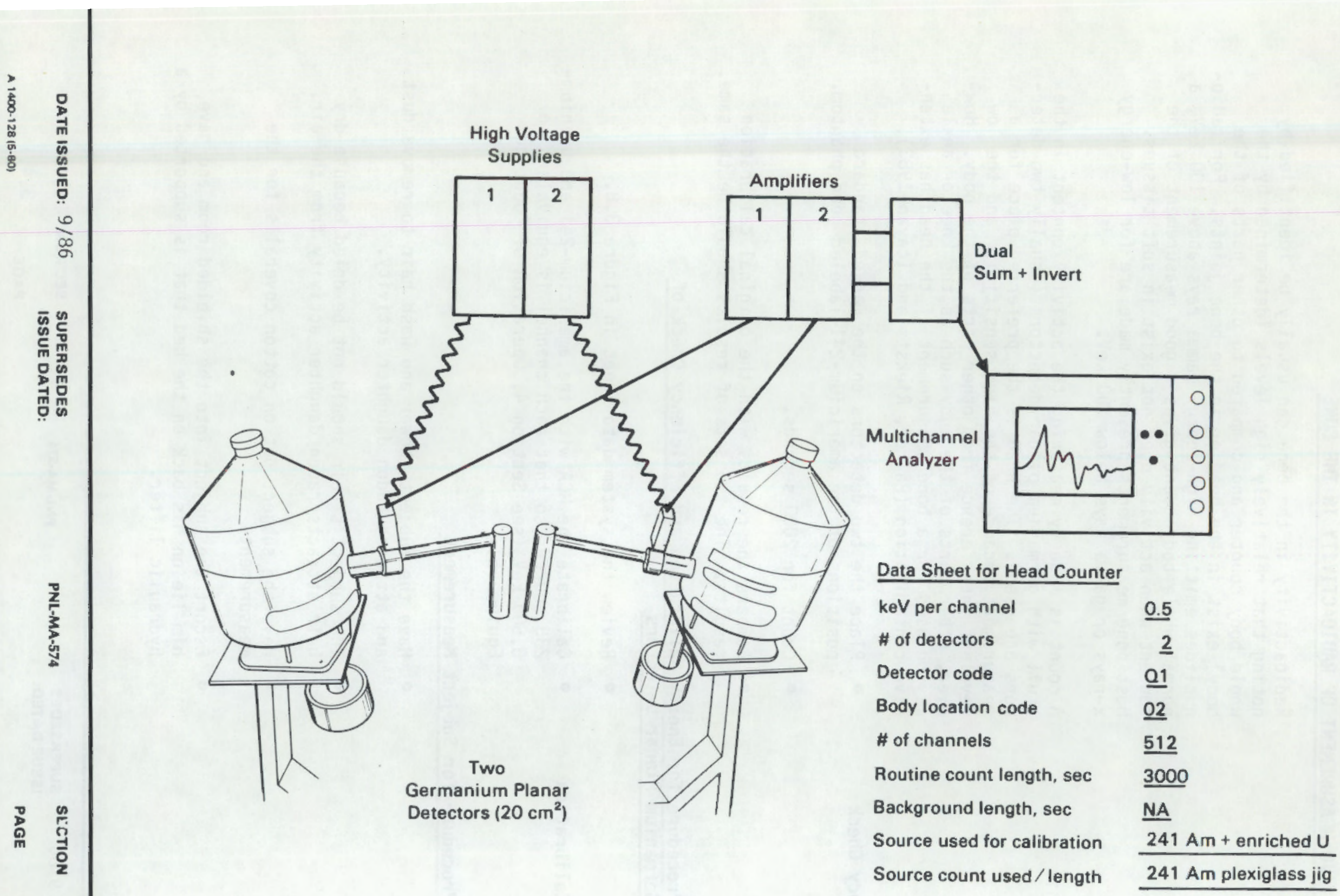

FIGURE 3.8. Head Counter Schematic and Data Sheet 


\subsubsection{Procedure for Subject Measurement \\ (contd)}

- Place the detectors lightly against the subject's forehead by raising the bed up until the head comes into contact with the detectors. The detectors should be positioned so their front surfaces are tangent to the head surface (Figure 3.9 ).

- USE EXTREME CAUTION when bringing the subject's head into contact with the detectors. The detectors are evacuated underneath the 20-mil-thick beryl1ium windows. The windows are brittle and could possibly implode.

- never put the detectors over the eyes.

- Place a lead shield around the neck and over the chest of the subject to absorb radiation from the other parts of the body.

- Instruct the subject not to move his head and to keep it in contact with the detectors.

- Describe the use of the emergency button and the self-exit button.

- Close the shielded room door.

- Count for the preset time (usually 3000 seconds).

- When the count is over carefully remove the lead shield first and then remove the subject from beneath the counter and remind him to watch his step when he exits.

\subsubsection{Background Correction}

The background is subtracted using the 12-channel continuum above the photopeak or the 11-point smoothing method (Spitz et al. 1984).

\subsubsection{Calculation for Bone Activity}

The computer is programmed to provide calculations for the skull and the total skeletal content of radionuclides using the calibrated factors listed in Table 3.6 .

The calculation procedure determines the net count per minute in the region of interest and the net count is divided by the calibration factor given above to obtain the content in the skull. The skull content is multiplied by 6.67 to obtain the total skeleton content. 


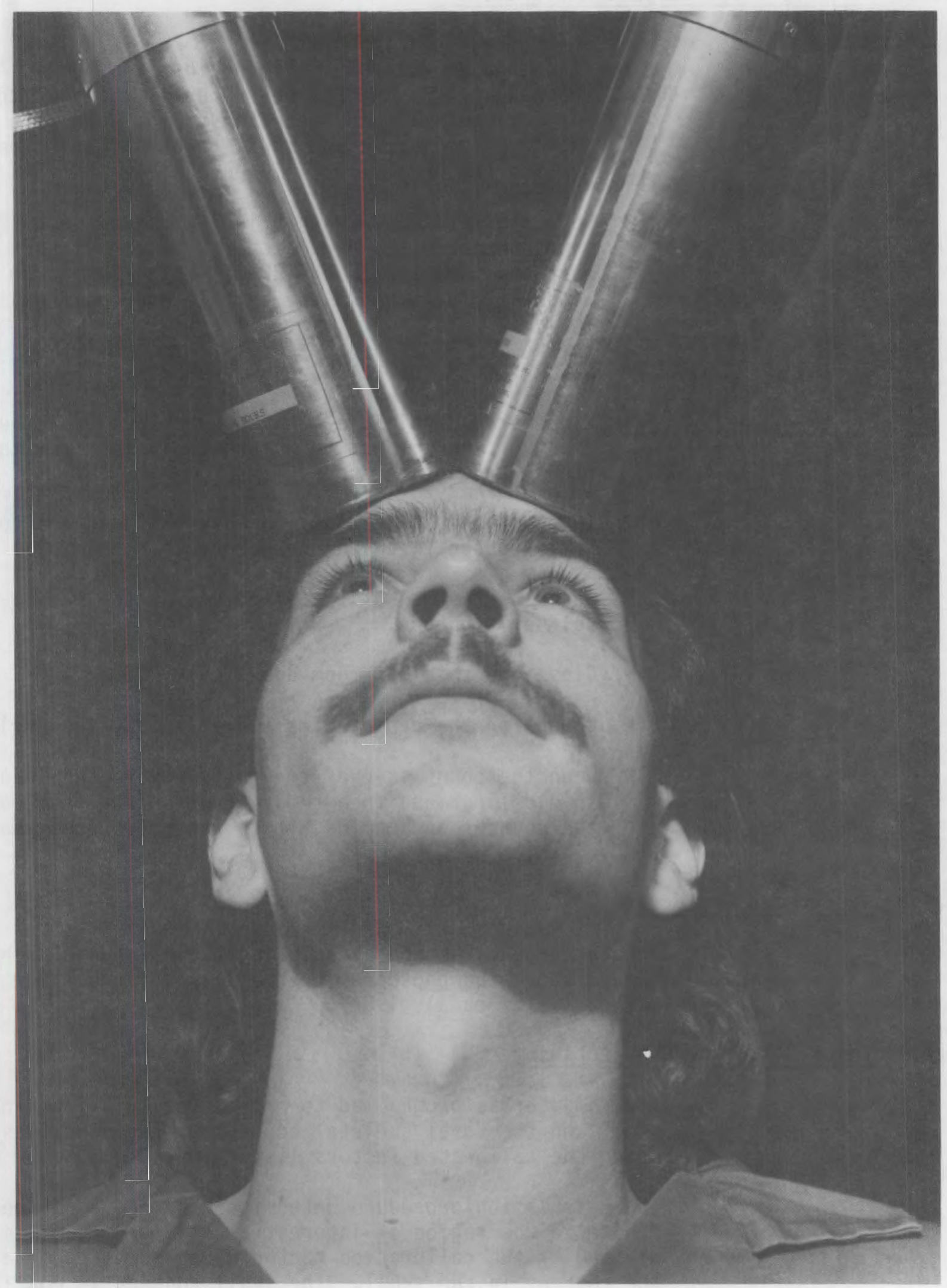

FIGURE 3.9. Position of Detectors for a Head Count

DATE ISSUED: $9 / 86$

SUPERSEDES

ISSUE DATED:
PNL-MA-574

:


TABLE 3.6 Calibration Data for Head Counts

\begin{tabular}{|c|c|c|c|c|}
\hline Radionuclide & $\begin{array}{c}\text { Photon Energy, } \\
\mathrm{keV}\end{array}$ & Channel Group & $\begin{array}{l}\text { Counts/min } / \mathrm{nCi} \\
\text { in Skull from } \\
2 \text { Detectors } \\
\end{array}$ & $\begin{array}{l}\text { Counts/min } / \mathrm{nCi} \\
\text { in Total Skeleton } \\
\text { from } 2 \text { Detectors } \\
\end{array}$ \\
\hline $241_{A m}(a)$ & 59.5 & 117 to 120 & 7.5 & 1.13 \\
\hline $210 \mathrm{pb}$ & 46.5 & 92 to 94 & 0.70 & \\
\hline${ }^{239} \mathrm{Pu}$ & 17.0 & 32 to 35 & 0.13 & 0.087 \\
\hline${ }^{238} \mathrm{Pu}$ & 17.0 & 32 to 35 & 0.033 & 0.022 \\
\hline
\end{tabular}

(a) From Palmer, Spitz and Rieksts (1985). 



\subsection{IN VIVO MEASUREMENT OF RADIOACTIVITY IN WOUNDS}

Small injuries to the hands and arms in plutonium processing facilities often result in plutonium-239 and associated americium-241 being injected into the skin and underlying tissue. This activity can be easily detected and quantified. The determination of the 239-plutonium content in the wound usually requires a correction for the amount of americium-241 present. The exact location and depth of the activity must also be determined in some wound areas.

\subsubsection{Procedure for Energy and Efficiency Calibration of the Coaxial Germanium Detectors in the Shielded Room or at the EDF}

\author{
Energy Calibration
}

\section{Efficiency Calibration}

- Review the system data sheet in Figure 3.10 .

- Locate the radioactive sources: americium-241, $116.5 \mathrm{nCi}$, \#40; plutonium-239, $125.5 \mathrm{nCi}$, \#42.

- Calibrate one coaxial germanium detector using a MCA so that each channel represents $0.500 \mathrm{keV}$. Therefore, the $59.5-\mathrm{keV}$ peak from americium-241 will be stored in channel 119 and the $185.5-\mathrm{keV}$ peak from uranium-235 will be stored in channel 371 .

- Position the americium-241 source on the coaxial germanium source so that the activity side of the source is closest to the detector and count for 60 seconds.

- When the count is finished, save the americium-241 spectrum in the computer and print a hard copy.

- Remove the americium-241 source.

- Position the plutonium-239 source on the coaxial germanium detector so that the activity side of the source is closest to the detector and count for 100 seconds.

- When the count is finished, save the plutonium-239 spectrum in the computer and print a hard copy.

- Remove the plutonium-239 source. 


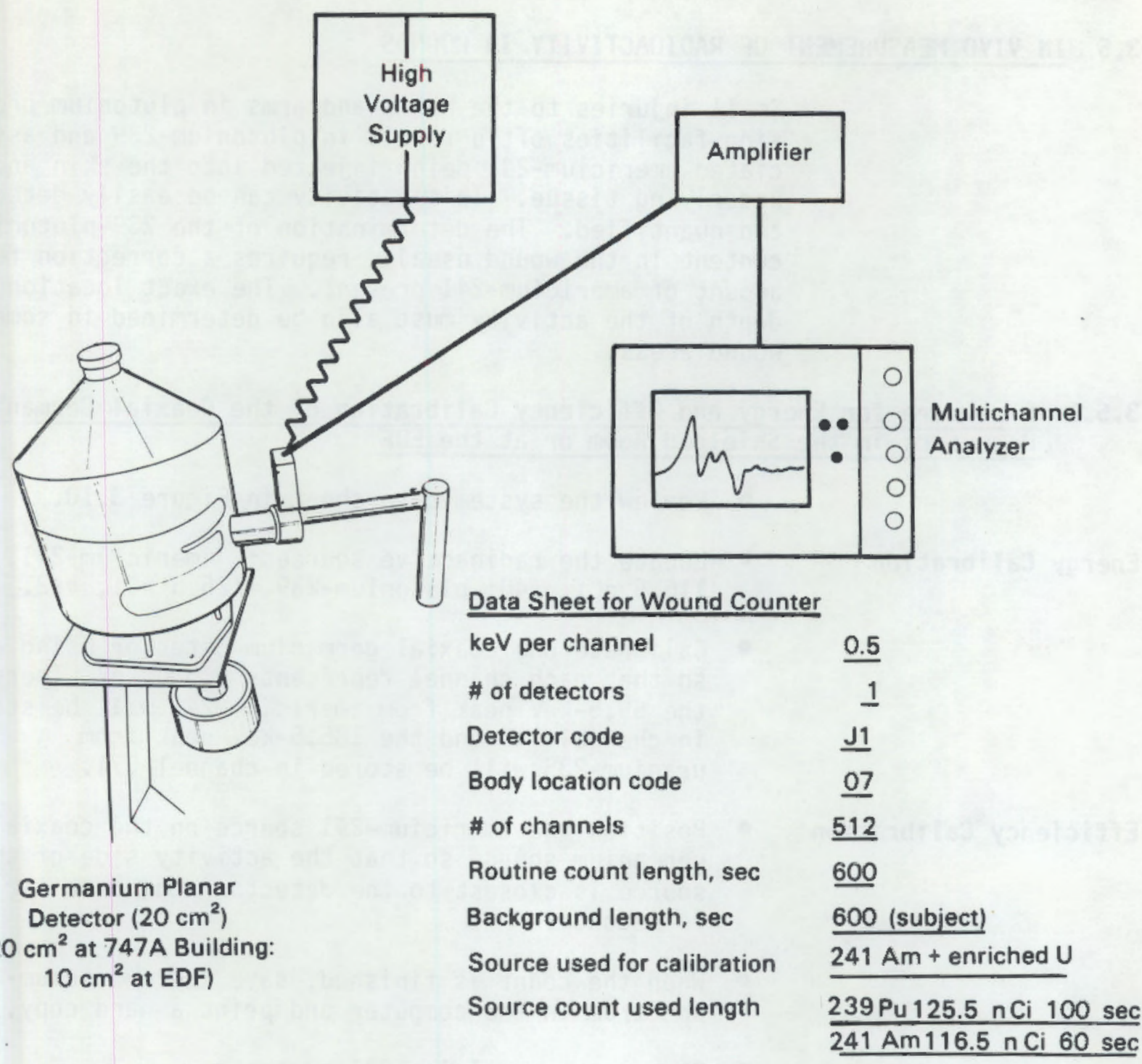

FIGURE 3.10. Wound Counter Schematic and System Data Sheet

\subsubsection{Procedure for Subject Measurement}

Count an Uncomtaminated Subject
- Take a count of an uncontaminated subject whenever possible.

- Position the uncontaminated subject's hand, finger, or body part corresponding to the body part of the contaminated subject in contact with the detector to simulate the same positioning when the actual subject's wound is counted.

- Set the count time for 600 seconds. 


\subsubsection{Procedure for Subject Measurement \\ (contd)}

Prior to Contaminated Subject's Count

Taking the Contaminated Subject's Count

When the Count is Finished
- Take the count.

- Save the spectrum in the computer and print a hard copy.

- Subject is normally not required to shower.

- If the radiation protection technologist has detected external contamination in the wound area and is unable to remove the activity, cover the detector with a thin plastic bag before counting the wound.

- Position the subject comfortably with the wound centered and in contact with the detector.

- Use only light pressure against the beryllium window to avoid imploding.

- Instruct the subject to keep the wound area in contact with the detector during the count.

- Describe the use of the emergency button and the self-exit procedure.

- Close the shielded room door.

- Count for 600 seconds.

- Save the spectrum and print a hard copy.

- Have the subject carefully leave the counter.

- Remind the subject to watch his step.

\subsubsection{Background Correction}

The background is subtracted using the 12-channel continuum method above the photopeak or the 11-point smoothing method (Spitz et al. 1984) when calculating the background for americium-241. The background from the uncontaminated subject is used when calculating the plutonium-239 activity.

\subsubsection{Calculations for Shallow Wound Activity}

The computer is programmed to provide the quantified activity using the calibration factors in Table 3.7 for measurements made using a $20-\mathrm{cm}^{2}$ detector at the 747A Building. 
TABLE 3.7 Calibration Data for Wound Counts

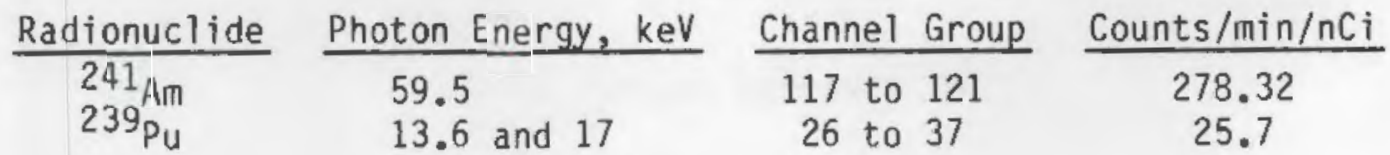

\subsubsection{Calculations for Shallow Wound Activity (contd)}

The basic method of calculation by hand is:

$$
\text { activity in wound in } n C i=\frac{A-B}{C-B} \times D
$$

where $A=$ counts/min in wound

$B=$ background counts $/ \mathrm{min}$

$\mathrm{C}=$ counts/min in source

$\mathrm{D}=$ source strength in $\mathrm{nC} i$

The detection level calculation is:

$$
M D A=\frac{A}{B-C} \times D
$$

$$
\text { where } \begin{aligned}
A & =3 \sqrt{\frac{\text { background }}{\text { min }}} \\
B & =\text { counts/min in source } \\
C & =\text { background counts/min } \\
D & =\text { source strength in } \mathrm{nCi}
\end{aligned}
$$

The calculation of plutonium-239 with the correction for americium-241 is:

$$
\mathrm{nC} i{ }^{239} \mathrm{Pu} \text { in wound }=\frac{A-B\left(\frac{C}{E}\right)}{D} \times \mathrm{F}
$$

where $A=$ net counts/min in channels 26 to 37 for wound

$B=$ counts/min in channels 117 to 121 for wound

$\mathrm{C}=$ counts/min in channels 26 to 37 for ${ }^{24} \mathrm{Am}$ source

$D=$ counts $/$ min in channels 26 to 37 for $239 p_{u}$ source

$E=$ counts/min in channels 117 to 121 for ${ }^{241}$ Am source

$F=n C i$ in ${ }^{239} \mathrm{Pu}$ source

The location of the activity is usually obvious from observation of the wound, but it always needs to be confirmed by placing a small (1/8-in.-diameter) lead disk over the suspected location to determine if all the activity is absorbed by the disk. If the wound is a long cut, a small lead slot collimator is useful in determining were the major portion of the activity is located. 


\subsection{IN VIVO MEASUREMENT OF RADIOACTIVITY IN THE THYROID}

For a person with normal thyroid function, about $20 \%$ of any radioiodine incorporated into the body will be taken up by the 20- to 25-gram adult thyroid gland. Because of this relatively high concentration compared to other body tissues, the amount of iodine-131 in the thyroid is of the most interest. A single 3-in. X 3-in. NaI(Tl) detector or the large coaxial germanium detector is effective for measuring iodine-131 and two germanium planar detectors are the most effective for measuring iodine-125. Using these detectors, the minimum detectable amount in the thyroid is $20 \mathrm{pCi}$ for iodine-131 in a 30-minute count and $3 \mathrm{pCi}$ for iodine-125 in a 30-minute count.

\subsubsection{Procedure for Energy Calibration of the Detectors for Thyroid Measurements}

Calibrate the MCA so that each channel is equivalent to $10 \mathrm{keV}$ for the iodine-131 measurement or $0.500 \mathrm{keV}$ for the iodine-125 measurement. (See Section 4, Operation of Counting Equipment.)

Because of the short half-lives of iodine isotopes an efficiency check using iodine-125 and iodine-131 is not possible. The detectors used for this procedure have undergone efficiency checks for other radionuclides during other whole body counting procedures.

\subsubsection{Procedure for Subject Measurement}

Safety Precautions

For an Iodine-131 Measurement

For an Iodine-125 Measurement
- Have the subject lie on his back and place the detector(s) over the thyroid gland.

- When using the germanium planar detectors be sure that the liquid nitrogen in the detectors does not spill on the subject.

- Use care when placing the germanium planar detectors on the body, so that the thin beryllium windows are not broken. Breaking the beryllium windows could result in a minor implosion.

- Place the 3-in. $\times 3-i n$. NaI(Tl) detector on its side against the neck and centered between the clavicle bones (located at the base of the neck) and the thyroid cartilage, also known as the "Adams apple" (see Figure 3.11).

- Center the two germanium planar detectors close together on both sides of the verticle center line of the neck and in between the clavicle bones and the thyroid cartilage (see Figure 3.12). 


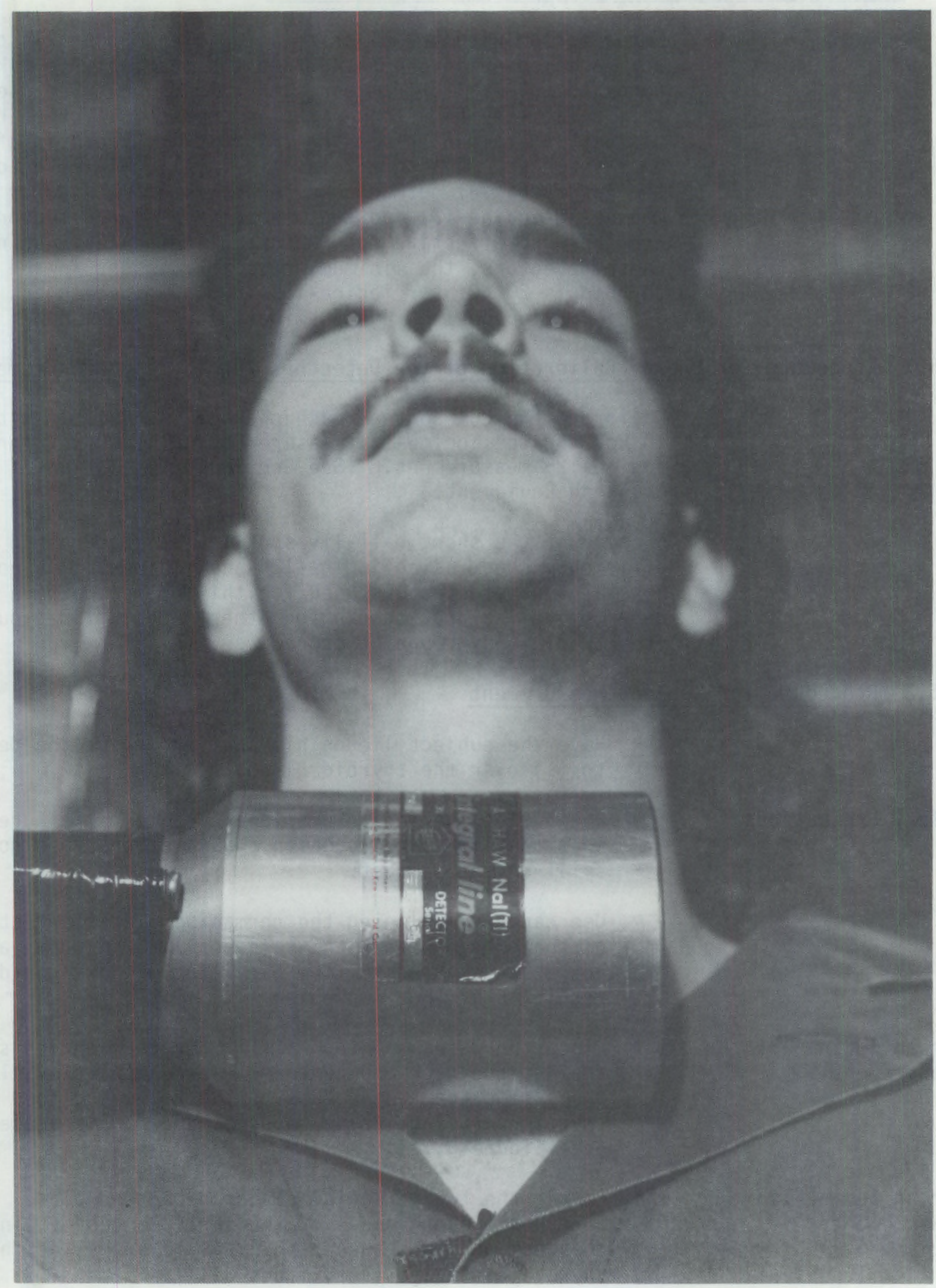

FIGURE 3.11. Placement of Detector for an Iodine-131 Measurement of the Thyroid

DATE ISSUED: $9 / 86 \quad$ SUPERSEDES
ISSUE DATED:
PNL-MA-574

SECTION $\quad 3.6$

PAGE $\quad 3.6 .2$ 


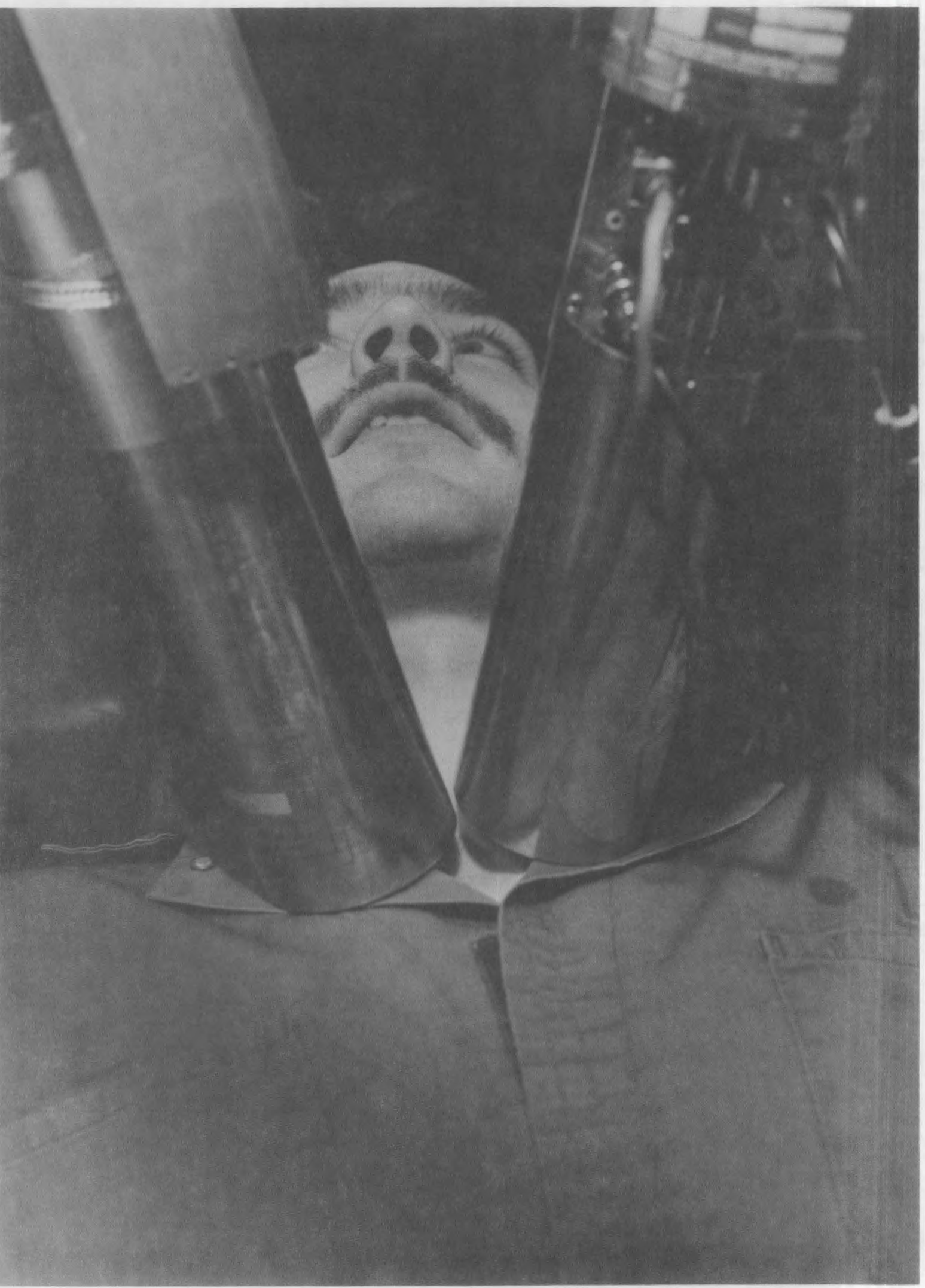

FIGURE 3.12. Placement of Detectors for an Iodine-125 Measurement of the Thyroid

DATE ISSUED: $9 / 86 \quad \begin{aligned} & \text { SUPERSEDES } \\ & \text { ISSUE DATED: }\end{aligned}$

SECTION

PAGE
3.6

3.6 .3 


\subsubsection{Procedure for Subject Measurement \\ (contd)}

Continuing Procedure

for Both the Iodine-131

and -125 Measurements

Taking the Thyroid

Count

When the Count

is Finished

- Angle the germanium planar detectors so that the end surface is parallel to the surface of the neck.

- Instruct the subject not to move and to keep his throat in contact with the detectors.

- Describe the use of the emergency button and the self-exit procedures.

- Close the shielded room door.

- Start the count.

- Count for preset time (usually 2000 seconds).

- Assist the subject from the counter.

- Remind the subject to watch his step upon exiting the shielded room.

\subsubsection{Background Correction}

The background of an uncontaminated person is subtracted from the subject counts for the iodine-131 measurement. (a) For the iodine-125 measurement, the background is subtracted using the 12-channel continuum method above the photopeak or the 11-point smoothing method (Spitz et al. 1984).

(a) The net count for the iodine-131 measurement can be determined without a background count using the following equation:

$$
\text { net } \text { count } / \min =\frac{A-B}{C}
$$

where $A=$ counts/min in channels 33 to 39

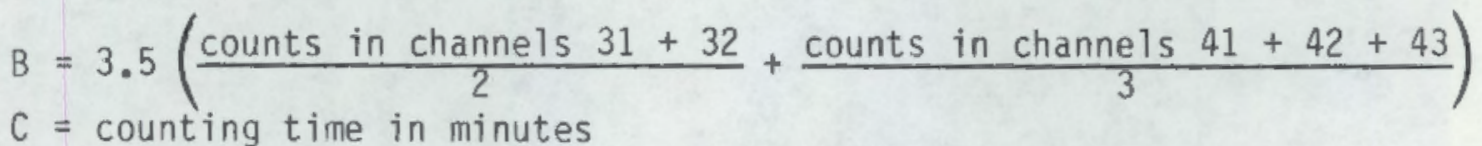




\subsubsection{Calculations for Thyroid Activity}

For Iodine-131

The computer is programmed to provide calculations for iodine-131 in the thyroid using the calibration factors listed below for a 3-in. $\times 3-i n$. NaI(T1) detector.

Channel Group Used

33 to 39

Counts/min-nCi

130

The equation for the calculation is:

$$
n C i \text { of iodine-131 }=\frac{\text { net counts } / \mathrm{min}}{\text { counts } / \text { min-nCi }}
$$

If other interfering radionuclides are present in the body a $35 \% \mathrm{Ge}(\mathrm{Li})$ detector may be used in the same way as the 3-in. $\times 3-i n$. NaI(TI) detector. The side of the detector is placed on the neck with the centerline of the throat at $2-1 / 4 \mathrm{in}$. from the end of the detector endcap. The calibration factor for the $35 \% \mathrm{Ge}$ (Li) detector is 33.4 counts/min/nCi of iodine-131 in the thyroid.

For Iodine-125

The computer is programmed to provide calculations for the iodine-125 content in the thyroid using the calibration factor below.

Channel Group Used 54 to 56

Counts $/ \mathrm{min} / \mathrm{nCi}$

159

The equation for the calculation is:

$$
n C i \text { of iodine }-125=\frac{\text { net counts } / \mathrm{min}}{\text { counts } / \mathrm{min} / \mathrm{nCi}}
$$





\subsection{IN VIVO MEASUREMENT OF TRANSURANIC NUCLIDES IN AXILLARY LYMPH NODES}

Small insoluble particles of transuranic nuclide contamination that enter the lymphatic system through contaminated wounds can become filtered out in the axillary lymph nodes located in the area of the armpit. This activity can remain in the lymph node area for long periods of time.

A single germanium planar detector placed in the region of the armpit over the location of the axillary lymph nodes is used to measure this activity. Determining the location and depth of the nodes is difficult.

\subsubsection{Procedure for Energy Calibration of the Germanium Planar Detector}

Calibrate an MCA connected to a germanium planar detector so that each channel is equivalent to $0.500 \mathrm{keV}$. Refer to Section 4, Operation of Counting Equipment and the data sheet in Figure 3.13 .

\subsubsection{Procedure for Subject Measurement and Efficiency Calibration}

- Have the subject lie on his back with the arm having the suspected contaminated lymph nodes raised up so the hand rests above his head (see Figure 3.14 ).

- If the wound is still contaminated, shield it with a lead sheet to absorb the radioactivity.

- Place the detector in contact with skin at the location shown in Figure 3.14 .

Data Sheet for Lymph Count

keV per channel

\# of detectors

Detector code

Body location code

\# of channels

Routine count length, sec

Background length, sec

Source used for calibration

Source count used/length

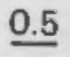

1

J1

으

$\underline{512}$

$\underline{2000}$

NA

$241 \mathrm{Am}+$ enriched U

241 Am Plexiglass jig.

300 sec.

FIGURE 3.13. Sample Data Sheet for Lymph Count 


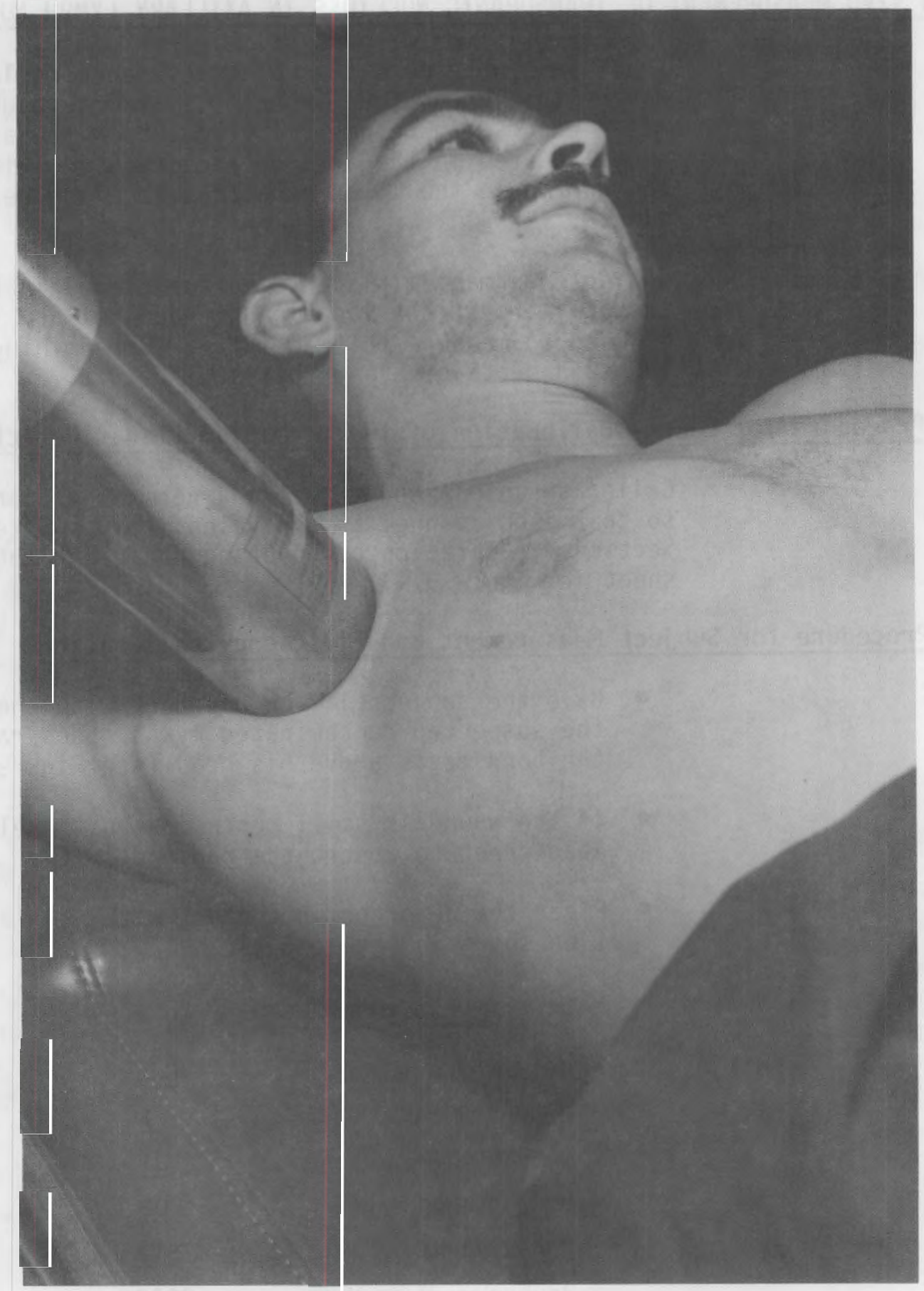

FIGURE 3.14. Proper Position of Detector for a Measurement of Radioactivity in the Axillary Lymph Node

DATE ISSUED: $9 / 86$ SUPERSEDES

ISSUE DATED:
PNL-MA-574

PAGE 3.7 .2




\subsubsection{Procedure for Subject Measurement and Efficiency Calibration (contd) \\ - Make several measurements at locations near the original location to determine the location giving the highest count rate.}

Efficiency Calibration

- Determine the depth of the lymph nodes using the ratio of the various photopeaks if there is sufficient activity. If the depth cannot be determined, assume a depth of 2 centimeters.

- Obtain a standard source of the activity that is present in the lymph node (usually americium-241 or plutonium-239).

- Place the source under a thickness of tissueequivalent $\mathrm{CaCO}_{3}$-loaded polyurathane that is the same as the estimated or assumed depth of the lymph node.

- With the detector in contact with the polyurethane plastic, measure the source activity for the same length of time as the lymph node count on the subject.

\subsubsection{Background Correction}

The background correction for the germanium planar detector is subtracted from all counts using the 12-channel continuum above the photopeak or 11-point smoothing method (Spitz et al. 1984).

\subsubsection{Calculation of Axillary Lymph Node Activity}

The activity in the axillary lymph nodes can be calculated manually using the following equation:

$$
\mathrm{nCi} \text { of radionuclide }=\frac{\mathrm{A}}{\mathrm{B}} \times \mathrm{C}
$$

where $A=$ net counts/min from the lymph node

$B=$ net counts/min from the standard source

$\mathrm{C}=\mathrm{nCi}$ in source 



\subsection{IN VIVO MEASUREMENT OF TRANSURANIC NUCLIDES IN TRACHEOBRONCHIAL LYMPH NODES}

Radioactivity in the tracheobronchial lymph nodes is difficult to detect and quantify because it is not easily distinguishable from lung-deposited activity. However, if a significant measurable fraction does exist in these lymph nodes, it can be detected and roughly quantified by making lateral scans of a cross section of both lung and tracheobronchial lymph nodes. This in vivo measurement method is still under development.

This measurement is done by using a collimated set of 2 germanium planar detectors shown in Figure 3.15. The slot collimater shown in Figure 3.16 extends 2 inches below the face of the detectors.

Figure 3.17 shows the response of such a scan with different fractions of americium-241 in the lymph nodes and lungs. Figure 3.17 also depicts the scan of a Hanford Site employee with americium-241 only in the lung. 


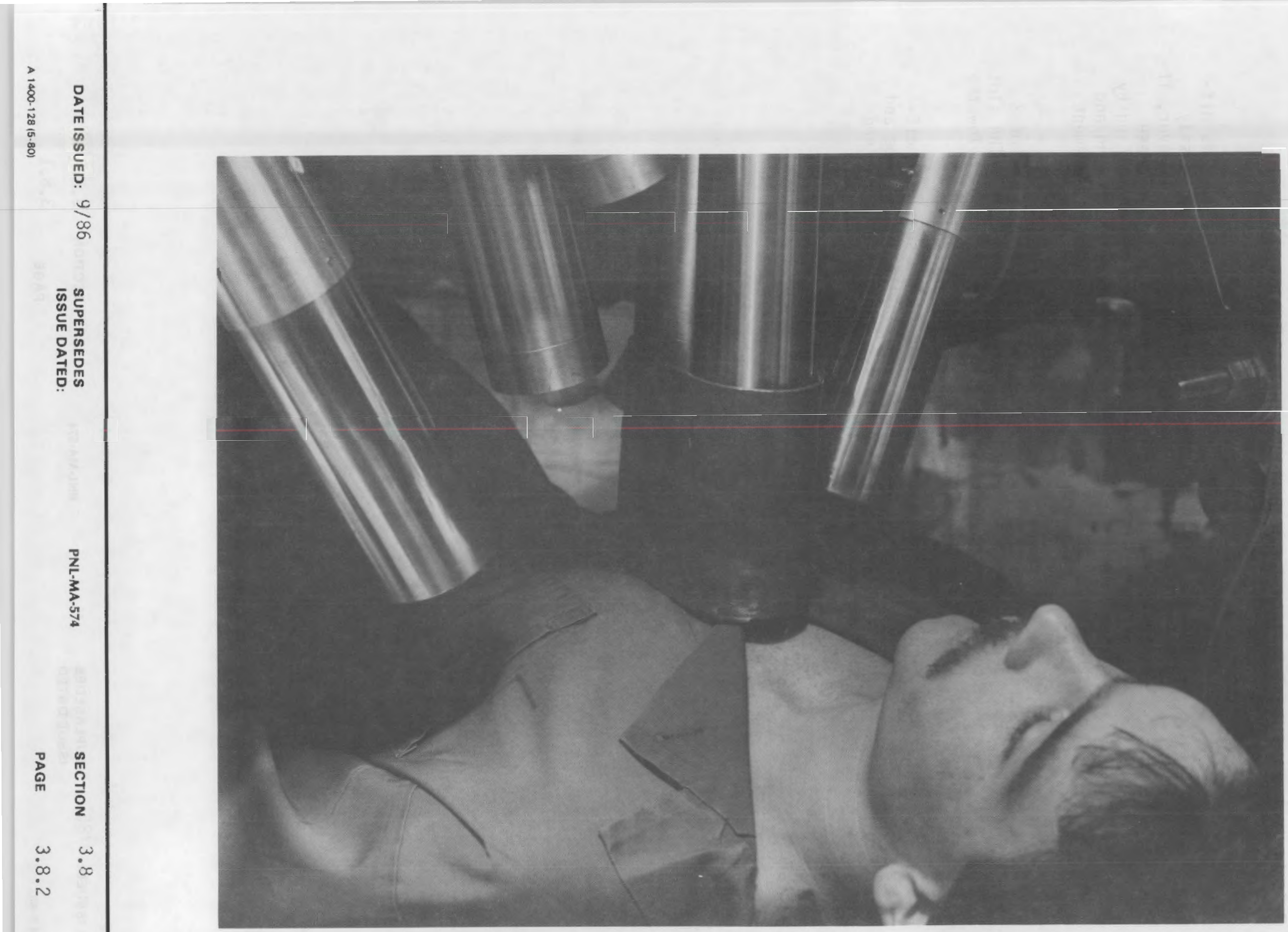

FIGURE 3.15. Two Germanium Planar Detectors Used to Measure the Tracheobronchial Lymph Nodes 


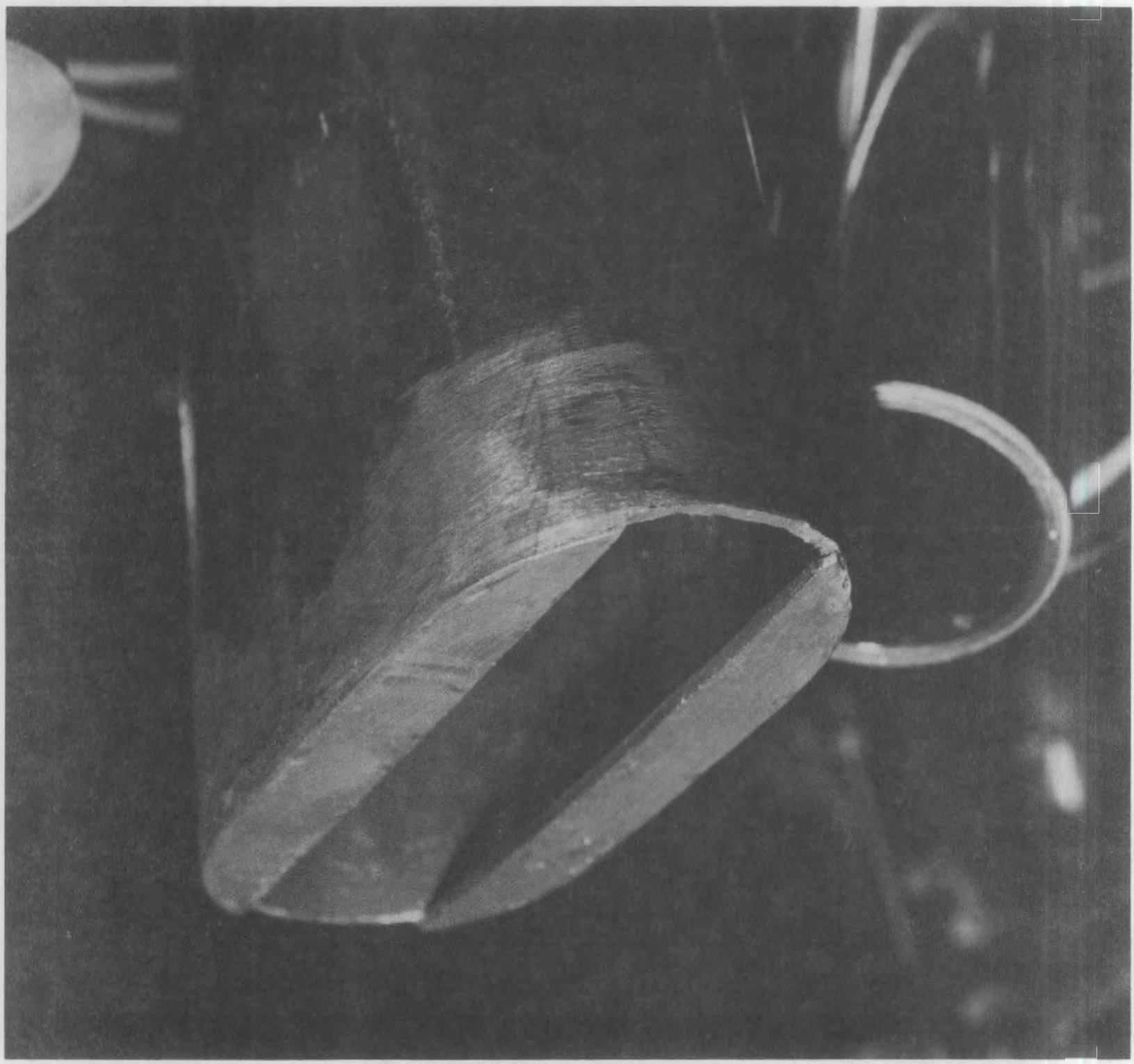

FIGURE 3.16. A Slot Collimator Which Extends Two Inches Below the Face of the Two Detectors Used to Measure the Tracheobronchial Lymph Nodes 


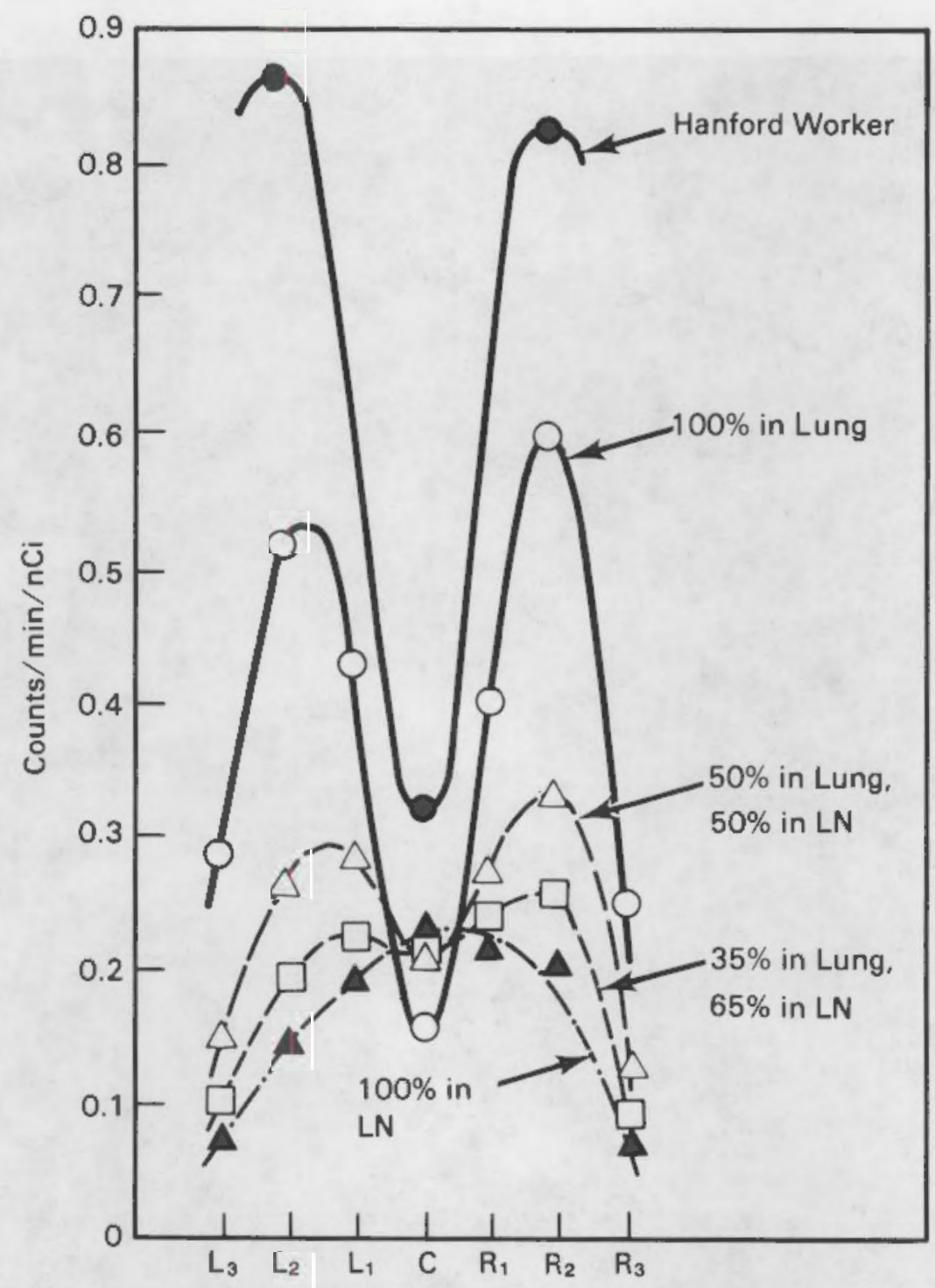

FIGURE 3.17. Posterior Lateral Scan of Activity in the Lungs and the Tracheobronchial Lymph Nodes (LN) 


\subsection{IN VIVO MEASUREMENT OF RADIOACTIVITY USING A LINEAR SCAN}

When the activity is not evenly distributed within the body, knowing the location of the activity can be of help to the Internal Dosimetry Group. Rough estimates of the locations of activity can be made by a rapid measurement in the preview whole body counter. For more precise location information the linear scan system must be used.

A collimated 4-in. $\times$ 4-in. $\times 16-i n$. NaI detector scanning from below the body is used to determine the location of the activity using a longitudinal scan of the body. The linear scanner is shown in Figures 3.18 and 3.19. The system uses a single-channel analyzer (SCA) to select a portion of the energy spectrum to better discriminate against background or even separate the location of one nuclide from another providing the nuclides have sufficiently separate characteristic energy peaks.

\subsubsection{Procedure for Calibration of the Linear Scan Detector}

- If possible set up the system using a source of the same nuclide as that observed in the subject. If such a source is not available, use the activity in the person.

- First the analyzer is set in the multichannel analyze mode; the SCA's output controls a linear gate that selects only a specific energy region output of the main amplifier. The resulting spectra on the MCA show exactly what energy region has been selected by the SCA as input to the multichannel scale mode.

- Observe the spectra on the MCA.

- Keep the calibration source on the detector and set the threshold and window settings of the SCA to select the major characteristic peak of the nuclide of interest.

- If more than one nuclide is present more sensitivity can be gained by using both peaks or all of the major peaks of interest.

- Switch the analyzer to the multichannel scale mode (MCS) to count the subject.

- Only the mode switch needs to be changed to the MCS mode since the analyzer has separate input ports for MCA and MCS functions.

- Now the same pulse that triggered the linear gate is fed to the analyzer in the MCS mode. This pulse is the output of the SCA and produces a square 


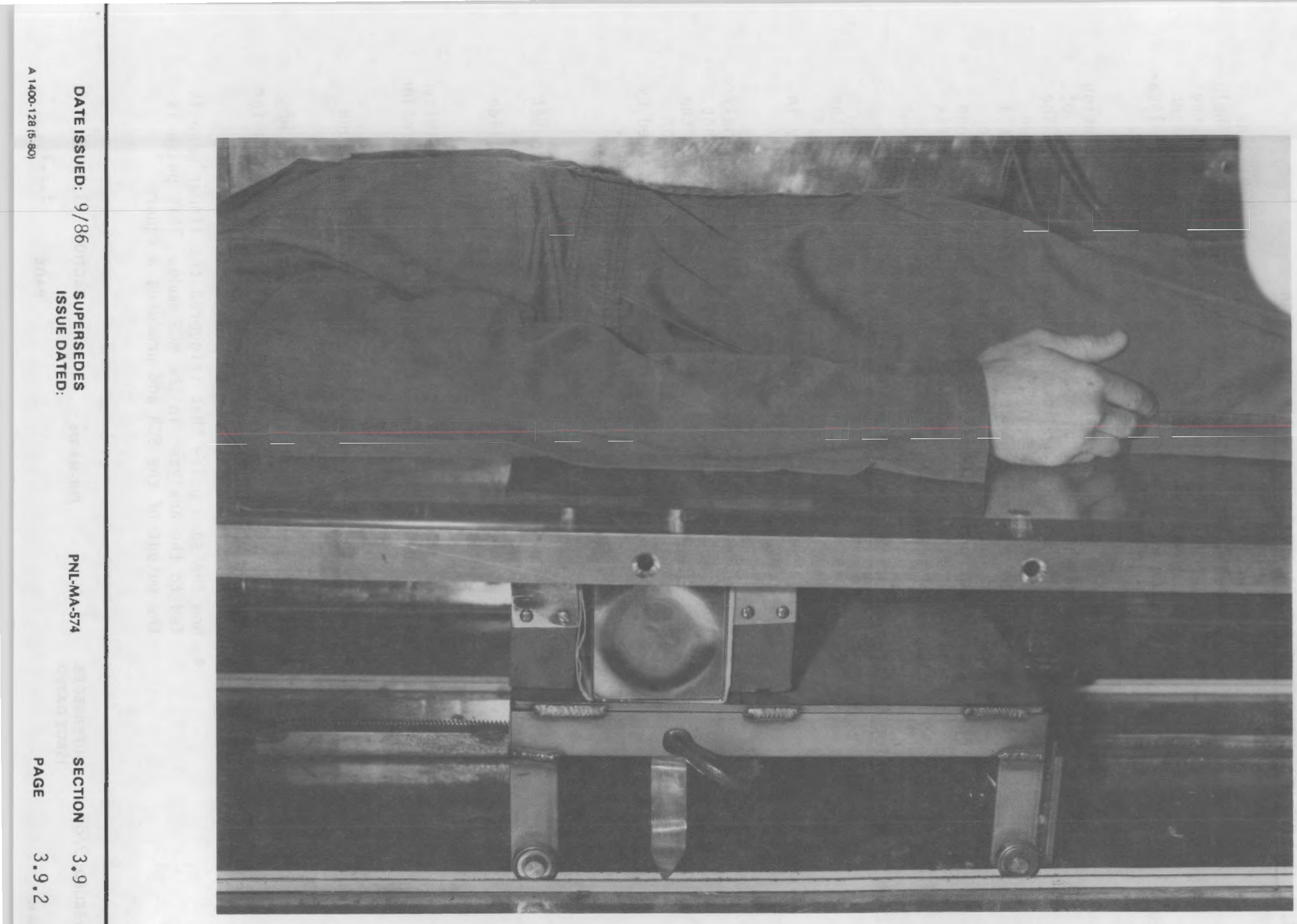

FIGURE 3.18. Subject Being Measured with the Linear Scan System (the detector scan from below the subject's body) 


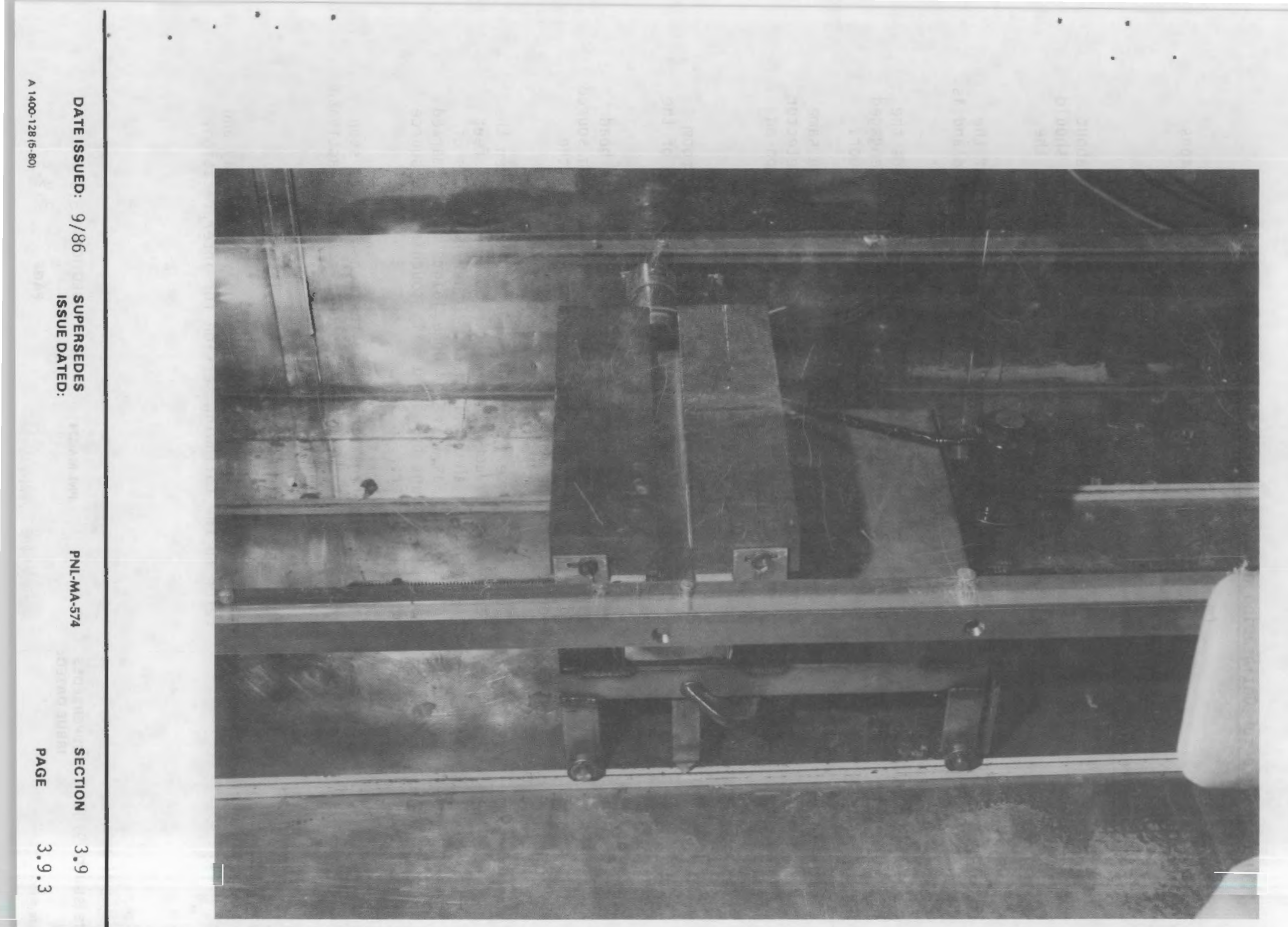

FIGURE 3.19. Components of Linear Scan System 


\subsubsection{Procedure for Calibration of the Linear Scan Detector \\ (contd)}

(monoenergetic) pulse for each pulse from the detector that meets the energy range restrictions specified by the SCA.

\subsubsection{Procedure for Subject Measurement}

- Position the subject on the bed centered and about 6 in. from the top of the bed. This position should place the collimator slit at about the top of the head for starting position.

- Position the collimator carriage to the top of the bed position. The carriage has only one speed and is powered only in a head-to-toe direction sweep.

- To move the carriage lift the handle that holds the gear and motor assembly until the gear is disengaged from the rack (geared teeth) bolted to the floor.

- Push the following three switches at about the same time to start the analyzer counting and the detector moving at the same time: 1) the acquire button on analyzer, 2) the MCS start button, and 3) the collimator carriage drive start switch.

- Keep calibration source handy but out of the room except when the collimator slit is at the top of the head.

- When the collimator slit is at the top of the head and the count has begun, touch the calibration source to the detector end momentarily, then remove the source from the room.

- Touch the source on the detector end again when the scan is nearly complete and the bottom of the feet are even with the collimator. Other positions of interest such as liver or bone joints may be marked during the count by momentarily touching the source or the detector.

- Stop the carriage by pushing the red carriage stop switch, or let the carriage stop microswitch activate automatically when it reaches the far end.

- Print out the spectrum and label it.

- Plot the spectrum or study the analyzer display and refer to the following section for interpretation. 


\subsubsection{Calculations for Activity Detected with the Linear Scan}

The spectrum should clearly show a peak at each end. The peak on the left of the spectrum represents the head position when the collimator slit was above the head and the source was touched to the detector. The peak at the right of the spectrum represents the foot position when the collimator slit was at the end of the feet and the source was touched to the detector.

By calculating the number of channels between the peaks and dividing the subject's height in centimeters by the number of channels between the calibration peaks and entering this number as the keV per channel value as input data to plot the spectrum, a means of referencing activity to distance from the top of the head in centimeters is obtained.

\subsubsection{Alternate Modes of Use}

This system can be operated in two different modes depending on the time allowed and the precision desired. The normal longitudinal count is about 15 minutes; the movement of the collimated detector is motorized and the analyzer is operated in the MCS mode.

Resolution and sensitivity can be increased by varying the slit width of the collimator, by manually moving the detector carriage to increase the dwell per position, and by leaving the carriage stationary during each counting period. In this mode each position merits having the whole spectrum saved for each location counted.

Although the manual scan method is more versatile in the types of information to be gained, it also takes more time during analysis than continuous movement of the MCS mode. The MCS mode produces a histogram of relative activity versus location and can be stored or plotted by normal spectrum-handling routines. 

The chest wall thickness among adult males varies between 2 and $4 \mathrm{~cm}$. The variation among women is even greater. Since the half thickness (half value layer) for $17-\mathrm{keV}$ $x$-rays in muscle and fat tissue is about $7 \mathrm{~mm}$, it is essential that the chest wall thickness be measured. In addition, a thicker chest wall causes the detectors to be located at a greater distance from the lungs which aiso results in a reduced count rate. The chest wall thickness can be measured within \pm 1 mm using ultrasound equipment designed for this purpose.

\subsubsection{Procedure for Determining Chest Wall Thickness}

\section{Required Supplies}

- 2 bottles aquasonic transmission gel

- 3 packages Polaroid Film Type 107

- 3 bath towels

- template for 6 intrinsic germanium detector configuration (Figure 3.20)

- washable felt tip marker

Prior to Ultrasound Measurement
Preliminary adjustments for optimum clearness and machine calibration should be performed before an ultrasound measurement is taken. Refer to the routine settings listed on the machine and allow a 5-minute warmup.
Subject's

Right Lung
Subject's

Left Lung

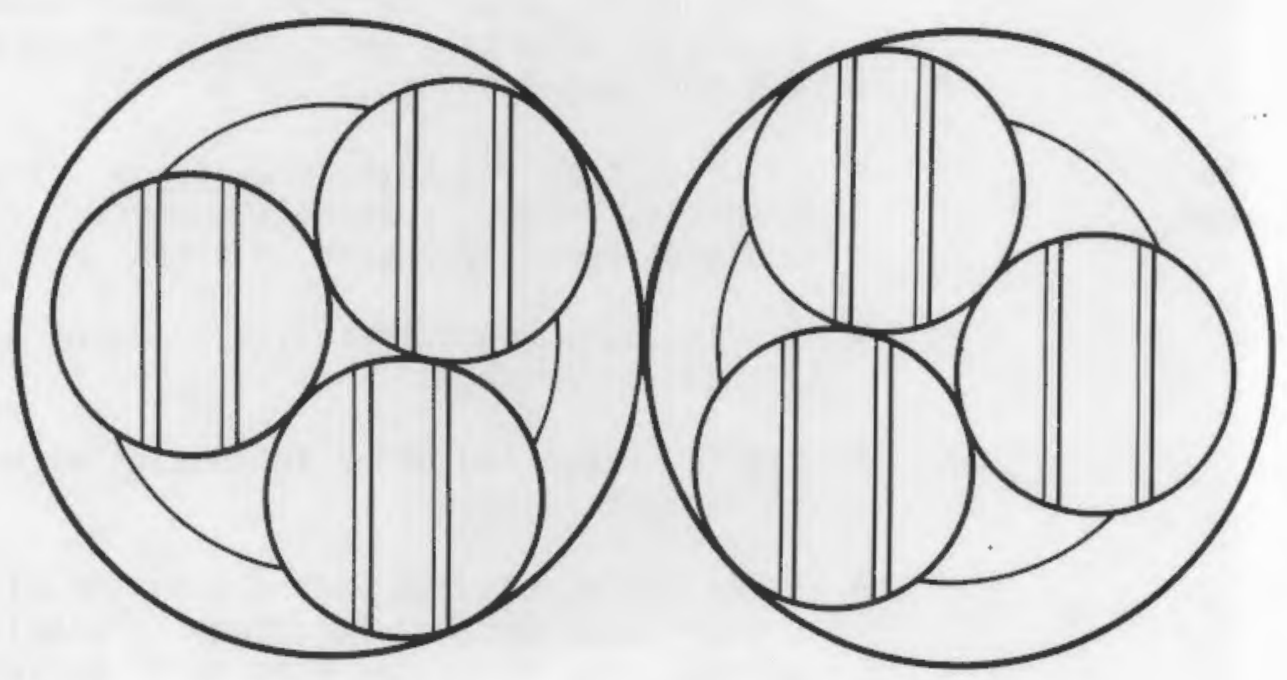

FIGURE 3.20. Template Configuration 


\subsubsection{Procedure for Determining Chest Wal1 Thickness}

Subject Preparation

- Place towel on recliner where subject will lie.

- Take special precautions to ensure the subject's privacy during this measurement.

- Instruct the subject to remove all clothing above the waist.

- Place one bath towel from the lower breast area down to the waist.

- Inform the subject that removable ink marks will be drawn on the chest to simulate the actual detector placement of the 6 intrinsic germanium detectors used for the in vivo lung exam.

- Position the edge of the template which has cut outs simulating the actual placement of the detectors in line with the subject's clavicle.

- Insert marker into the cut-out slots of the template and lightly draw all 12 vertical lines while holding the template in place (Figure 3.21).

- Remove the template.

- Inform the subject that the ultrasound transmission gel will be slightly cool when applied to the skin.

- Slowly squeeze gel and apply approximately 1/8-in.thick to all drawn vertical lines. Apply the gel slowly to eliminate excessive air bubbles in the gel and for even application.

Taking the Measurement
- On the ultrasound keyboard, key in the current date, 2 spaces, subject's payroll number, 2 spaces, and the position number you wish to ultrasound first.

- Slowly apply approximately $1 / 8$ in. of gel to the ultrasound probe.

- Lightly place the probe in contact with the gel on the subject's chest.

- Carefully adjust the controls on the ultrasound unit until a well defined interface is displayed on the screen. The probe may need to be rocked slightly back and forth to obtain a good interface (Figure 3.22). 


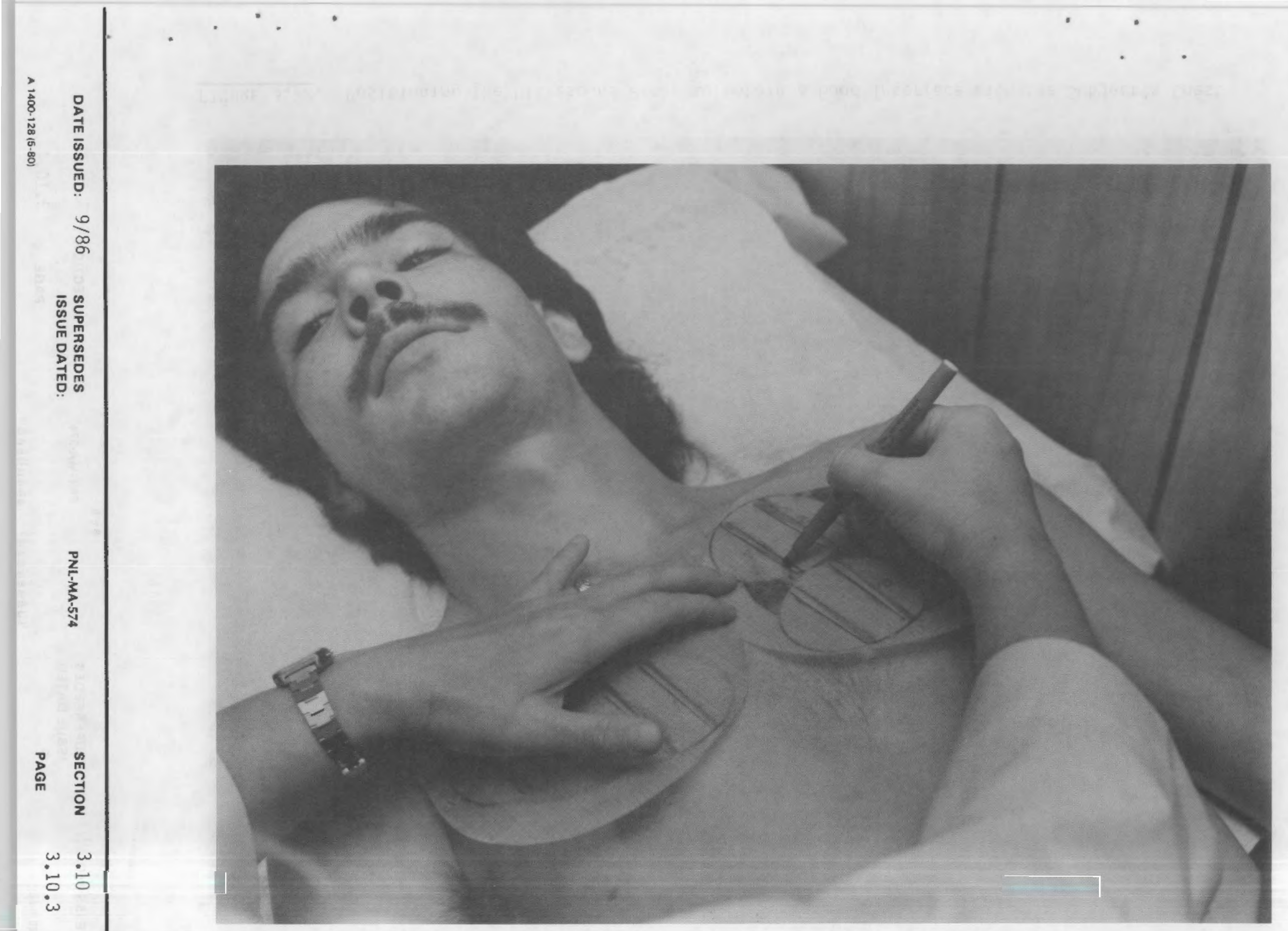

FIGURE 3.21. Using the Template to Draw the Lines That Indicate U1trasound Probe Placement 


\subsubsection{Procedure for Determining Chest Wall Thickness \\ (contd)}

After Ultrasound Measurements Have Been Taken
- Make sure the probe is in the proper position before taking a poloroid picture.

- Remove the photograph and set it aside for at least one minute for development.

- Erase the old position number on the screen by using the red clear (CL) key.

- Enter the next uitrasound position on the screen.

- Apply more gel to the probe, carefully position the probe and photograph the next interface.

- Separate the photograph from the developer after 60 seconds.

- Repeat the process until all 12 positions have been recorded on photographs.

- Examine developed photos closely to determine if any positions require retakes.

- Use the third towel to remove the excess gel from the subject's chest.

- Subject may return to the main lobby of the WBC.

- Using calipers, determine and record the actual chest wall thickness for each position on the Uitrasound Measurement forms (Exhibit 3.1).

- Add all 12 positions and divide the total by 12 for an average thickness in centimeters. 



\subsection{IN VIVO COUNTING FOR CRITICALITY ACCIDENTS}

The exposure of workers to neutrons will result in induced radioactivity in the body from the activation of the major elements of body composition such as calcium, nitrogen, sodium, chlorine, etc.

A neutron dose of $20 \mathrm{mrad}$ of fission spectra neutrons will produce approximately $10 \mathrm{nCi}$ of sodium-24 in the body. Immediately after exposure calcium-49, sodium-24, chlorine-38, aluminum-28 and nitrogen-13 are easily measured, but because of the short half-lives, only sodium-24 is measurable by the time the worker is transported to the whole body counter. The assessment of sodium-24 in workers exposed to neutrons from a criticality accident provides a means of estimating the neutron dose.

After all the gamma ray emmitters have decayed away in an exposed person, measurements of bremstrahlung radiation from phosphorous-32 in the bone may give information on which portions of the body received the highest dose. Details of the bremstrahlung measurements are not given in this procedure.

\subsubsection{Procedure for Energy and Efficiency Calibration}

- Use a cesium-137 and a potassium-40 source for an energy calibration of the MCA.

- Adjust MCA until each channel is equivalent to 20 $\mathrm{keV}$.

- Use the standard potassium-40 source and geometry to confirm that the counting efficiency is unchanged.

- Calibration details for determining the sodium-24 content are located in the Whole Body Counter Laboratory Notebook \#1, (11/11/59) HWN-2454, pages 134-135, assigned to the WBC manager.

\subsubsection{Procedure for Measuring Activity Resulting from Criticality Accidents}

Since the level of sodium in the body of the worker exposed to a criticality event may be relatively high, the procedure used to evaluate the amount will depend on the quantity present.

Low levels can be quickly assessed by the preview whole body counter (measurement procedure described in Section 3.1), which will automatically calculate the results. For a more precise assessment, or for levels that exceed the preview counter's capacity, follow the procedure below. 


\subsubsection{Procedure for Measuring Activity Resulting from Criticality Accidents (contd)}

If Body Burden is Greater than $5 \mu \mathrm{Ci}$

\section{Taking the Count}

- Take the measurement in the lead room using the tilted chair geometry with the 4-in. $\times 93 / 8-i n$. $\mathrm{NaI}(\mathrm{T} 1)$ detector in the normal position.

- See Figure 3.23 for chair and detector positioning.

- Determine the amount with the detector in the normal position at the distance shown in Figure 3.23.

- Close the lead room door

- Start the count with preset time at 5 or 10 minutes.

- Observe the MCA display to determine whether the count will overscale.

- If analyzer indications suggest that it will overscale before the count is finished, stop the count.

- Raise the detectors up to the distances shown in Figure 3.24 and begin counting again.

- Count for 1 to 10 minutes, depending on the leve1 of activity.

\subsubsection{Background Correction}

The background is subtracted using a previously determined background or appropriate fraction of a long background count done with an uncontaminated person sitting in the chair. If the alternate position was used (detector raised), a background count with the detector in the same position should be used for the precise calculation of the background.

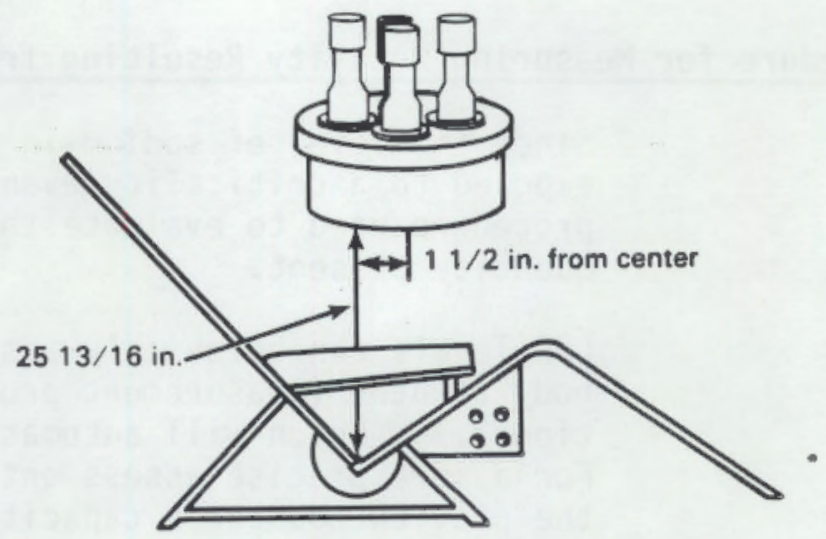

FIGURE 3.23. Detector in Normal Position 


\subsubsection{Background Correction (contd)}

By the time the exposed person arrives at the WBC, all interferring radionuclides will usually have decayed away.

\subsubsection{Calculations of Activity}

Calculating the Sodium-24 body burden

Calculating the Neutron Dose
The calibration factor for determining the body burden of sodium-24 using a 4-in. $\times 93 / 8-i n$. NaI(TI) detector in the normal chair position (shown in Figure 3.23 ) is 6522 counts per minute per $\mu \mathrm{Ci}$. The counts per minute are determined from the $2.75 \mathrm{MeV}$ peak using channels 128 to 143 inclusive. Equation (3.14) determines the total body content of sodium-24.

$\mu \mathrm{Ci}$ of ${ }^{24} \mathrm{Na}$ in the body $=\frac{\text { net counts } / \mathrm{min}}{6522}$

The calibration factor for the detector in the raised position (Figure 3.24) is __ (factor to be determined).

The average total-body fast neutron dose calculated from total-body sodium-24 measurements is shown (Hanford Laboratories 1963; Harris 1961):

dose in rads $=\frac{{ }^{24} \mathrm{Na} \text { activity in } \mu \mathrm{Ci}}{\text { weight of subject in } \mathrm{kg}} \times 226$

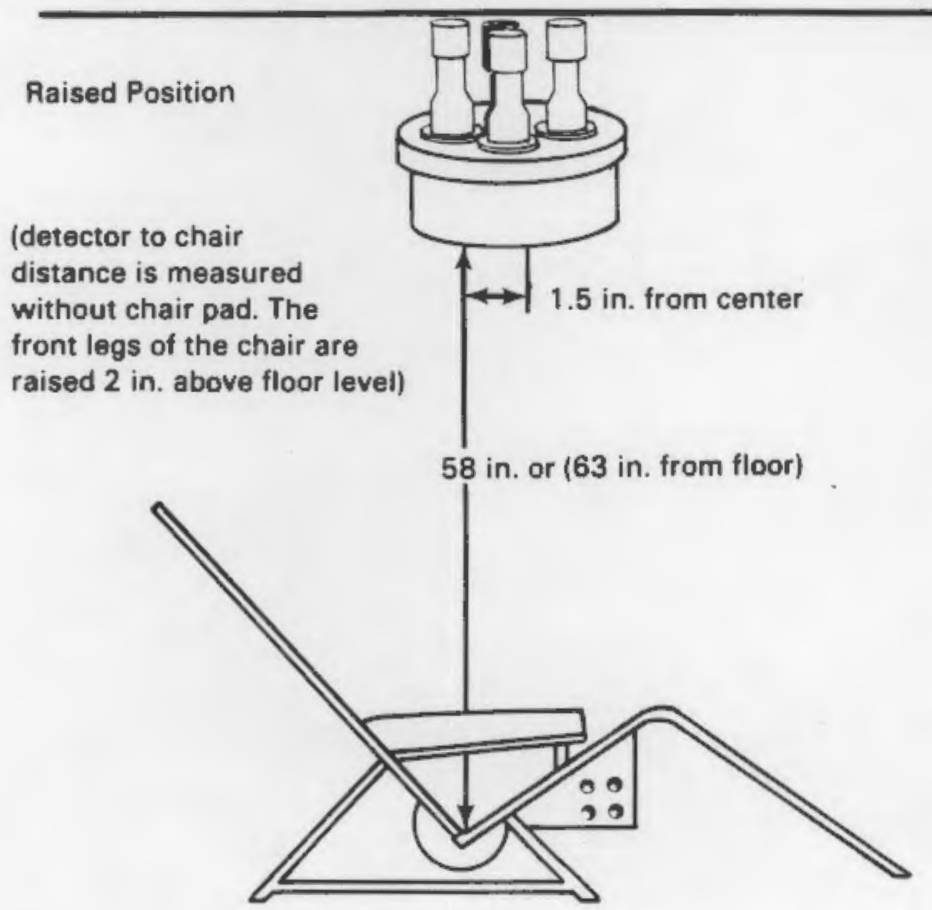

FIGURE 3.24. Detector in Raised Position 



\subsection{IDENTIFICATION OF UNKNOWN RADIONUCLIDES}

Most of the radioactivity found in the Hanford employees is easily identified because it has been observed many times before. Occasionally a radionuclide is observed which is not immediately identified. This usually occurs as a result of a radiopharmaceutical that has been given to the person as part of a diagnostic nuclear medical procedure at a hospital or a new process or procedure being used at Hanford.

\subsubsection{Procedure to Identify Unknown Radionuclides}

- Use the germanium planar detectors at the WBC to determine the exact energy of unknown radionuclides.

- Determine the exact energy of all the unknown photopeaks in the spectrum. Remember that more than one radionuclide may be present.

- Observe the relative heights of the various photopeaks.

- Refer to Slater (1962), and note radionuclides with gamma-ray energies corresponding to those in the spectrum from the contaminated subject.

- Keep in mind that the radionuclides with a half-life of 1 day or less are not usually present unless they are a daughter of a long-lived parent.

- Select one or two possible radionuclides.

- Go to the spectra catalogues in the library and compare the spectrum from the body with that in the catalogue, taking in consideration that absorption occurs in the body at lower energies. The photopeak energy in conjunction with radionuclide gamma ray energy tables and gamma ray spectra catalogues usually provide all the information needed to identify any unusual radionuclides.

- If the presence of a radiopharmaceutical is detected, notify the Internal Dosimetry Group of this nonoccupational exposure. 



\subsection{REFERENCES}

Hanford Laboratories, General Electric Company. 1963. "Dosimetry Investigation of the Recuplex Criticality Accident." Health Physics. 9(7):757-768.

Harris, P. S. 1961. "Special Supplement on Acute Radiation Death Resulting from an Accidental Nuclear Critical Excursion." Journal of Occupational Medicine. 3(3):179-180 (available in the WBC Library).

Kocher, D. C. 1981. Radioactive Decay Data Tables. DOE/TIC-11026, National Technical Information Service, Springfield, Virginia.

Palmer, H. E., G. A. Rieksts and E. E. Icayan. 1983. "1976 Hanford Americium Exposure Incident: In Vivo Measurements." Health Physics. 45(4): 893-910.

Palmer, H. E., H. B. Spitz and G. A. Rieksts. 1985. "Part III: Gamma-Ray Measurements." Health Physics. 49(4):577-586.

Slater, D. N. 1962. Gamma-Rays of Radionuclides in Order of Increasing Energy. Butterworths, Washington D. C.

Spitz, H. B., R. L. Buschbom, G. A. Rieksts and H. E. Palmer. 1984. "A New Method for Analyzing High-Resolution Spectra From Whole-Body Counter In Vivo Measurements." Health Physics 49(6): 1085-1096. 

Name: Date:

Payroll No: Height: Weight:

Comments :

\section{ULTRASOUnd POSITIONS}
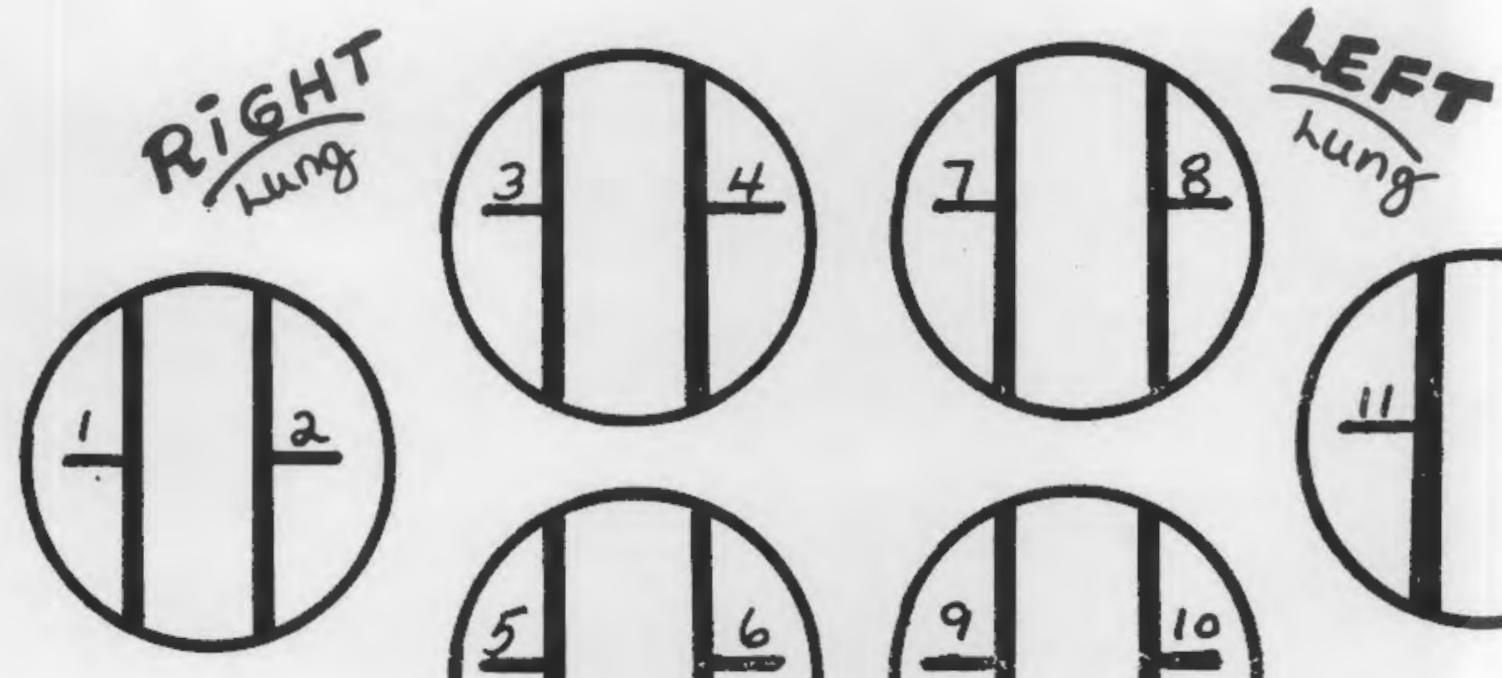

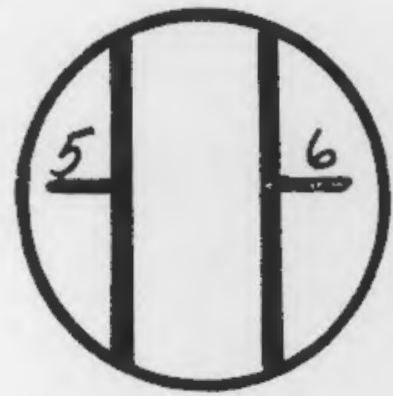

Position 2:

Position 5:

Position 8:

Position 11:
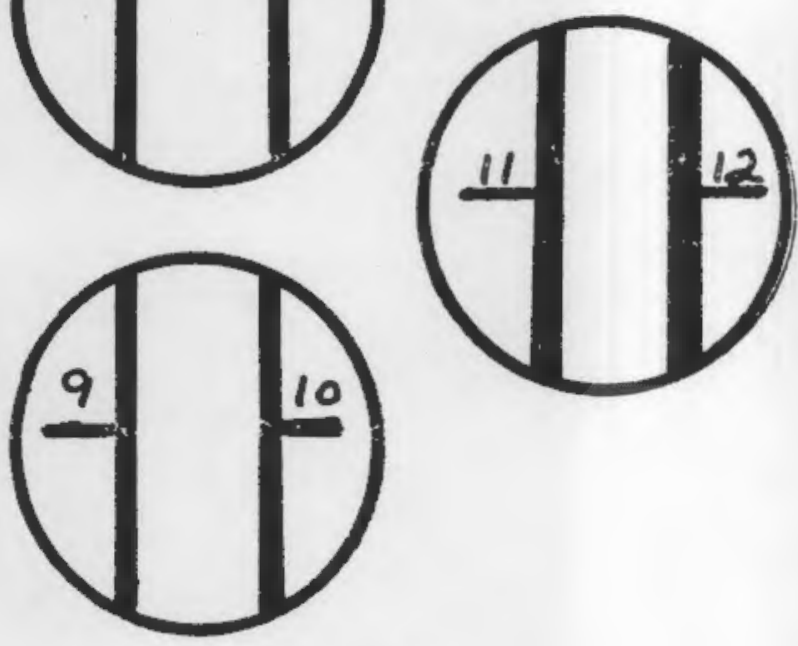

Position 3:

Position 6:

Position 9:

Position 12:

Position 10:

Total of all 12 Positions =

Divided by 12

$=$

Chest Wall Thickness in centimeters

NOTE: Configuration is for six intrinsic germanium detectors

$3-19-84$

DATE ISSUED: $9 / 86$

SUPERSEDES

ISSUE DATED:

A $1400-128(5-60)$
PNL-MA-574

SECTION 3: EXHIBIT

PAGE 1 of 1 



\subsection{OPERATION OF COUNTING EQUIPMENT}

This section describes the operation and maintenance of the WBC counting equipment which consists of detectors, preamplifiers, amplifiers, and multichannel analyzers (MCAs).

\subsection{DETECTORS}

High Voltage

Required
In Section 2 the detectors were briefly described. In this section, the operation, construction, maintenance, and repair of the detectors will be discussed.

\subsubsection{Detector Types}

The two types of detectors used in the WBC are the scintillation and semiconductors. Both types of detectors require very little maintenance but require close observation to detect any malfunction.

High voltage is required for the operation of both types of detectors. The scintillation detectors require positive high voltage, typically 800 to $1200 \mathrm{~V}$; the semiconductor detectors require 2000 to $5000 \mathrm{~V}$ of positive or negative voltage, depending on the type of semiconductor detector.

CAUTION

High voltage can be very dangerous. The detectors must be turned off and disconnected whenever they are being moved or repaired.

\subsubsection{Detector Hookup Design}

The scintillation detectors are connected to the high voltage supply and signal processing instrumentation as shown in Figure 4.1 .

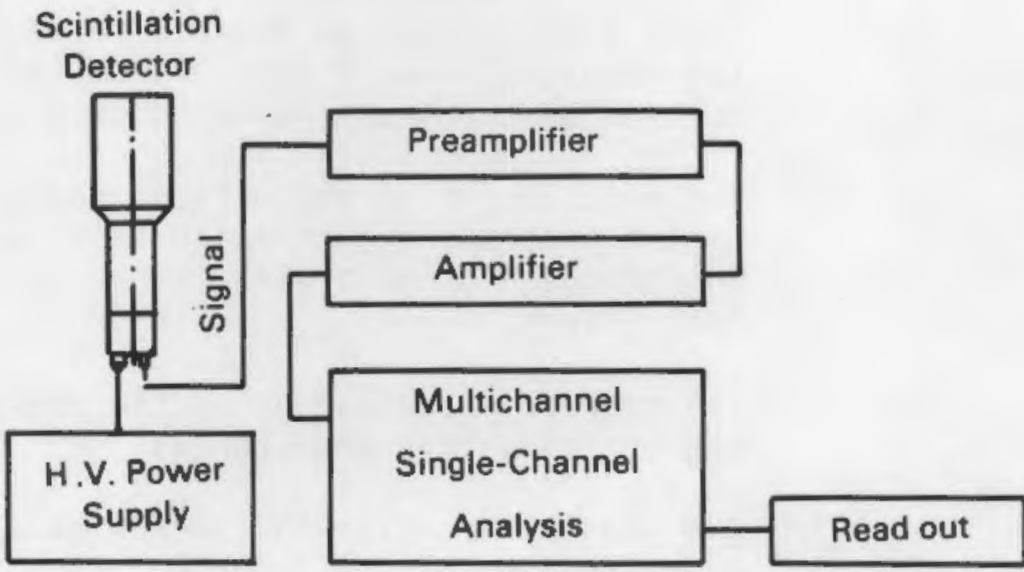

FIGURE 4.1. Schematic of a Scintillation Detector 


\subsubsection{Detector Hookup Design \\ (contd)}

The semiconductor detectors are connected to the high voltage and signal processing instrumentation as shown in Figure 4.2 .

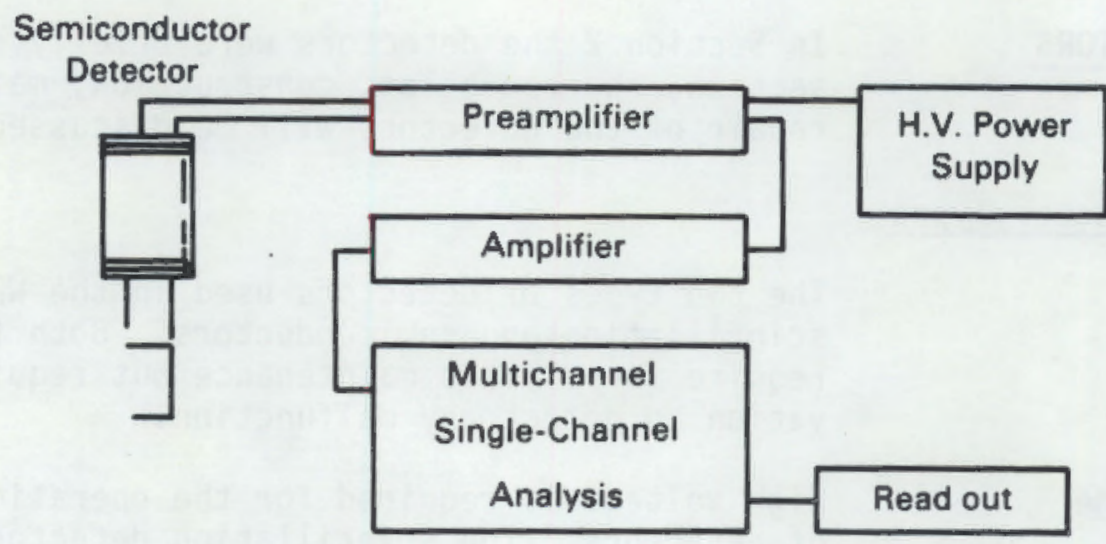

FIGURE 4.2. Schematic of a Semiconductor Detector

\subsubsection{Detector Maintenance and Repair}

Semiconductor Detectors

\section{Scintillation Detectors}

The only maintenance required for the semiconductor detectors is keeping them cooled with liquid nitrogen. All repairs on these detectors must be done by the manufacturer.

The $\mathrm{NaI}(\mathrm{Tl})$ scintillation detectors operate at room temperature and require only minimal maintenance. This maintenance includes balancing the photomultiplier tubes every 6 months and replacing the optical coupling compound between the photomultiplier tubes and the detector windows every 2 or 3 years as needed. Deterioration of the detector resolution would result from the imbalance of photomultiplier tubes and hardened coupling compound.

The replacement of the optical coupling can be performed by the instrument technician assigned to WBC. The balancing of the photomultiplier tubes is done by the WBC technicians.

The procedure for balancing the photonultiplier tubes in the scintillation detector is:

- Center a cesium-137 source at least 12 inches from the face of the detector.

- Disconnect all high voltage leads from the photomultiplier tubes. 


\subsubsection{Detector Maintenance and Repair \\ (contd)}

\section{CAUTION}

\subsubsection{Determination of Detector Resolution}

A scintillation detector's performance is typically stated as a value of pulse height resolution, full width at half maximum (FWHM), for a particular gamma-ray peak.

Although any gamma line may be used, the most usual specified value is for the $662-\mathrm{keV}$ gamma ray from cesium-137. With the source at least 12 inches away from the center face of the detector, accumulate counts until there are at least 5000 counts in the peak channel. Avoid high counting rates that will result in a "dead time" which exceeds $25 \%$ on the MCA.

From the resulting spectrum, calculate the resolution by dividing the peak channel into the number of channels comprising the upper half of the peak (see Equation 4.1 and 


\subsubsection{Determination of Detector Resolution}

(contd)

Figure 4.3). Resolution values for the large $\mathrm{NaI}(\mathrm{Tl})$ detectors should be in the range of $8 \%$ to $9 \%$ for the $662-k e V$ gamma ray.

$$
\text { resolution }=\frac{\text { channel } C-\text { channel } A \times 100}{\text { channel } B}
$$

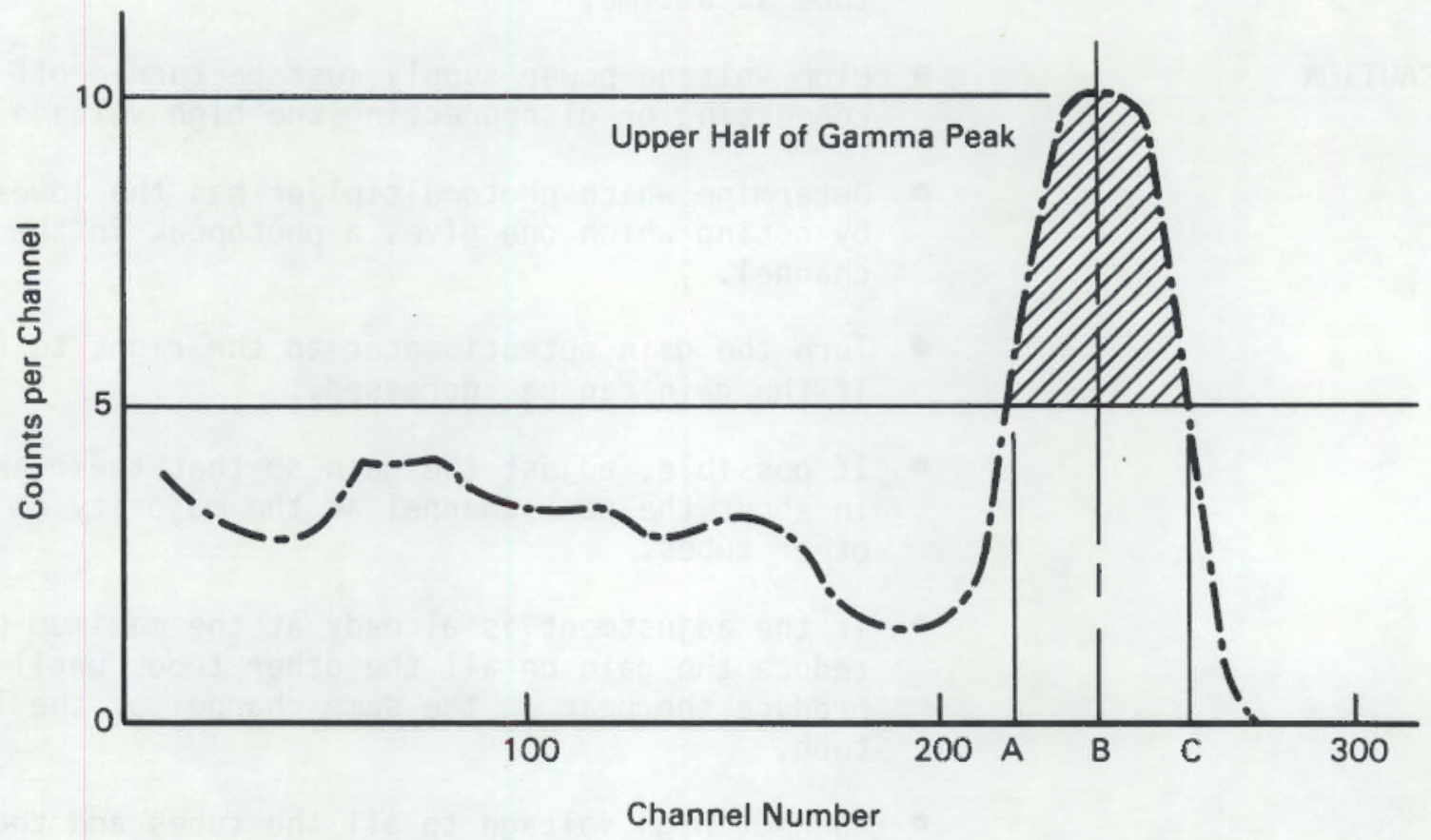

FIGURE 4.3. Calculation of Detector Resolution

\subsubsection{Diagnosing Detector Problems}

Noise in a spectrum is generally defined as the extraneous events counted near the zero-energy end of the spectrum. In scintillation detectors it is nearly always a result of spontaneous emission from the photocathode of the photomultiplier tube and the tube may need to be removed.

It is acceptable for noise to occur in channels corresponding to 0 to $20 \mathrm{keV}$ for the large detectors with multiple tubes. For the thin crystal detectors used for plutonium-239 counting, the acceptable noise level is 0 to $10 \mathrm{keV}$.

Noise can also appear as discrete peaks at high energies. If unidentified peaks appear in a spectrum that has a peak 


\subsubsection{Diagnosing Detector Problems \\ (contd)}

width narrower than a gamma peak of equal energy, it is certain to be the result of a malfunction of the electronic system. If the peak is the same width as a gamma ray line, look for unshielded sources near the detector.

\subsection{PREAMPLIFIERS AND AMPLIFIERS}

The section describes the operation of the preamplifiers and amplifiers.

\subsubsection{Preamplifiers}

The output from a detector is a small charge pulse. It is necessary to precondition the output so that it can be utilized in a linear amplifier system. The linear amplifier system in turn provides the necessary pulse shaping and amplification required for use with the measuring unit. A preamplifier is generally inserted immediately after the detector to provide integration of the charge output of the scintillation/photomultiplier detector or semiconductor detector.

The output of the preamplifier is connected to pulseshaping main amplifiers. Impedance matching between the detector output and the pulse-shaping and amplifier stage that follow are provided by the preamplifier. Connecting the preamplifier as close to the detector as possible increases the signal-to-noise ratio.

For further details on the operating instruction, refer to the manuals for the specific preamplifiers that are located in the WBC library.

\subsubsection{Amplifiers}

Main Amplifier

The main amplifier further increases the signal from the preamplifier so that it can be used within the dynamic operating range of the system.

\section{Linear Amplifier}

Linear amplifiers are required to ensure that the relationship between the input and output signal is maintained.

To measure individual signals, independent of previous ones, the signal decay time must be reasonably short compared with the input repetition rate in order to reduce pulse pile-up distortion. In addition, to be proportional to the amplitude of the signal from the preamplifier (and therefore the charge from the detector) the duration of the output signals from the amplifier must be longer than the rise time of the input pulse.

DATE ISSUED: $9 / 86$ 


\subsubsection{Amplifiers \\ (contd)}

For further details on the operating instructions, refer to instruction manuals for the specific amplifiers, which are located in the WBC library.

\subsection{SPECTROSCOPY EQUIPMENT: THE MULTICHANNEL ANALYZER}

The MCA is the basic spectroscopy counting instrument used in the WBC. Because of the MCA's versatility and the facility of operation, it is often used in applications where a scaler or rate meter in combination with a single channel analyzer (SCA) might suffice.

MCA Operation

Types of MCAs

Operation of MCAs
The MCA converts the pulse received from the amplifier into an equivalent digital number that is stored in memory location which most closely corresponds to the pulse amplitude. The processing time for each pulse is typically $100 \mathrm{\mu sec}$.

There are ten different MCAs used at the WBC facilities representing five different models. These range from manually controlled devices to programmable microcomputercon'trolled instruments capable of highly automated sequences.

There are five basic steps that are necessary to properly set up and operate the MCAs. These steps are:

- Erase the selected memory.

- Start analyzer acquiring.

- Stop analyzer and be able to recognize that it has timed out.

- Display a portion of the spectrum in sufficient detail to be able to ascertain what channel represents the peak energy.

- Output the spectrum on some permanent medium such as paper tape or a printed page to be able to identify the channel number and the contents of that channel relatively easily.

These steps must be practiced by the WBC technicians until they can be done well. Improper execution of these functions will result in wasted time, unrealistic results, and may destroy valuable acquired data. 


\subsubsection{MCA Calibration}

Before the MCA can be used for either quantitative or qualitative analysis, it must be calibrated to a standard energy scale of pulse height distribution. In other words, it must be adjusted so that each channel represents a predetermined energy range and that a plot of pulse heights versus channel number has a zero intercept.

There are two MCA parameters that can be changed which will allow the MCA to be calibrated for any range of radiation energy desired. The two parameters are gain (either amplifier- or MCA-conversion gain) and the zerolevel of set adjustment.

Gain

When the gain is changed, the energy peaks shift to a channel position proportional to the change in gain. If two photopeaks were initially falling in channels 60 and 100 , and the gain is doubled, the peaks would then fall in channels 120 and 200. Initially the peaks were separated by 40 channels but after the gain change the peak separation is 80 channels (see Figure 4.4 ).
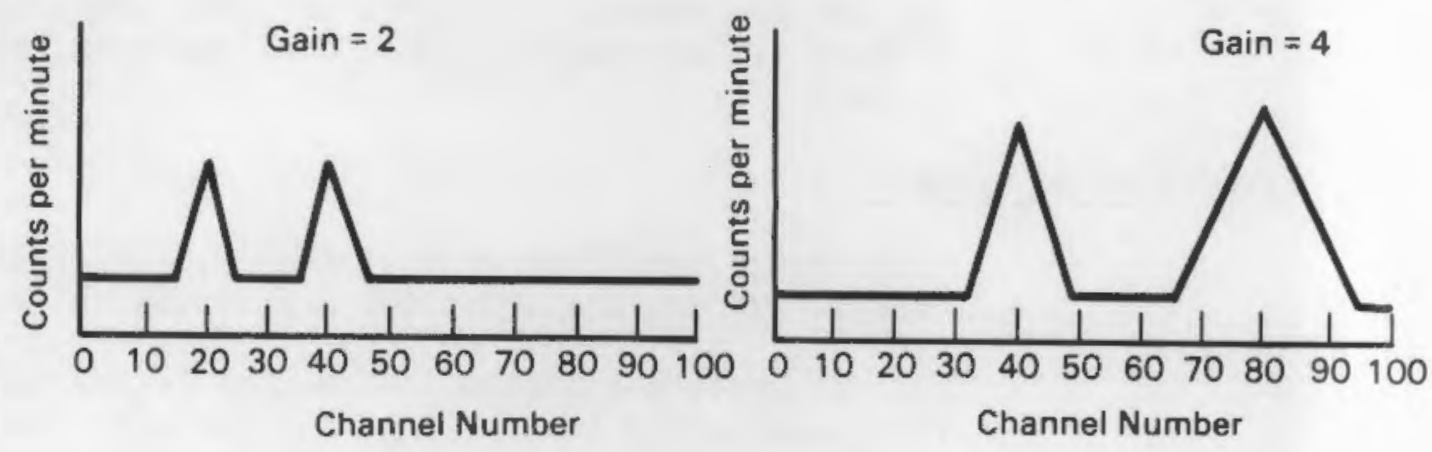

FIGURE 4.4. Change in Peak Location with Conversion Gain

Zero Leve1

Example
In the case of the zero level offset adjustment, the two peaks would shift the same number of channels (see Figure 4.5$)$, and the number of channels between the peaks remain the same. With these two adjustments, the MCA can be calibrated for any energy region or range desired.

As an example for calibration, assume that a setup for an MCA to measure low-enery photons ranging from 0 to $256 \mathrm{keV}$ at $0.5 \mathrm{keV}$ per channel with a zero intercept is desired. 

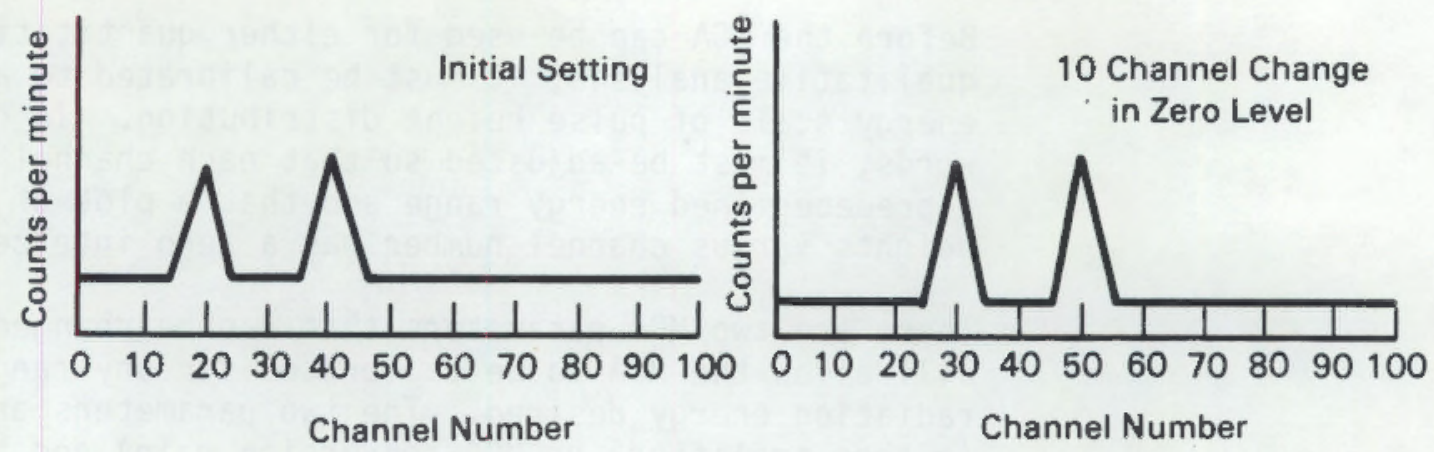

FIGURE 4.5. Change in Peak Location with Zero Level Offset Adjustment

\subsubsection{MCA Calibration (contd)}

This can be done by using an americium-241 source which emits a $59.5-\mathrm{keV}$ gamma ray and a uranium-235 source which emits a 185.5-keV gamma ray. To calibrate the MCA at $0.5 \mathrm{keV}$ per channel, the 59.5-keV peak needs to center in channel 119 and the 185.5-keV peak needs to center in channel 371.

\subsubsection{Example of Adjustment}

What change should be made if the $59.5-\mathrm{keV}$ peak falls in channel 126 and the $183.5-\mathrm{keV}$ peak falls in channel 384 ?

When properly calibrated, the number of channels between the peaks should be 371 minus 119, or 252. In the above situation there are 384 minus 126, or 258 channels. Since there are 6 channels too many between the peaks the first step would be to reduce the gain until 252 channels exist between the peaks. We can reduce the gain until the 185.5-keV peak is in channel 375 and the $59.9-\mathrm{keV}$ peak is in channel 123.

At this point there are 252 channels between the peaks, which is the number desired, but both peaks are 4 channels higher than what is needed. The next step is to change the zero level offset so that the spectrum shifts down by 4 channels and the energy calibration is then complete when the peaks fall in channels 119 and 371 .

Some final, very small adjustment in gain or lower level offset may be necessary so that the 2 peaks are precisely centered in the appropriate channel. 


\subsection{QUALITY ASSURANCE}

Whole body counting results are a very important part of an employee's documented work history. The WBC operations must conduct all work with the highest standard of quality commensurate with the requirements of internal dosimetry; cost; employees' time, safety, and comfort; and availability of equipment.

The quality assurance procedures are included in each of the measurement procedures described in Section 3; a summary of the overall quality assurance program as it relates to quality results is presented in this section. All WBC measurements are performed according to Quality Assurance Plan No. OREP, Revision 4, dated September 11, 1986. This Quality Assurance Plan is included in Appendix B.

\subsection{EQUIPMENT CALIBRATION}

Two types of basic calibrations--an energy calibration and an efficiency calibration--are made every time the equipment is used, or at least once a day for equipment in daily use.

\subsubsection{Energy Calibration}

Since all of the measurements are derived from energy spectra, the instrumentation and detectors must be calibrated for energy response so that a unit of energy of the output is exactly proportional to the energy of the radiation detected. At least two points on the energy spectrum, widely separated in energy, are needed for an energy calibration.

For example, the whole body counter is usually calibrated at $20 \mathrm{keV}$ of gamma ray energy per channel of data output, whereas the lung counter is usually calibrated at $0.5 \mathrm{keV}$ per channel.

\subsubsection{Efficiency Calibration}

After the detectors and instrumentation are calibrated for energy response, they are then calibrated for the primary efficiency response by measuring a National Bureau of Standards (NBS)-traceable, known quantity of a radionuclide in a phantom or organ as described in Section 3.

\section{Daily Calibration} Checks
The daily check of the efficiency is done with secondary reference sources that have long half-lives and that were measured for standard length of time in a reproducible geometry with respect to the detector at the time of the efficiency calibration. These secondary sources are 


\subsubsection{Efficiency Calibration}

(contd)

Quarterly Calibration Checks contained in a matrix which does not change with aging so the geometry or the self-absorption of the source does not change.

A daily measurement of the background is also made. The daily efficiency count and the daily background are stored as retrievable computer data that are dated and accompany the employee measurement spectra data for that day.

If either of the daily efficiency check or background measurement do not fall within the expected limits of variance, the cause must be determined and eliminated before whole body counts are done. If the cause is a malfunctioning detector which must be replaced, a primary efficiency calibration with a phantom may be necessary.

The individual components of the measuring system such as detectors, amplifiers, high voltage supplies, and MCAs are not checked individually for sensitivity or linearity performance unless the total system fails to produce the proper count rate when measuring the standard reference source. If the count rate does not fall within acceptable limits of variability, the failing component is traced and replaced or repaired. Table 5.1 lists the quality assurance checks performed on each counting system.

At quarterly intervals, the daily background and source efficiency counts are listed, the standard deviations

TABLE 5.1. Summary of Quality Assurance Checks for Counting Systems

\begin{tabular}{|c|c|c|c|c|c|}
\hline Counting System & $\begin{array}{l}\text { Frequency } \\
\text { of } Q A \text { Check }\end{array}$ & $\begin{array}{l}\text { Balance } \\
\text { Multiple } \\
\text { Detectors } \\
\end{array}$ & $\begin{array}{c}\text { Energy } \\
\text { Calibration } \\
\end{array}$ & $\begin{array}{l}\text { Secondary } \\
\text { Efficiency } \\
\text { Calibration } \\
\end{array}$ & $\begin{array}{c}\text { Background- } \\
\text { Interval }\end{array}$ \\
\hline Preview counter & Daily & Yes & Yes & Yes & Yes $-1000 \mathrm{sec}$ \\
\hline $\begin{array}{l}\text { Germanium array } \\
\text { lung counter }\end{array}$ & Daily & Yes & Yes & Yes & Yes $-1000 \mathrm{sec}$ \\
\hline $\begin{array}{l}\text { Shadow shield } \\
\text { counter }\end{array}$ & Each use & Yes & Yes & Yes & Yes -10 min \\
\hline Wound counter & Each use & $\mathrm{NA}(\mathrm{a})$ & Yes & Yes & Yes $-600 \mathrm{sec}$ \\
\hline $\begin{array}{l}\text { Head and liver } \\
\text { counter }\end{array}$ & Each use & Yes & Yes & Yes & $N A(a)$ \\
\hline
\end{tabular}

(a) $\mathrm{NA}=$ not applicable 


\subsubsection{Efficiency Calibration}

(contd)

\author{
Frequency of Primary \\ Efficiency \\ Calibrations
}

calculated, and the listing reviewed for any trends that indicate changes in detector or instrumentation response that need attention. All measurements, whether absolute or relative, are referenced to an NBS-traceable radioactive source measured in a fixed reproducible position.

Primary efficiency calibrations are only done every 5 or 10 years. However, if the secondary reference source counts indicate a change in the counting efficiency, or if the detector size or resolution changes, or a different geonetry is used, then the system must be recalibrated with a NBS-traceable radioactive source in a standard phanton.

\subsection{WHOLE BODY COUNTER RECORDS QUALITY ASSURANCE}

A11 WBC measurements must be documented and stored for one year at the $W B C$. The documentation must be prepared with sufficient detail so that someone skilled in the work can reconstruct the calculation and confirm that energy and efficiency calibrations were performed and maintained on that day.

Fortunately, the natural potassium-40 existing in the body of every person acts as an internal standard of identification of any shifts in energy calibration and also gives a rough indication that the counting efficiency was satisfactory. Only the WBC final results are sent to Radiation Records for permanent record storage.

Records from the balancing of multiple detectors and energy calibration are not kept. The data from the efficiency calibration checks and the background are observed each day to note compliance with established good performance and then stored in the computer each day of its use.

Each quarter these data are listed on hard copy output that is placed in a notebook. These notebooks are located in the library. The data are studied for any trends that might indicate instrumentation or detector problems.

The resolution of detectors is not checked on a daily basis. Any significant change in resolution will result in a loss of counting efficiency and therefore will be discovered during the source count. Periodic checks of resolution and balancing of photomultiplier tubes on detectors with multiple photomultiplier tubes will be done every 6 months for each detector used for in vivo counting. These checks provide valuable information on degradation trends in the detectors. 



\subsection{WHOLE BOOY COUNTER OATA PROCESSING}

The WBC facility utilizes a computer for most data processing functions. The following is a list of the eight general functions of the WBC computer:

- reduction of spectra from different sources into a standard format

- combination of descriptive alphanumeric information with the spectra into an easily retrievabie record on a data base

- rapid calculation of results and storage of the results on the data base record

- comparison of the alphanumeric record with previously stored records to verify the accuracy of the alphanumeric record

- quick retrieval of records for recalculation

- plotting, printing, or sumining of the regions of interest and tabulating results for additional analysis of single or grouped data

- transmission of data to a larger computer for reporting results to the fieid and permanent storage by records facilities or groups

- derivation of count information for cost accounting: numer of counts, count type, and company statistics.

A detailed description of the data processing programs is included in two reports located in the WBC Library:

"Whole Body Counter Computer Programming Notes HP 9000/550 Executive Program," (a) and "Whole Body Counter Computer Systems Programmers Guide."(b)

(a) PNL internal report by D. M. Nieuwsma prepared for the Whole Body Counter facility, December 6, 1985.

(b) PNL internal report by $K$. K. Johnson prepared for the Whole Body Counter facility, May 28, 1986. 


\subsection{OATA SOURCES ANO FORMAT}

Each measurement or "count" done at the WBC represents a spectrum or histogram of the number of events versus the energy as detected by a given detector in a given geometry.

The multichannel analyzers (MCAs) that collect this information are from various manufacturers; therefore, the MCA information output can vary greatly in terms of the headers, the number of bits per word, parity, and other parameters. Spectra can also be entered manually, from magnetic tape, or through links to other computers. Input programs convert data to a uniform format so that all the data, whatever the source, may be handled by the same series of programs.

\subsection{RECORD STORAGE}

All spectra are assigned a unique serial number and if available, combined with descriptive alphanumeric information. The combination of a spectrum, alphanumeric descriptors, and the calculated results becomes a record that is stored in the computer's data base.

This data base can now be accessed by many different programs to plot, print, calculate, or do any number of statistical analyses. The descriptive information can be verified against previous entries in master files to assure the accuracy of social security numbers, payroll numbers, names, and initials. These data are essential for making results available to authorized parties.

Presently, the results from completed records are sent on the occupational radiation exposure (ORE) data base in a batch mode on about a weekly cycle.

\subsection{SUPPORTING PROCESSING FUNCTIONS}

Calibration spectra are analyzed to develop factors used by the calculational programs. Daily background and source count spectra are organized and analyzed for quality assurance purposes. Curvefitting and statistical programs reduce data to equations for easier use in computation or to indicate trends such as gradual loss of sensitivity or increases in background levels. 


\subsection{NEEKLY PROCESSING OF IN VIVO RESULTS}

On a weekly basis, in vivo resuits, spectra, and supporting files are transferred from the "current" processing directory to a "past" directory. Once files have been moved, a rigorous checking routine is performed on the results before a magnetic tape is generated containing the finalized record input to the ORE data base.

Calculations are produced for all non-DOE-contractor measurements, and supporting documentation is provided for all positive examinations or nonroutine requests (unusual exposures, field-evaluator requests, follow-ups). Quickreference spectra logs which contain the name, date, body/ detector code, spectra numbers, and summarized results are also verified for accuracy and appropriate editing of information is performed as required.

Once the thorough checking of supporting data is completed, the recorded results are written to magnetic tape. A detailed listing of all records to be entered to the ORE data base are printed. One copy is sent with the magnetic tape as confirmation for internal dosinetry records accountability with the ORE data base. Another copy is retained at the $W B C$ for future reference.

The number of measurements written to magnetic tape categorized by individual contractor is stored in a permanent file to generate unit costs. Supporting files in the past directory are then deleted after sufficient magnetic backup tapes are produced.

Compiled results, listings, and tapes are given to the senior WBC technician for additional verification. Results are rechecked and then approved by the support staff before the magnetic tape containing the finalized results is delivered to the Radiation Records staff for entry to the ORE data base.

Non-DOE-contractor measurements are typed in a report format and then mailed to the designated company contact. Any data required for future reports are extracted from the weekly listing and the approved calculations are filed.

\subsection{CHECKING RESULTS}

After the results have been written to magnetic tape for submission to the ORE data base, visual record verification is performed. Results and other pertinent information are quickly scanned to assure that the proper calculation methods were used. Values calculated without computer automation are rechecked for accuracy. 


\subsection{CHECK ING RESULTS}

(contd)

Whenever errors are discovered, the weekly tape is corrected before submission to the ORE data base. If any errors are detected after the tape is submitted, a letter of correction is sent to the Internal Dosimetry Group requesting that the record be revised and stating the reason for the required change. This letter should be addressed to Internal Dosimetry Specialist, and should contain the following information:

- Measurement identification (name, serial no., date, type, etc.)

- Correct result and data of correction

- Original result

- Reason for change

- Signature

\subsection{WHOLE BODY COUNTER ANNUAL REPORT PREPARATION}

The WBC manager prepares an annual report summarizing the activities of the routine counting program, research development, special studies, and improvements. The data for this report come from a $\log$ that is updated weekly. The following information is required for this document:

1. In Vivo Measurements During the Year (by individual contractor)

Contractor Whole Body Counts Lung Counts Thyroid Wound Other Total

2. Number of Incident Cases

3. Incident Case Classification

Type of Count $<$ MDA MDA to $10 \mathrm{nCi} \geq 10 \mathrm{nCi}$ Whole Body

Lung

Wound

Total 


\subsection{UNIT COST ACCOUNTING AND SUBMISSION OF CHARGES}

Whole body counting charges for all contractors (DOE and non-DOE) are submitted on a monthly basis to PNL cost accounting.

Unit charges are designated by four categories:

Type $101=$ Head and Lung Counts

Type $102=$ Whole Body Counts

Type 103 = Special/0ther Counts (thyroid, liver, wound, Type $104=$ Overtime. ultrasound, lymph, etc.)

Automatic summing of count types is performed by computer for a designated time period for whole body, lung, head, abdomen, knee, throat, hand, special, and other counts.

Summing of group charges into type 101 and type 103 categories is performed manually. Ultrasound, retrocalculations, and overtime charges are recorded in a $l$ log book and are then manually added to the final sums. One unit of overtime (type 104) is charged for every hour a technician works.

The final totals are submitted by category to PNL cost accounting by noon of the Thursday before the last Sunday of the month. Copies of the totals are aiso sent to the financial representative, section manager, and $W B C$ manager. At the beginning of the fiscal year, the financial representative provides work orders for each contractor. The WBC manager is advised of any work order number changes.

Exhibits 6.1 and 6.2 contain examples of the computerized summation and derived cost submission.

Costs are recorded for each contractor on a separate summary from the monthly submission. The fiscal year end totals are given to the financial representative for addition verification. Examples of recorded totals are shown in Exhibits 6.3 and 6.4 .

\subsection{MONTHLY COUNT SUMMARIES}

Daily count totals are recorded in five categories and summed at the end of the month. A letter report is generated from the WBC manager and is sent to the PNL Personnel oosimetry section manager, the Internal Dosimetry group manager, Radiation Records manager and the DOE contact in Envirominent Safety and Health Division. An example of the monthly count summary is contained in Exhibit 6.5 . 

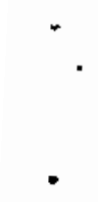


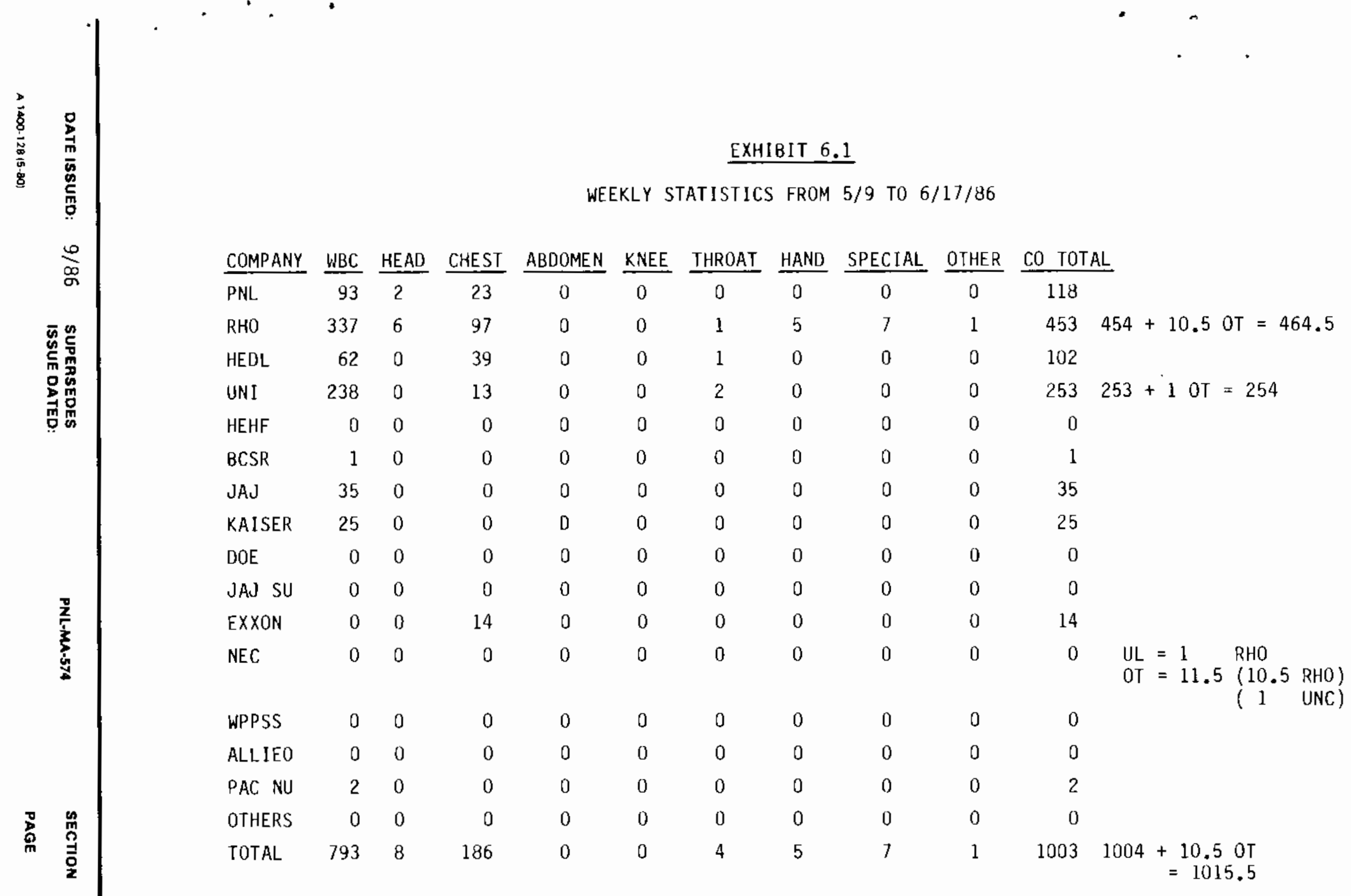

WEEKS SUMMED ABOVE. INCLIJDE

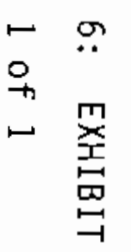
$20=131 \quad 21=297 \quad 22=277 \quad 23=298$ 


\section{EXHIB1T 6.2}

EXAMPLE OF A MONTHLY COST SUBMISSION FOR DOE- AND NON-DOE CONTRACTORS(a)

WHOLE BODY COUNTER SMALL JOB CENTER

$$
5-19-86 \text { TO } 6-17-86
$$

\begin{tabular}{|c|c|c|c|c|c|c|}
\hline \multirow{2}{*}{$\begin{array}{l}\text { SERVICER - } 98039 \\
\text { CONTRACTOR }\end{array}$} & \multicolumn{2}{|c|}{ : TOE 957} & \multicolumn{4}{|c|}{$\begin{array}{l}\text { JOB TICKET \# } \\
\text { NUMBER OF IN VIVO COUNTS }\end{array}$} \\
\hline & $\cos T$ & $\mathrm{CODE}$ & 101 & 102 & $\underline{103}$ & $104^{(b)}$ \\
\hline PNL. & D7H71 & M05706 & 25 & 93 & & \\
\hline $\mathrm{RHO}$ & D7H71 & C06107 & 103 & 337 & 14 & 10.5 \\
\hline HEOL & D7H71 & A21499 & 39 & 62 & 1 & \\
\hline UNC & D7H71 & B26976 & 13 & 238 & 2 & 1 \\
\hline JAJ & D7H71 & A66330 & & 35 & & \\
\hline $\mathrm{DOE}$ & D7H71 & M17701 & & & & \\
\hline $\mathrm{KEH}$ & $\mathrm{D} 7 \mathrm{H} 71$ & C31916 & & 25 & & \\
\hline $\mathrm{BCS}$ & D7H71 & 877513 & & 1 & & \\
\hline HEHF & D7H71 & B59203 & & & & \\
\hline U.S. ECOLOGY & D7H71 & M17707 & & & & \\
\hline EXXON & D7H71 & W01734 & 14 & & & \\
\hline ALLIED NUCLEAR & D7H71 & W05152 & & & & \\
\hline PACIFIC NUCLEAR & D7H71 & W05343 & & 2 & & \\
\hline TELEDYNE WAH CHANG & $\mathrm{D} 7 \mathrm{H} 71$ & M08166 & & & & \\
\hline \multirow[t]{3}{*}{ PRECISION CASTING } & $\mathrm{D} 7 \mathrm{H} 71$ & W05151 & & & & \\
\hline & & TOTALS & $\underline{194}$ & 793 & 17 & 11.5 \\
\hline & & & GR & TOTA & $L=\underline{10}$ & 5.5 \\
\hline
\end{tabular}

(a) This is usually a computer-generated form. The numbers entered under the In Vivo Measurement Categories are usually handwritten.

(b) Overtime 


\section{EXHIBIT 6.3}

FISCAL YEAR ENO TOTALS OF COSTS FOR ALL DOE AND NON-DOE CONTRACTORS (a)

\begin{tabular}{|c|c|c|c|c|c|}
\hline & $\begin{aligned} & 101 \\
& \text { Lung and Head } \\
&\end{aligned}$ & $\begin{array}{r}102 \\
\text { WBC } \\
\end{array}$ & $\begin{array}{c}103 \\
\text { Other } \\
\end{array}$ & $\begin{array}{l}104 \\
0 . T\end{array}$ & $\begin{array}{l}\text { Monthly } \\
\text { Totai } \\
\end{array}$ \\
\hline $8-19 / 9-20-85$ & 189 & 858 & 3 & & 1,050 \\
\hline $7-15 / 8-16$ & 160 & 776 & 5 & 4 & 945 \\
\hline $6-24 / 7-12$ & 95 & 453 & 2 & 16 & 566 \\
\hline $5-17 / 6-21$ & 157 & 806 & 7 & 2.5 & 972.5 \\
\hline $4-22 / 5-17$ & 172 & 693 & 4 & 18 & 887 \\
\hline $3-22 / 4-19$ & 174 & 729 & 6 & & 909 \\
\hline $2-11 / 3-22$ & 208 & 922 & 5 & 9 & 1,144 \\
\hline $2-8 / 1-14$ & 162 & 621 & 5 & 1 & 789 \\
\hline $12-17-84 / 1-11-85$ & 110 & 471 & 4 & & 585 \\
\hline $11-12 / 12-14-84$ & 184 & 762 & 9 & 7.5 & 962.5 \\
\hline $10-15 / 11-12-84$ & 160 & 690 & 26 & 3.75 & 879.75 \\
\hline \multirow[t]{2}{*}{$9-15 / 10-12-84$} & 151 & 636 & $\underline{5}$ & 9.75 & 801.75 \\
\hline & 1922 & 8417 & 81 & 71.5 & $10,491.5$ \\
\hline
\end{tabular}

(a) This is usually a handwritten form. 


\section{EXHIBIT 6.4}

FISCAL YEAR END TOTAL COST FOR ONE CONTRACTOR(a)

\begin{tabular}{|c|c|c|c|c|c|}
\hline & $\begin{array}{l}101 \\
\text { Lung and Head }\end{array}$ & $\begin{array}{r}102 \\
\mathrm{WBC} \\
\end{array}$ & $\begin{array}{c}103 \\
\text { Other }\end{array}$ & $\begin{array}{l}104 \\
0 . T . \\
\end{array}$ & $\begin{array}{l}\text { Monthly } \\
\text { Total } \\
\end{array}$ \\
\hline $8-19 / 9-20-85$ & 28 & 77 & 1 & & 106 \\
\hline $7-15 / 8-16$ & 17 & 87 & & & 104 \\
\hline $6-24 / 7-12$ & 14 & 57 & & & 71 \\
\hline $5-17 / 6-21$ & 26 & 116 & 2 & & 144 \\
\hline $4-22 / 5-17$ & 33 & 87 & & & 120 \\
\hline $3-22 / 4-19$ & 27 & 105 & & & 132 \\
\hline $2-11 / 3-22$ & 38 & 129 & 1 & 0.5 & 168.5 \\
\hline $2-8 / 1-14$ & 38 & 102 & 2 & 1 & 143 \\
\hline $12-17-84 / 1-11-85$ & 27 & 75 & 3 & & 105 \\
\hline $11-12 / 12-14$ & 26 & 116 & 4 & & 146 \\
\hline $10-15 / 11-12$ & 11 & 106 & 5 & & 122 \\
\hline \multirow[t]{2}{*}{$9-15 / 10-12$} & 30 & $\underline{85}$ & $\underline{1}$ & $\underline{1.5}$ & 117.5 \\
\hline & 315 & 1,142 & 19 & 3 & 1,479 \\
\hline
\end{tabular}

(a) This is usually a handwritten form.

PNL-MA-574

SECION

PAGE
6: EXHIBIT

1 of 1 


\section{EXHI8IT 6.5}

MONTHLY COUNT SUMMARY
Date
May 16, 1986
Ju Jech
Mu Sula
To
J. R. Houston
File (2)
From
H. E. Palmer
Subject
In Vivo Count Summary for April 1986
LB

\begin{tabular}{|c|c|c|c|c|c|c|c|}
\hline Date & $\begin{array}{l}\text { Whole } \\
\text { Body }\end{array}$ & $\begin{array}{l}\text { Add. } \\
\text { Pos. } \\
\text { Counts } \\
\end{array}$ & Lung & Wound & $\begin{array}{l}\text { Thyroid, } \\
\text { Liver } \\
\text { \& Other } \\
\text { Organs }\end{array}$ & Head & $\begin{array}{l}\text { Daily } \\
\text { Totals }\end{array}$ \\
\hline $04-01-86$ & 29 & & 8 & & 1 & 1 & 39 \\
\hline $04-02-86$ & 34 & & 8 & & & & 42 \\
\hline $04-03-86$ & 28 & & 11 & & & & 39 \\
\hline $04-04-86$ & 31 & & 4 & & & 3 & 38 \\
\hline $04-07-86$ & 29 & & 12 & & & & 41 \\
\hline $04-08-86$ & 27 & & 12 & & & & 39 \\
\hline $04-09-86$ & 35 & & 13 & & & & 48 \\
\hline $04-10-86$ & 33 & & 11 & & & 2 & 46 \\
\hline $04-11-86$ & 20 & & 2 & & & & 22 \\
\hline $04-14-86$ & 36 & & 11 & & 1 & & 48 \\
\hline $04-15-86$ & 30 & & 10 & 1 & & 2 & 43 \\
\hline $04-16-86$ & 35 & & 12 & 6 & 2 & 2 & 57 \\
\hline $04-17-86$ & 39 & & 13 & 2 & 2 & & 56 \\
\hline $04-18-86$ & 27 & & 6 & 1 & & & 34 \\
\hline $04-21-86$ & 45 & & 6 & 1 & & 1 & 53 \\
\hline $04-22-86$ & 24 & & 11 & & & & 35 \\
\hline $04-23-86$ & 29 & & 8 & & & & 37 \\
\hline $04-24-86$ & 25 & & 12 & & & & 37 \\
\hline $04-25-86$ & 19 & & 4 & & & 1 & 24 \\
\hline $04-28-86$ & 42 & & 9 & & & 1 & 52 \\
\hline $04-29-86$ & 33 & & 11 & & & 1 & 45 \\
\hline $04-30-86$ & 33 & & 10 & & & & 43 \\
\hline \multirow{2}{*}{$\begin{array}{l}\text { Delayed } \\
\text { Entry* }\end{array}$} & & & & & & & \\
\hline & & & & $\underline{23}$ & 21 & 5 & 49 \\
\hline Totals & 683 & & 204 & 34 & 27 & 19 & 967 \\
\hline \multicolumn{8}{|c|}{ *Special measurements } \\
\hline \multicolumn{8}{|l|}{ hep/cb } \\
\hline CC: G. & es & $-D C$ & & & & & \\
\hline
\end{tabular}




\subsection{MINIMUM DETECTABLE AMOUNT, ACCURACY, AND PRECISION OF IN VIVO MEASUREMENTS}

The statistical aspects of in vivo measurements, which are not as precise and as easily determined as those for meas uring radioactive sources, are discussed in this section.

\subsection{MINIMUM DETECTABLE AMOUNT}

The value of the minium detectable amount (MDA) indicates the ability of the WBC equipment to discern between the count rate from an internally deposited radionuclide and the count rate from the person if he were not internaliy contaminated.

Because of the variation in body size and shape in the general population, and the variable distribution of radioactivity within the body or organ, the MDA values are given for a uniform distribution in the body or organ for a "Reference Man" (ICRP 1975). The measurement sensitivity values will be less for thinner, smaller people and more for larger people because of differences in selfabsorption.

Until the publication of this manual, the MDA values at the WBC were calculated as the equivalent to a count rate that is three times the standard deviation of the estimated background. This method did not give the same MDA that is recommended by Brodsky (1986), and the draft ANSI Standard N13.30 (1985) which uses 4.65 times the standard deviation of the background. This ANSI N13.30 method yields MDAs that are $55 \%$ higher than the values determined from 3 standard deviations.

For the measurements made with the germanium planar detectors, low-energy gamma, and x-rays above $25 \mathrm{keV}$, the photopeak can be visually observed on a plot of the spectrum when an amount equal to 3 standard deviations is present. The use of 4.65 standard deviation is very conservative for these measurements.

For measurements of x-rays below $25 \mathrm{keV}$ with the germanium detectors and for high-energy gamma rays with the NaI(TI) detectors, the MDA calculated by 4.650 is probably more appropriate. The MDA values for various radionuclides in the body or organs measured at the $W B C$ facilities are given in Tables $7.1,7.2$, and 7.3 . 
TABLE 7.1. Accuracy and Sensitivity for In Vivo Measurements of Common Radionuclides Using Various Numbers of Germanium Planar Detectors

\begin{tabular}{|c|c|c|c|c|c|c|c|}
\hline \multirow[b]{2}{*}{ RAdlanuelide } & \multicolumn{7}{|c|}{$\operatorname{MOA}(0)=\frac{4.650}{K T}+\frac{3}{K T}$} \\
\hline & Photon Energy & $\begin{array}{l}\text { Tlme, } \\
\text { sec } \\
\end{array}$ & organ & $\begin{array}{l}\text { Number of } \\
\text { Detactors }\end{array}$ & $\begin{array}{l}\text { 95\% Confldence WDA or } \\
\text { stat Istical Error. nci }\end{array}$ & $\begin{array}{c}10 \\
\text { Praclsion (b) } \\
\text { (b) }\end{array}$ & $\begin{array}{l}\text { 10 Estlmate of } \\
\text { Body Shape and } \\
\text { Slze Error, }\end{array}$ \\
\hline${ }^{239} \mathrm{Pu}$ & $59.5-k e \gamma^{242} \mathrm{Ann}_{30}+\mathrm{ag}$ & 2000 & Lung & 6 & 2.4 & 10 & 20 \\
\hline & ulth 15:1, ${ }^{239}$ Pui & 2000 & Llver & 3 & 2.1 & 7 & 20 \\
\hline & 241 Am $\mathrm{Ca}^{+10^{(C)}}$ & 3000 & Bone & 2 & 3.4 & 10 & 20 \\
\hline${ }^{259} \mathrm{Pu}$ & 59.5-keV 241 Am tag & 2000 & Lung & 6 & 0.9 & 10 & 20 \\
\hline & ith 5:1, ${ }^{239}$ P4: & 2000 & LIver & 3 & 0.7 & 7 & 20 \\
\hline & ${ }^{241}$ Am Rotio & 3000 & Bone & 2 & 1.0 & 10 & 20 \\
\hline${ }^{239} \mathrm{Pu}$ & $17.0-$ ond $20.4-k$ or & 2000 & Lung & 6 & 75 & 20 & 40 \\
\hline & $x-r$ ays from pure & 2000 & Liver & 3 & 150 & 20 & 40 \\
\hline & ${ }^{239} \mathrm{Pu}, 3 \mathrm{~cm} \mathrm{CWT}\{\mathrm{d}\}$ & 3000 & Bono & 2 & 75 & 10 & 30 \\
\hline & & 600 & Wound & 1 & 0.09 & 10 & 20 \\
\hline${ }^{238}$ Pu & $17.0-$ and 20,4 -hov & 2000 & Lung & 6 & 30 & 20 & 40 \\
\hline & $\mathrm{X}$-rays trom ${ }^{238} \mathrm{Pu}$ & 2000 & Liver & 3 & 60 & 20 & 40 \\
\hline & $3 \mathrm{~cm} \mathrm{cWrt}$ & 3000 & Bone & 2 & 30 & 10 & 30 \\
\hline $241_{N}$ & $59.5 \mathrm{keV}$ & 2000 & Lung & 5 & $0.1 \mathrm{~g}$ & 10 & 20 \\
\hline & & 2000 & It tver & 3 & 0.15 & 7 & 20 \\
\hline & & 3000 & Bone & 3 & 0.36 & 10 & 15 \\
\hline & & 600 & Wound & 1 & 0.0015 & 10 & 15 \\
\hline $238_{u}$ & $93 \mathrm{keV}$ trom ${ }^{234} \mathrm{Th}$ & 2000 & Lung & 6 & $1.8 \mathrm{nCl}(5.4 \mathrm{mg})$ & 10 & 20 \\
\hline $235 \mathrm{u}$ & $183.7 \mathrm{keV}$ & 2000 & Lung & 6 & $0.12 \mathrm{nCl}(0.056 \mathrm{mg})$ & 10 & 20 \\
\hline${ }^{232} \mathrm{Th}$ & $239 \mathrm{kaH}$ trom $212_{\mathrm{Po}}$ & 2000 & Lung & 6 & 0.57 & $\theta$ & 15 \\
\hline $144 \mathrm{Co}$ & $134 \mathrm{kBV}$ & 2000 & Lung & 6 & 0.60 & B & 15 \\
\hline 154Eu & $123 \mathrm{kgV}$ & 2000 & Lung & 6 & 0.07 & $\theta$ & 15 \\
\hline & & 3000 & Bone & 2 & 0.22 & 7 & 15 \\
\hline${ }^{155} \mathrm{Eu}$ & $86.5 \mathrm{keV}$ & 2000 & Lung & 6 & 0.18 & 10 & 20 \\
\hline & & 3000 & anene & 2 & 0.37 & 1 & 20 \\
\hline $210 p 0$ & $46.5 \mathrm{keV}$ & 2000 & Bone & 3 & 3.0 & $\theta$ & 15 \\
\hline 1251 & 27 hey & 2000 & Thyrold & 2 & 0.004 & 10 & 15 \\
\hline
\end{tabular}

(a) See Equation 3.1 . compored to the preclstion error.

(c) This assumed ratlo doas not mean that this is a commonly found ratlo nor deas it mean that the rat lo of ${ }^{239} \mathrm{Pu}_{\mathrm{P}}$ to 241 An rematns constont as It transfers from lung or wound to IIver and bone.

(d) CWT * chest wall thlckness. 
TABLE 7.2. Accuracy and Sensitivity for Whole Body Counts in the Preview Counter

\begin{tabular}{|c|c|c|c|c|c|c|}
\hline Radronuc II do & $\begin{array}{l}\text { Gonmo Ray } \\
\text { Enargy. }\end{array}$ & 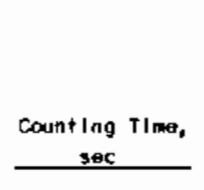 & Organ & $\begin{array}{l}\text { (a) }=\frac{4.65 \mathrm{O}}{\mathrm{KT}}+\frac{3}{\mathrm{KT}} \\
958 \text { Confidance } \mathrm{NoA} \\
\text { Stat } 1 \text { stical Error, } \mathrm{KCl}\end{array}$ & $\begin{array}{c}10 \\
\text { Praclsion }\end{array}$ & $\begin{array}{c}1 \sigma \\
\text { EstImste of Body Shapo } \\
\text { B SIze Error, } x^{\prime d i j)} \\
\end{array}$ \\
\hline${ }^{137} \mathrm{Cs}^{137}{ }^{13 \mathrm{Bo}}$ & $0.662 \mathrm{my}$ & 200 & W & $2.4^{3}$ & $\begin{array}{l}5 \\
5\end{array}$ & $\begin{array}{l} \pm \neq 10 \\
\$ 10\end{array}$ \\
\hline${ }^{51} \mathrm{cr}$ & $0.32 \mathrm{mav}$ & 200 & WB & $\begin{array}{l}22 \\
18\end{array}$ & 5 & $\begin{array}{l} \pm \$ 5 \\
\$ 15\end{array}$ \\
\hline${ }^{60} \mathrm{Co}$ & $\{: 1\}$ and & 200 & i & $2.4^{3}$ & 5 & $\begin{array}{l} \pm 10 \\
\pm 10\end{array}$ \\
\hline 1311 & $0.36 \mathrm{mov}$ & 200 & $i$ & $4.5^{6}(\theta)$ & $\begin{array}{l}5 \\
5\end{array}$ & $\begin{array}{l} \pm \pm 15 \\
\pm 20\end{array}$ \\
\hline${ }^{59} \mathrm{Fe}$ & $\begin{array}{l}1.10 \text { and } \\
1.29 \text { in }\end{array}$ & 200 & $\mathrm{HB}^{\mathrm{B}}$ & $\begin{array}{r}6 \\
4.5\end{array}$ & $\begin{array}{l}5 \\
5\end{array}$ & $\begin{array}{l} \pm 10 \\
\pm 10\end{array}$ \\
\hline${ }^{54} \mathrm{mn}$ & $0.84 \mathrm{Hov}$ & 200 & $i^{\theta}$ & $2.4^{3}$ & 5 & $\begin{array}{l}\$ 10 \\
\pm 10\end{array}$ \\
\hline $106_{\mathrm{Ru}}-{ }^{106_{\mathrm{Rn}}}$ & $0.31 \%$ & 200 & ${ }_{L}^{W B}$ & 12 & 5 & $\begin{array}{l} \pm 10 \\
\pm 10\end{array}$ \\
\hline${ }^{40} \mathrm{~K}$ & $1.46 \mathrm{va}$ & 200 & m & 15 & 5 & \pm 10 \\
\hline${ }^{110}{ }_{\mathrm{Ag}}$ & 0.658 y & 200 & 里 & $2.4^{3}$ & 5 & $\begin{array}{l} \pm 10 \\
\pm 10\end{array}$ \\
\hline${ }^{22} \mathrm{Na}$ & $1.28 \mathrm{y}$ & 200 & 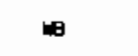 & 1.5 & 5 & \pm 10 \\
\hline${ }^{24} \mathrm{NO}$ & $\begin{array}{l}1.37 \text { and } \\
2.75\end{array}$ & 200 & $x$ & 0.7 & 3 & \pm 10 \\
\hline${ }^{232} 2_{\mathrm{Th}}$ & $\begin{array}{l}45 \ln 908 \\
2.61\end{array}$ & 200 & L & $1.5^{2}$ & 5 & $\begin{array}{l} \pm \pm 0 \\
\pm 10\end{array}$ \\
\hline${ }^{65} \mathrm{zm}$ & $1.12 \%$ & 200 & 1 & $\begin{array}{l}4.5 \\
3.4\end{array}$ & 5 & $\begin{array}{l} \pm 10 \\
\pm 10\end{array}$ \\
\hline${ }^{95} \mathrm{Zr}_{-}{ }^{95} \mathrm{Nb}$ & $\begin{array}{l}0.724 \text { and } \\
0.756\end{array}$ & 200 & L & $2.4^{3}$ & 5 & $\$ 10$ \\
\hline 12550 & $176 \mathrm{KeV}$ & 200 & $i$ & 4.5 & $\begin{array}{l}5 \\
5\end{array}$ & \\
\hline $154 \mathrm{Eu}$ & 1.274 & 200 & L & $3.5^{(1)}$ & $\begin{array}{l}5 \\
5\end{array}$ & $\begin{array}{l} \pm \pm 0 \\
\pm 10\end{array}$ \\
\hline $144 \cos ^{-144} \mathrm{pr}_{\mathrm{r}}$ & 2.18 & 200 & i & ${ }_{75}^{100^{(1)}}$ & 5 & $\begin{array}{l} \pm 10 \\
\pm 10\end{array}$ \\
\hline 140 La & 1.596 & 200 & L & 1.5 & $\begin{array}{l}5 \\
5\end{array}$ & $\begin{array}{l}\$ 10 \\
110\end{array}$ \\
\hline \multicolumn{7}{|c|}{ 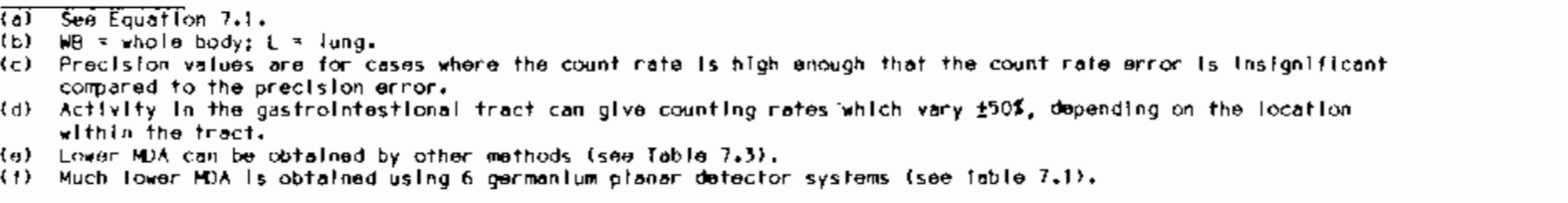 } \\
\hline
\end{tabular}


TABLE 7.3 Accuracy and Sensitivity for Selected In Vivo Measurements

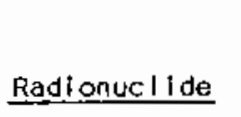

131 ,

Fission

products in

wounds

${ }^{60} \mathrm{CO}$

$241_{\text {Am }}$
$99 \%$ confidence

MA Statistical

Photon Energy, MeV

0.36

${ }^{137} \mathrm{Cs}$ as

an example

- Organ

Detector System

Thyroid$$
3-10
$$

35in. $x^{3-i n . ~ N a l(T J) ~}$

$35 x$ Gell

4" $\times 111 / 2 " \mathrm{Nal}(\mathrm{TI})$

Wound

$35 \%$ GeL 1

Whale body Two $35 \%$ GeL

1.33

0.595 error, nCi

0.030
0.020
0.03

0.016

$\begin{array}{ll}5.0 & \pm 58 \\ 0.01 & \pm 108\end{array}$
\pm 108
$\pm 10 \%$ $\pm 10 x$
Estimate of Body Size and Shape Precision $\pm 20 \%$ $\pm 5 \%$ $\begin{array}{ll}\text { Axillary } & 20-\mathrm{cm}^{2} \text { germanium } \\ \text { Iymph } & \text { planar }\end{array}$ Iymph 


\subsection{MINIMUM DETECTABLE AMOUNT}

(contd)

These MDAs are calculated using the ANSI N13.30recommended formula shown below.

$$
\begin{aligned}
& M D A=\frac{4.65 \sigma}{K T}+\frac{3}{K^{\prime} T} \\
& \text { where } \sigma=\text { the standard deviation in the count of an } \\
& \text { uncontaminated person } \\
& K=\text { the calibration factor in appropriate units as } \\
& \text { counts per unit of time per } \mathrm{nCi} \text { in the body or } \\
& \text { organ. } \\
& T=\text { the counting time interest used in consistent } \\
& \text { time units. }
\end{aligned}
$$

\subsection{ACCURACY AND PRECISION}

The in vivo determination of radioactivity in the body or in an organ is not a highly accurate measurement because of the variable body size, shape, and distribution of radioactivity. Despite these shortcomings, the determinations are as accurate or more accurate than the radiation dose calculations which use the in vivo measurement results. For measurements of radionuclides that are rather uniformly distributed in the body such as potassium-40, cesium-137, and sodium-24, the precision and accuracy is relatively good but varies according to the amount in the body and the counting time. The accuracy and precision values have been estimated from human data such as those described in a study of $92 \mathrm{~m}_{\mathrm{Nb}}$ in the lungs of 9 males and 11 females (Newton et al. 1985; Gunston and Jefferies 1986) and are given in Tables $7.1,7.2$, and 7.3 .

Radioactivity that is not uniformly distributed in the body or which changes distribution with time is measured with less precision and accuracy. However, the measurement equipment has been designed to minimize the effects of nonuniform and changing distribution. The estimated values of precision and accuracy are given in Tables 7.1 , 7.2 , and 7.3 . 


\subsection{REFERENCES}

American National Standards Institute (ANSI). 1985. "Performance Criteria for Radiobioassy." Draft ANSI Standard N13.30.

Brodsky, A. 1986. Accuracy and Detection Limits for Bioassay Measurements in Radiation Protection - Statistical Considerations. NUREG-1156 (Draft), U.S. Nuclear Regulatory Comrnission, Washington, D.C.

Gunston, K. J., and S. J. Jeffries. 1986. Calibration of X-Ray Counters for Assessment of Internal Lung Contamination, with Low Energy X-Ray Emitters, in Women, Part I Measurements Made at AWRE. Final Report to IAEA, Technical Contract 3362/TC. Vienna, Austria.

International Commission on Radiological Protection (ICRP). 1975. "Report of Task Group on Reference Man." ICRP Publication 23, Pergamon Press, New York.

Newton, D., A. C. Wells, S. Mizushita, R. E. Toohey, J. Y. Sha, R. Jones, S. J. Jeffries, H. E. Palmer, G. A. Rieksts, A. L. Anderson and G. W. Campbell. "The Livermore Phantom as a Calibration Standard in Assessment of Plutonium in Lungs." In Proceedings of IAEA Symposium on the Assessment of Radioactive Contamination in Man, PP. 189-199. IAEA-SM-276/01, International Atomic Energy Agency, Austria, Vienna. 
APPENDIX A

BROCHURE: "THE HANFORD WHOLE BODY COUNTING CENTER"

(on back cover)

DATE ISSUED:

SUPEASEDES

ISSUE DATED:
PNL-MA-574

SECTION

PAGE 
APPENDIX B

QUALITY ASSURANCE PLAN

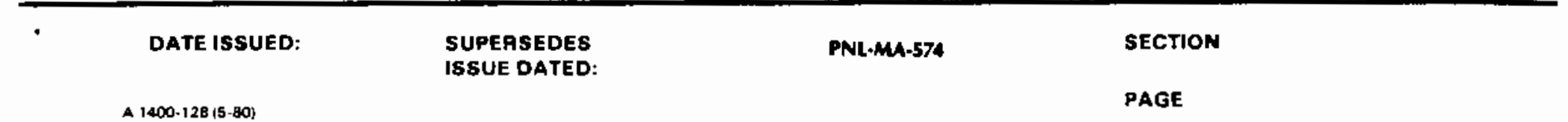


Battelle

Pacitic Nortment Labotalortes

DA PLAN$$
\text { . }
$$

Project/Service Activity:
QAP No. Rev. 0

Issue Date September 11, 1986

Page 1 of $\frac{9}{-2}$

Sponsor: DOE, Hanford Contractors and other companies, agencies as requested

Author ized By (DOC. No.):

N/A (Service Activity)

OA Requiremem Soecification:

(Specity) 1. DOE-RL Order 5700.1A, Quality Assurance, as interpreted by PNL-MA-65

2. This $Q A$ Plan replaces $0 \& E P-16$, Rev. 3

The Sections or selected paragraphs of PNL-MA-65 (as identified by section of paragraph number) designated in this QA Plan are applicable to this Project/ Service Activity. Additional information is also provided when useful to provide clarification of the selected requirement.

Approvals:

\begin{tabular}{|c|c|}
\hline DATE APPAOVED & $\begin{array}{l}\text { SIGNATUAE (QUALITY ENGINEER) } \\
\text { J. C. Langford }\end{array}$ \\
\hline $\begin{array}{r}\text { DATE APPROVED } \\
9 / 11 / 026\end{array}$ & $\begin{array}{l}\text { SIGNATURE (Q.E. MANAGER) } \\
\text { D. E. Ryder } \\
\end{array}$ \\
\hline PATE APPROVED $9-10 \cdot 86$ & $\begin{array}{l}\text { SIGNATURE PAOJECT/ACEHAY MANAGEFI } \\
\text { H. E. Palmer }\end{array}$ \\
\hline $\begin{array}{c}\text { DATE APPROVED } \\
9-/ C \geqslant b\end{array}$ & $\begin{array}{l}\text { SIGNATUAE ILINE MANAGEAl }|a| \\
\text { J. R. Hous ton }\end{array}$ \\
\hline
\end{tabular}

Distribution: (Project QA Files, QAO, and others as appropriate)

J. R. Houston

J. C. Langford

H. E. Palmer

D. E. Ryder

M. J. Sula

QAD C/O G. R. Schmidt

Records $\mathrm{c} / \mathrm{O}$ H. W. Hunt

(a) Depertment or Section Monager as designated by Department Policy or tho Project Plan Document. 
QA PLAN INDEX

1.1 Organization

1.1.1 QAO Organization

11.2 OAO Responsibilities

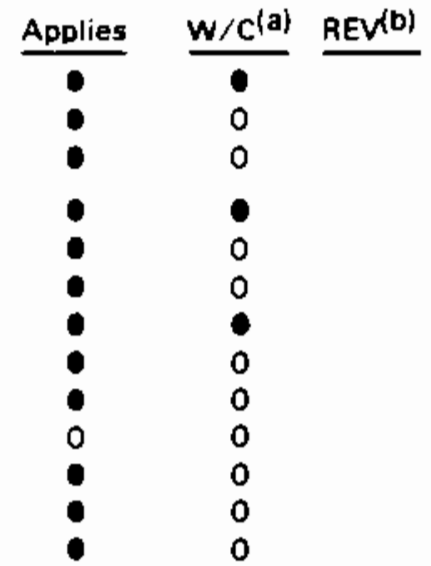

2.3 Job Quality Plan-applies to work performed by Facılities

Engineering Section and Major Projects and Planning Organizacions

2.3.1 Requirements

2.3.2 Preparation and Approval

2.3.3 Revisions

23.4 Records

3.1 Design Control and Method Review

3.1.1 Design Planning

3.1.2 Project Approach and Method

3.1.3 Design and Engineering Control

3.1.3.1 Desıgn Document Control

3.1.3.1(3) Non-Official Engineering Drawings

3.1.3.2 Design Criteria

3.1.3.3 Design Configuratian Control

3.1.3.4 Engineerıng Hold Points

3.1.3.5 Modifications

3.1.4 Caleulation (Data) verification

31.5 Interface Controls

3.1.6 Design Review and Verification

3.1.6.1 Design Data on OED

3.1.6.2 Engineering Work in Support of

$$
\text { Design }
$$

3.1.6.3 Formal Design Review

3.1.6.4 Development Testing

317 Revisions

4.1 Procurement-Applies if a purchase requisition is processed (procurement or subcontract)

4.1.1 Procurement/Subcontract Document

Preparation and Approval

412 Source Inspection Activities

41.3 Supplier/Subcontractor Selection

41.4 Procurement Document Close-Out

$\begin{array}{ll}0 & \\ 0 & 0 \\ 0 & 0 \\ 0 & 0 \\ 0 & 0 \\ 0 & 0 \\ 0 & 0 \\ 0 & 0 \\ 0 & 0 \\ 0 & \\ 0 & 0 \\ 0 & 0 \\ 0 & \end{array}$

5.t Instructions. Procedures, and Drawings

51.1 Ident. \& Content

5.1.2 Transmil of QA ReQ

5.1.3 Compliance

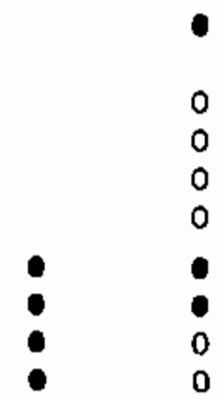

(a) W/C-With clarification presented in this QA Plan

(b)REV -Indicates revision number in which changes were made 
Actiyity: Whole Body Counting

\section{QA PLAN INDEX (cont'd)}

6.1 Document Contral

6.11 Cuntrol of Select Documents

6.1.2 Ruvisions

Applies
0
0
0

9.1 Performance of Inspections and Tests

9.1.1 Recelving Inspection

9.1.2 Other Inspectrons (Nonreceiving)

9.1.3 Content of ITI

9.1.4 Records, Tagging and Noncomformances

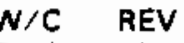

10.1 Control of Measuring and Test Equipment

10.1.1 Basic Responsiblities

10.1.2 Performance Checks

10.1.3 Calibration of M\&TE

t0.1.4 Calibration Discrepancy

10.1.5 New Equipment

10.1.6 Records

11.1 Handling, Storage and Shipping

11.1.1 General Guidance

11.1.2 Special Instfuctions

12.1 Status of Inspection. Test 8 Operating Condition

12.1.1 Stetus Indication Authorities

12.1.2 Status Indication Requirements

13.1 Nonconformance \& Corrective Action

13.1.1 Occurrences

13.1.2 Control of Nonconforming Item

13.1.3 Corrective Action

14.1 QA Fecords

14.1.1 General Guidance

14.1.2 OA Record Requirement

14.1.3 Laboratory Record Books

15.1 Audits - Applies when s project or activity is selected as part of the base for a OA audit.

Additions

See Parts 3 and 5 of this QA Plan. 
QA Plan HPD-26, Rev. 0

Activity: Whole Body Counting

\section{ORGANIZATION}

1.1 The Personnel Dosimetry Section of the Health Physics Department is responsible for DOE-RL's Pacific Northwest Laboratory Whole Body Counting Activity. This program provides technical and administrative support to DOE-RL's Hanford site-wide radiation protection services.

Other supporting agencies are listed below:

- BCS Richland, Inc. receives the whole body counting data and organizes it into reports.

- The Radiation Records Service Activity is responsible for the permanent storage of Whole Body Counting Data.

\section{QA PROGRAM}

This QA Plan applies to the training of whole body counting personnel and the administration of whole body counting services provided for any sponsor.

2.1 The Battelle QA Program shall be applied as described in this QA Plan.

2.1.3.3 Annual training of staff members shall be documented. This training shall include an annual review of the W.B.C. training manual by each staff member.

\section{DESIGN CONTROL AND METHOD REVIEW}

3.1.2 The activity approach and method is documented in the Work Package. Review and approval by the Activity Manager and the appropriate Section Manager shall be noted by signature and date on the cover page or other means traceable in the Work Package.

3.1.3.1(3) This paragraph applies when a sketch or worksheet is used to transmit information to another organization.

3.1.7 This section applies when a revision is made to a sketch or worksheet.

In addition:

- Calculations and analysis performed in support of activity results reported to the sponsor shall be documented and traceable from the primary data and its source, through the assumptions and/or interpretations made, to the corresponding calculation and/or reported analysis. 
- The accuracy and precision of the measurements shall be determined. This data shall be recorded in a report and delivered on request to the sponsor as part of a performance report.

- Documentation of computer codes used shall include:

- Identification of the mathematical technique of coded model

- Assumptions and constraints that apply to the model

- Definition of input and important variables

- Data input requirements

- Input and output variables

- Users instructions

- Listing

- Verification of code model and operation

- Review and approval of code and documentation

Previously verified codes shall be reviewed by the Activity Manager for adequacy with the activity, as well as adequate documentation (i.e., user's guide/instruction, tests and results). This review shall be documented, and retained as a QA record. A list of all computational computer codes shall be maintained.

- Changes to existing verified activity codes shall be documented as they are made and used in the activity. Documentation shall be maintained by the user of the code and shall include:

- code title and version

- changes made (compare original to modification)

- date

- persons reviewing and approving the change

Verification shall be performed on changed codes prior to use when the results are expected to be reported to the sponsor.

If a computer is used for analysis or calculations, each computer output containing results to be reported to the sponsor shall be traceable to the:

- computation performed (titie or number)

- data set used (input)

- time and date of run

- code model and version used

- Data Control

Data on computer systems shall be protected and controlled by implementation of the following requirements: 
QA Plan HPD-26, Rev. 0

Page 6 of 9

Activity: Whole Body Counting

- Each computer run reported or used for reporting information in project reports shall have a copy of the output stored as a QA record.

- Data on computer tapes, disks, and other memory devices shall be identified.

- Computer system configuration and software source(s) shall be documented and retained as an activity record.

- The data transferred between computer systems shall be controlled, verified, documented, and retained as an activity record.

- Master copies of computer data on tapes, disks, and other memory devices shall be stored in a secure manner which will protect them from tampering, loss and/or damage.

The above whole body counting data results/records are transferred on a weekly basis to the Radjation Records Group for permanent storage, protection, and control. These records will be available in the whole Body Counting Group on a temporary basis.

4. PROCUREMENT

4.1 This section applies when a purchase requisition is processed. The applicable parts of Sections 9.1 and 12.1 shall apply if receiving inspection is to be applied to a specific procurement.

5. INSTRUCTIONS, PROCEDURES, AND DRAWINGS

5.1 This section applies and additional information is provided in the following statements.

5.1.1 Activities that require written procedures and/or instructions shall be determined by the Activity Manager. This includes the following procedures:

- Whole Body Counter Manual

- Hewlett-packard 9000 Manual

- EXEC User Manual

- Radiation Safety Practices and Procedures Training Guide

In addition:

A description of the research procedures and methods actually used or deveioped shall be recorded in the Laboratory Record Books. (Note: It is only necessary to make reference to established procedures.) Design decisions and related information shall aiso be recorded in the Laboratory Record Books. 
6. DOCUMENT CONTROL

6.1 Documents shall be controlled in accordance with this section and a control list of the distribution of the manuals shall be maintained. This includes, but is not limited to, the procedures identified in 5.1 .1 above.

6.1.1.2 Controlled documents shall be reviewed by authorized personnel and approved for use by the task leader and the cognizant line manager. Approvals shall be indicated by signatures and date on the document.

7. IDENTIFICATION AND CONTROL OF ITEMS

7.1 This section applies and additional information is provided in the following statements.

7.1.1 This paragraph applies especially to the identification and control of computational computer items (disks, tapes, printouts) used for this activity. The controls applied will be documented in procedures as noted in Part 3, In Addition.

7.1.2 Emergency accident evaluations shall be traceable to the computed results (spectral results are not retained as permanent records).

9. INSPECTION AND TEST

9.1 This section applies to the procurement of appropriate measuring and test equipment (M\&TE).

10. CONTROL OF MEASURING AND TEST EQUIPMENT

10.1.2 Performance of operational checks and adjustments shall be recorded on the computer records. Note the procedure used, if appropriate. Quarterly reviews of daily measurements are printed and transferred to a Laboratory Record Book.

10.1.3.2 Critical measurements for this activity include radiation measurements and spectral measurements.

10.1.3.3 The measuring and test equipment (M\&TE) which have impact upon the accuracy of the data and in this activity are listed below along with their calibration level. 
QA Plan HPD-26, Rev. 0

Activity: Whole Body Counting

Page 8 of 9

Measuring and Test Equipment

Calibration Leve!

Multichannel Analyzers

2

NaI (TI) detectors

Phoswick detectors

Ge (Li) detectors

Intrinsic gemanium detectors

Analytical balances

11. HANDLING, STORAGE, AND SHIPPING

11.1.2.1 The handling and storage of sealed radioactive samples require special controls and identification which are described in the Radiation Safety Practices and Procedure Training Guide.

14. QA RECOROS

14.1 The Activity Manager shall assure that a file is maintained wich contains or references the location of QA Records. These records shall include but are not limited to those identified in Management Guide 4.3 and the following documents:

QA Plan HPO-26

Procurement Documents

Calibration Records

Work Packages

Sketches and Worksheets

Inspection Test Instructions (ITIs)

Radiation Safety Practices and Procedure Training Guide

Personnel Training Documentation

Sample Log Book

Records Plan/Index listing records type, custodian and location

Record retention periods and final disposition shall be in accordance with requirements of the sponsor. The retention and storage of records for this activity are the responsibility of Radiation Records task group.

14.1.3 Laboratory Record Books used to record research activity data and results shall be dedicated solely to this activity. Entries in Laboratory Record Books shall be in ink accompanied with the individuals signature and date. Changes shall be made only by a single line drawn through the original entry accompanied with the initials and date by the individual making the change. The reason for the change shall be noted unless obvious. Attachments included in the Laboratory Record Book shall be permanently affixed and Identified with the page and book number. Laboratory Record Books shall be used to record the following information: 
QA Plan HPD-26, Rev. 0

Activity: Whole Body Counting

- Test results and raw data

- Level 2 calibration records

- Calculations

- Description of research procedures and methods used or developed

- Unusual conditions

- Equiment operation checks and maintenance

Note: These Laboratory Record Books shall reference the location of all other data not contained in Laboratory Record Books. 


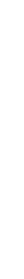


No. of

Copies

OFFSITE

30 DOE Technical Information Center ONSITE

4 DOE Richland Operations Office

J. J. Sutey/P. K. Clark

R. E. Gerton

K. H. Rising

G. R. Yesberger
No. of

Copies

61 Pacific Northwest Laboratory

C. P. Brim

G. R. Hoenes

J. R. Houston

H. E. Paluner (50)

Publishing Coordination (2)

Technical Report Files (5)

Health Physics Department Library, RTL 


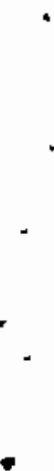

?

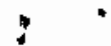




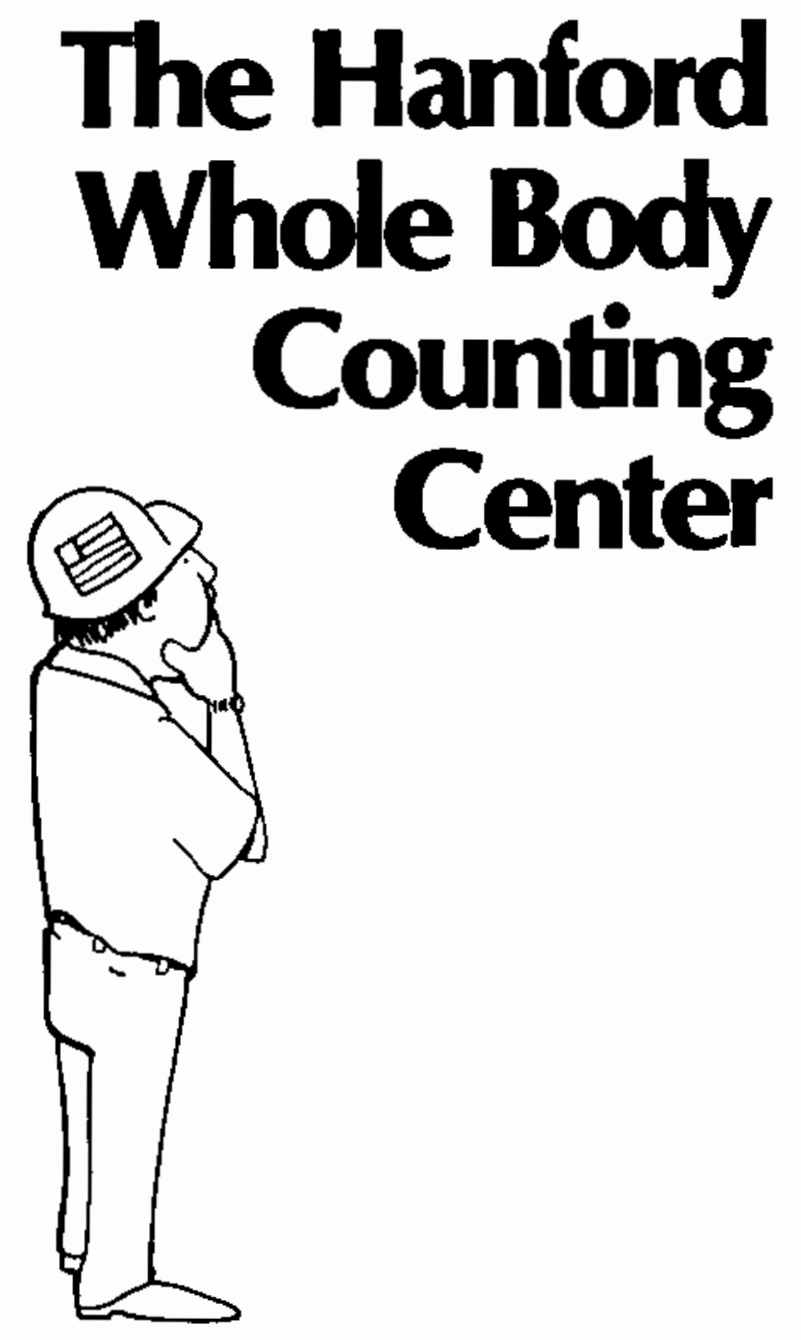




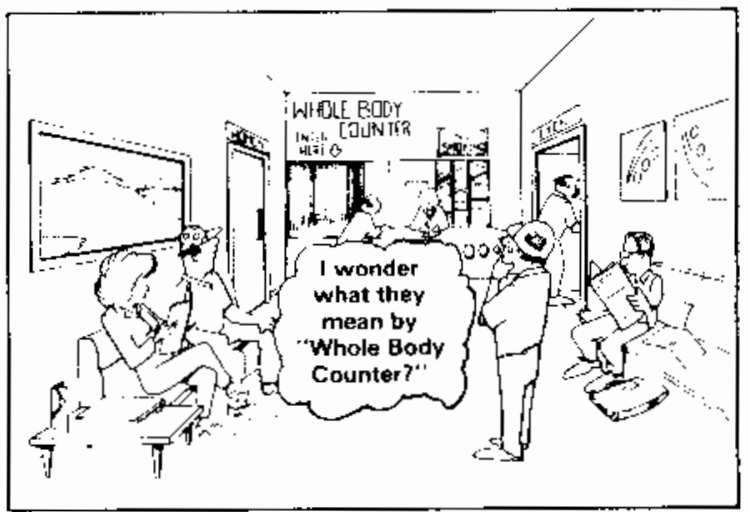

Welcome to the Hanford Whole Body Counting Center. Hanford workers who are assigned to areas where radioactive materials are processed or stored may be scheduled for exams at the Whole Body Counting Center. Your examination provides another measure of assurance that the work place is safe and that the controls established to prevent and limit internal radiation exposure are adequate.

What Does the Whole Body Counter Do?

Your examination at the Whole Body Counting Center can detect the presence of very small quantities of gamma-emitting, radioactive materials that may be deposited in your body. For example, detectors at the Whole Body Counting Center can detect smaller quantities of gamma-emitting radioactive materials than the portable survey instruments and portal monitors at your workplace. 
When are Exams Scheduled?

If you are a new employee and have formerly worked with or expect to work with radioactive substances, you will probably have an examination at the Whole Body Counting Center before you enter a radiation zone. You may also have an exam whenever a change in your job task or working condition involves a different type or form of radioactive substance. Most people who work in radiation zones at Hanford are examined on an annual basis; these exams establish a normal or "background" value against which future results can be compared. You also would be examined in the unlikely event you accidentally became exposed at work.

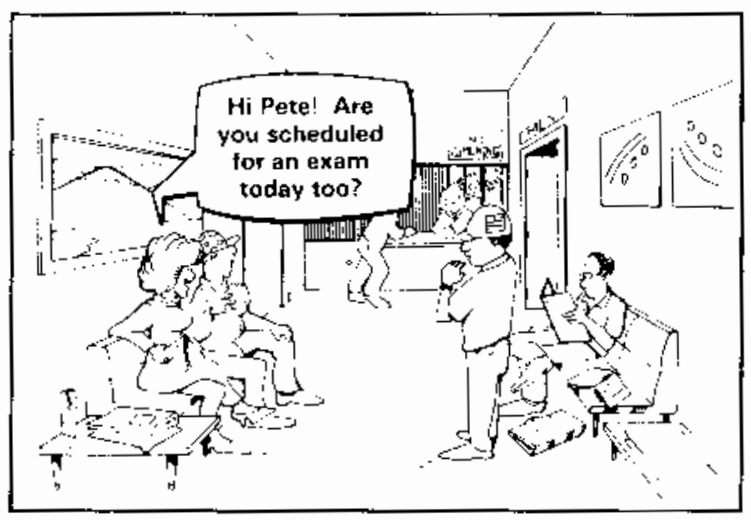

Results of most whole body exams are normal, meaning no radioactive substances from the site were detected in the body. However, if an intake is confirmed, additional exams are scheduled to observe the clearance of the material from your body. 


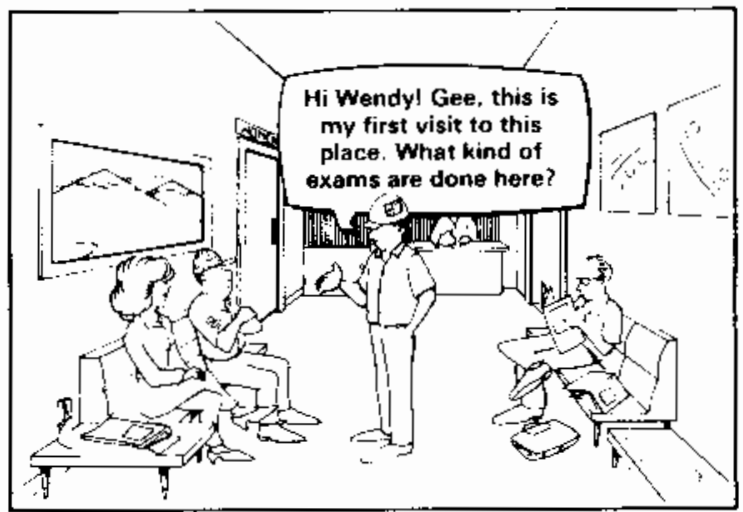

What Kinds of Exams are Performed?
Two types of examinations, the whole body count and the lung count, are performed routinely at the Hanford Whole Body Counting Center. The whole body count measures the entire body from head to foot to determine whether any detectable quantity of radioactivity is present. The lung count focuses on the respiratory system. It is designed to detect gamma radiation from americium, plutonium, and uranium, the radionuclides associated with processing nuclear fuels at Hanford.

Your radiation protection group establishes a monitoring schedule for you based on the radiation protection requirements of your specific job. Everyone scheduled for an exam has a whole body count, which takes only three minutes. If you work in the fuels fabrication or separation areas, then you will probably receive a lung count as well as a whole body count. 

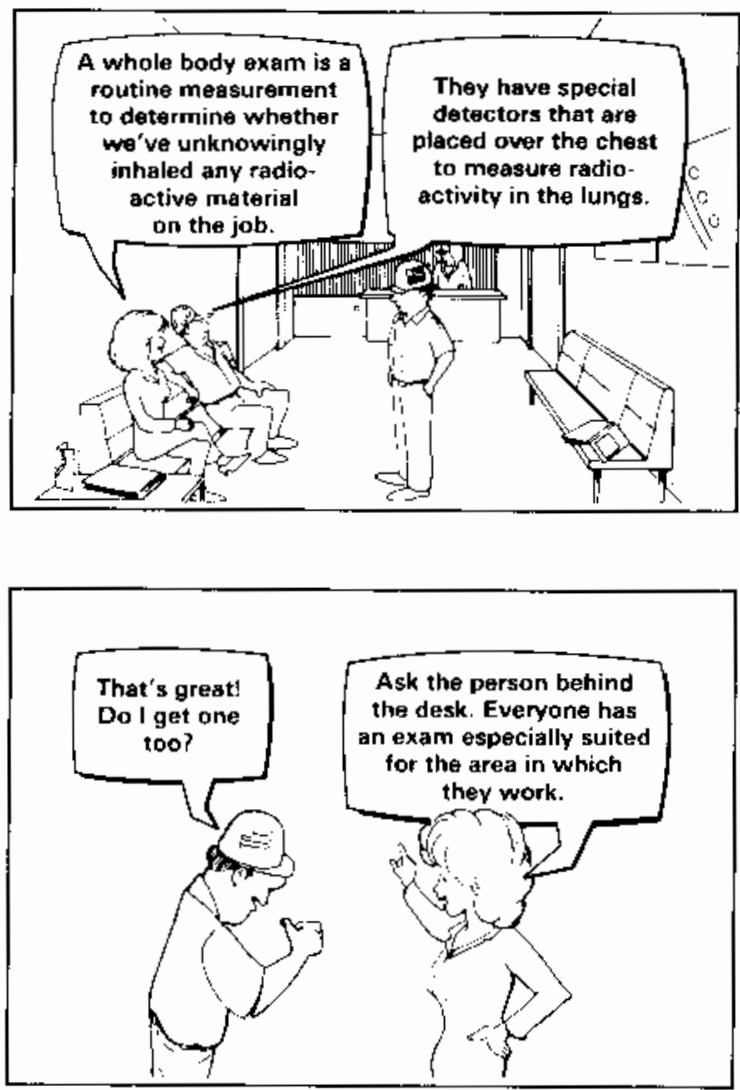

Many other types of examinations can be performed at the Whole Body Counting Center, but they are reserved for special circumstances.

Because exam results are an important part of your permanent radiation records, the technician first requests that you put your name, payroll number and other identifying information on a form. About five minutes after you return the form, the technician calls you for your exam. 


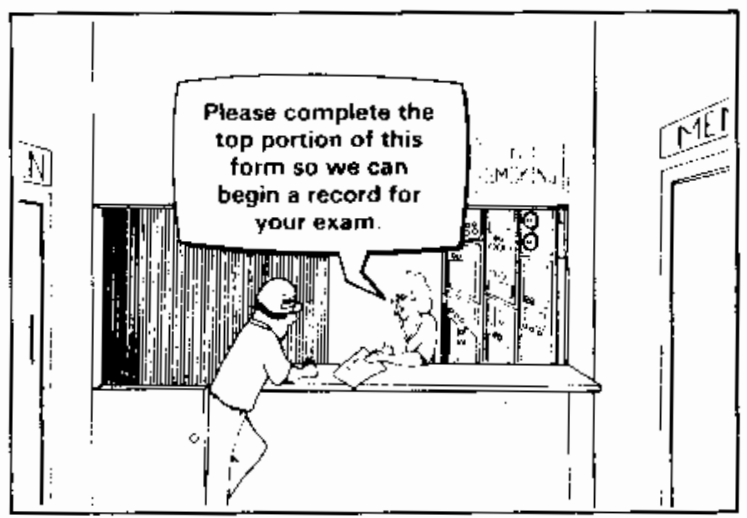

If you are having a lung count, the technician will ask you to shower and change into coveralls provided in the change rooms. These coveralls are required for the lung count because your personal clothing may have attracted small quantities of naturally occurring radioactivity from the air outdoors. Showers are also necessary prior to all lung counts because surface dust and naturally occurring radioactive particles from radon or thoron are attracted to the hair and skin and

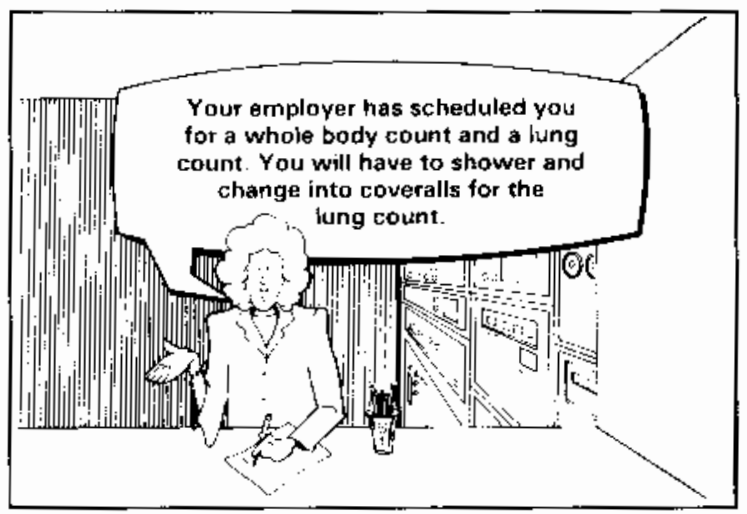


may interfere with the measurement. These interferences may cause a result to be invalid. Since the objective of the exam is to measure radioactive substances deposited within the body, these interferences must be washed off prior to the exam.
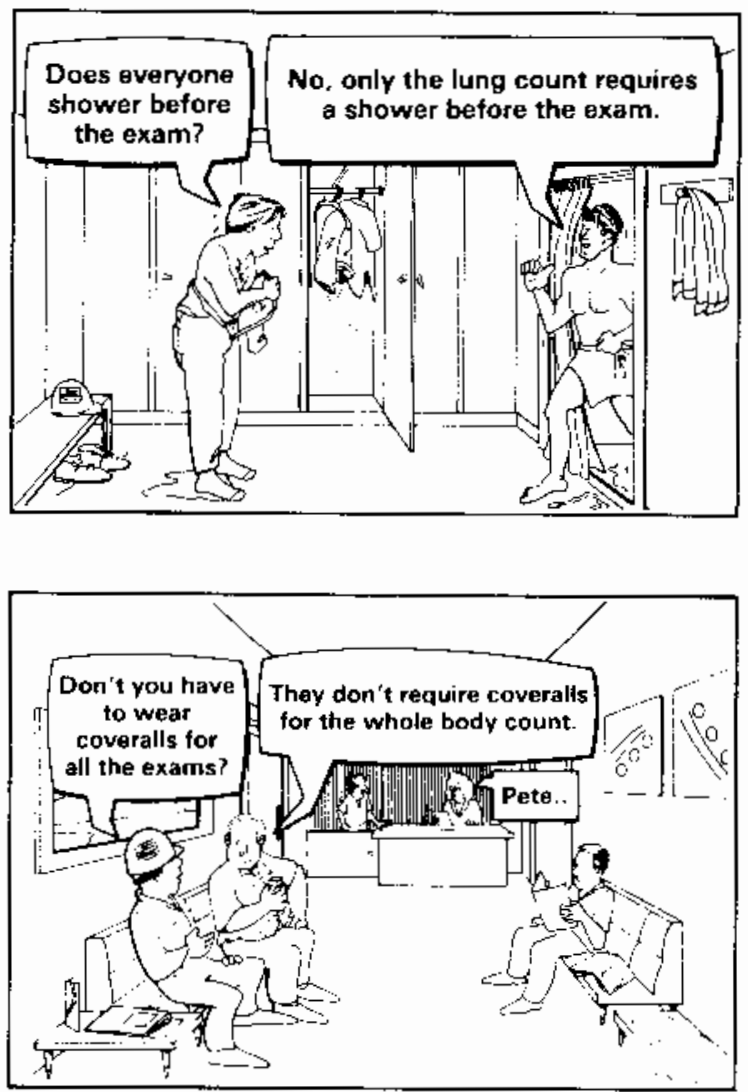


\section{The Whole Body Count}

For a whole body count, five large stationary detectors have been installed in a leadshielded booth. Lead shielding is necessary to reduce interference from natural sources of radiation in the environment.

When you step into the whole body counter booth, you are asked to stand upright against the detectors. The technician adjusts the detectors so that your chest is next to the one with the largest diameter. You need to lean against the detectors for about three minutes while electronic instruments and computers process the information they receive from the detectors.

No radiation is given off by these detectors. Instead, the detectors measure gamma rays emitted by radioactive substances deposited in the body. A computer analyzes the detector measurement to ensure that the results of your exam are accurate and reliable.

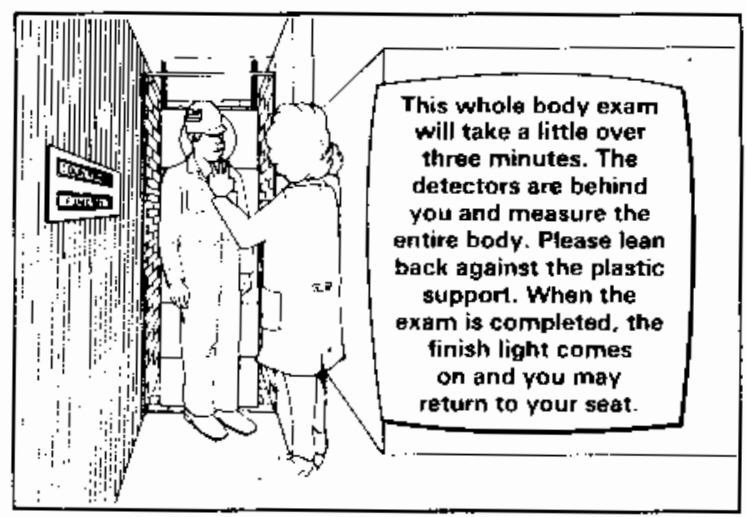


The final result of your whole body count may not be available immediately because processing takes time. In most cases, the lack of an immediate finding indicates that the result is normal. Your supervisor is informed of the findings and will pass the results to you. These results are maintained in your official permanent records.

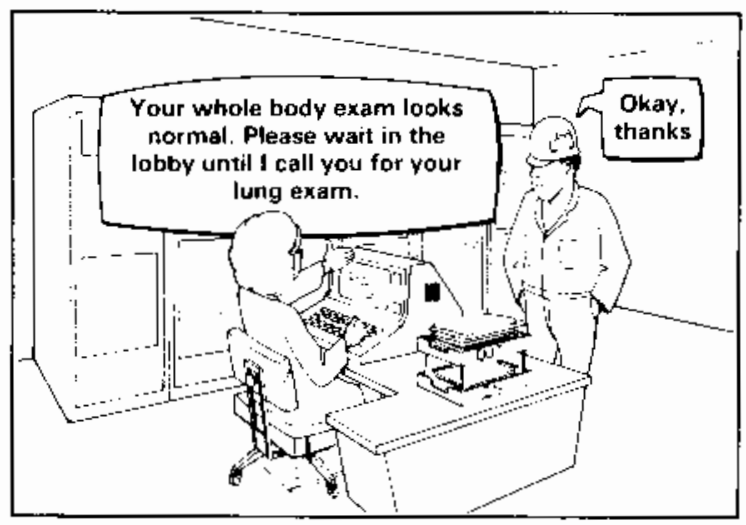

The lung count determines whether any detectable plutonium, americium, or uranium is deposited in your respiratory system. Before the lung count starts, you will lie on a bed and a technician will arrange a set of six individual detectors on your chest. (The position of the detectors is important for the measurement to be accurate.) The exam takes about fifteen minutes. 


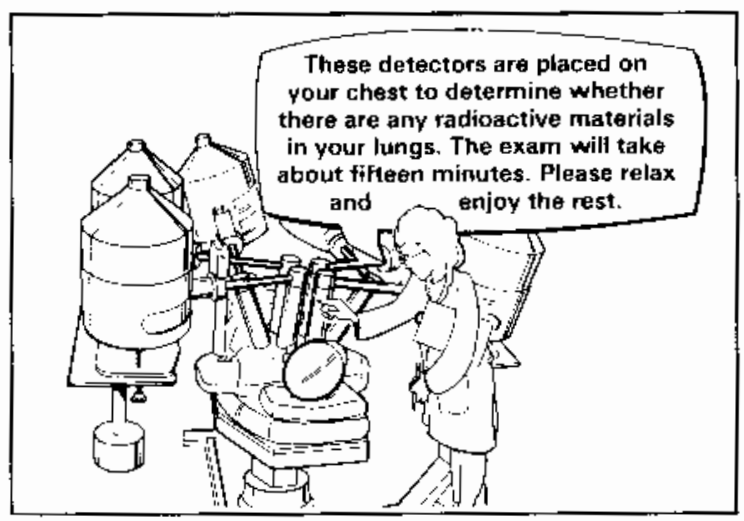

Because the detectors are very sensitive, the lung count must be performed in a room shielded with thick steel walls. This shielding reduces interference from natural sources of radiation in the environment.

Lung counts take more time for evaluation than whole body counts. In most cases you will know whether your exam was normal before you leave the laboratory, but detailed findings may not be available during your visit. Your supervisor will inform you of the findings and the results will also be in your official permanent records.

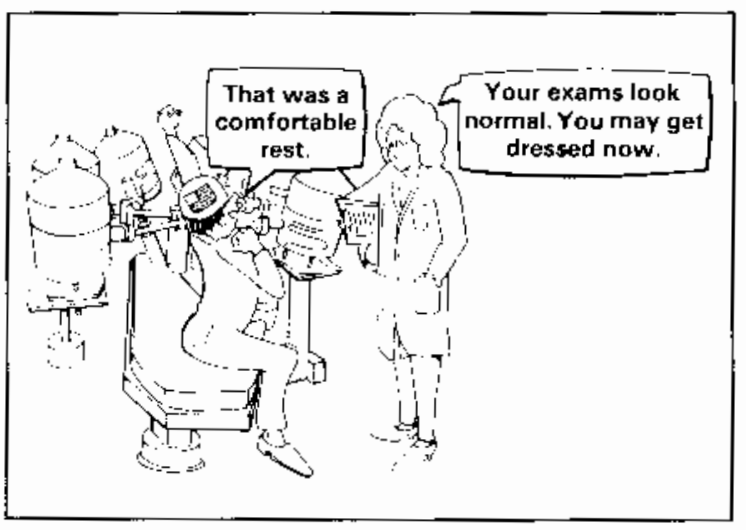




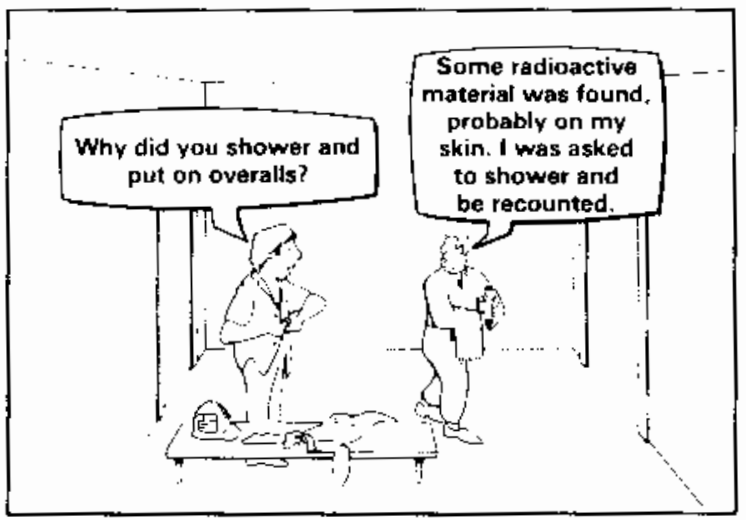

Sometimes

Exams are Repeated

Occasionally, an exam has to be repeated. For example, a small amount of radioactive material on the skin or clothing can cause a higher than normal reading. This material may be due to naturally occurring radioactive dust particles from radon or thoron that attach to the hair or skin. If you are asked to have a repeat whole body count, the technician will request that you shower, scrub your chest and wash your hair. If the result of the repeat whole body count is normal, the source of activity found in the initial exam is attributed to external contamination.

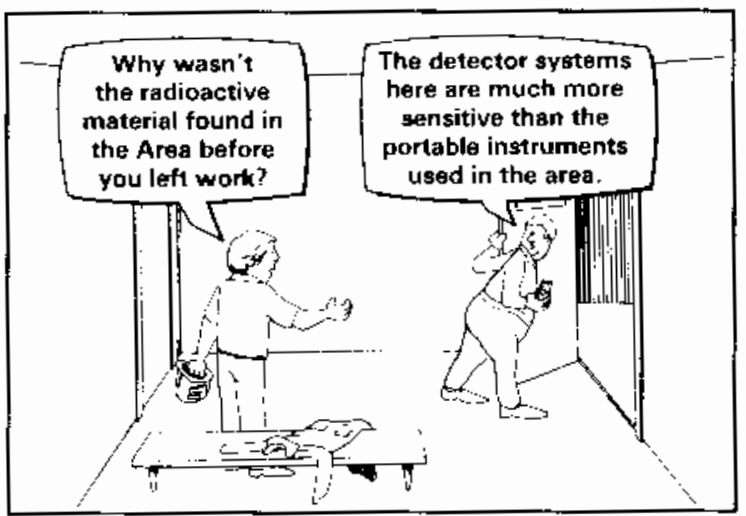


Although it is unlikely, sometimes an internal deposition of radioactive material is confirmed. Additional examinations may be performed to identify the location of the deposit and the type and quantity of material present.

Follow-up exams may also be scheduled to determine the rate of elimination from the body. Results of these exams and the radiation dose estimates become part of your personal Hanford radiation records and also are made available to your supervisor.

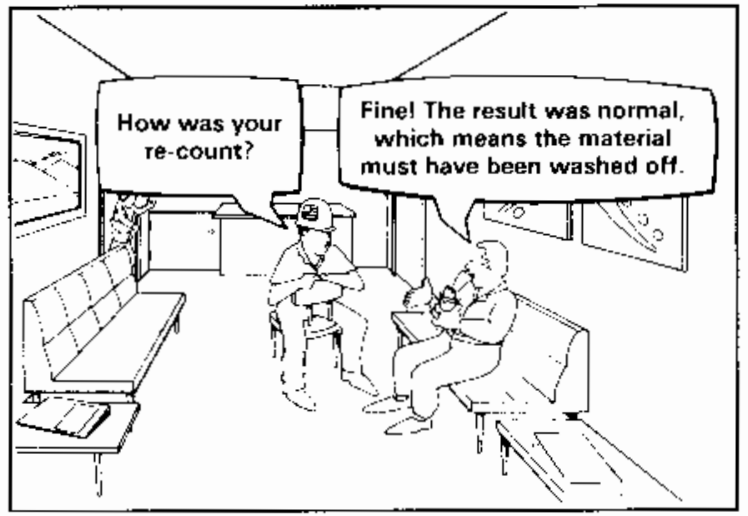

Natural Everyone has some internal body radioactivRadioactivity in the Body ity. Most of it comes from potassium 40 , the naturally occurring radioactive isotope of potassium. All plants and animals need potassium to live. An average person contains about 140 grams of potassium of which less than $0.07 \%$ is potassium- 40 . 
Sources Other radioactive materials measured in of Other Radioactive Materials in humans, such as cesium-137 and strontium90 , are not naturally occurring, but are due to fallout from atmospheric weapons testing.

Occasionally, small quantities of reactor fission products and radioactive cobalt, manganese and iron are found in workers who have been accidentally exposed while working on reactor piping. The cobalt, manganese and iron make up the stainiess steel that very slowly becomes corroded as the reactor operates. Also, if your personal physician has recently prescribed a diagnostic or therapeutic radiopharmaceutical, it may be detected during your whole body or lung count.

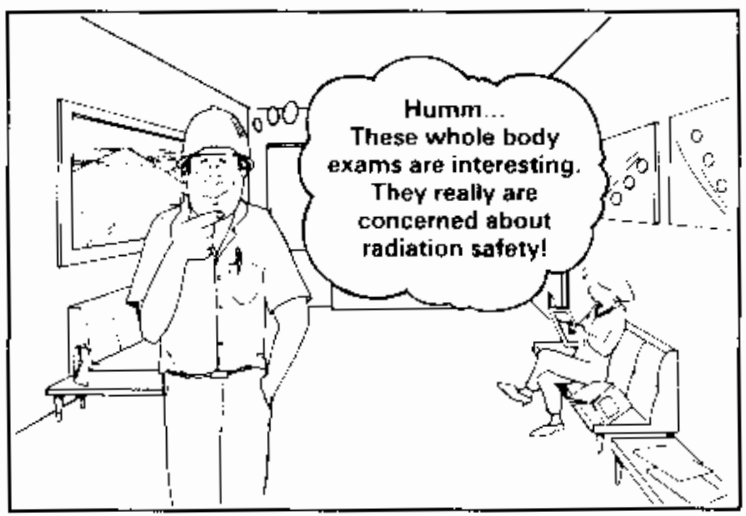

Questions?

If you have any questions regarding the systerns used to perform exams or the methods employed to calculate results, please ask one of the technicians to direct you to a member of our professional staff. Our phone number is 376-6102. We will be glad to answer your questions. 


\section{Acknowledgments:}

Author, Henry Spitz

Editor, Kathryn Lang

Cartoonist, Jolene Bruce

Graphic Artist, Dorothy Siebe 
Prepared for the U.S. Department of Energy under Contract DE-AC06-76RLO 1830 